Illinois State University

ISU ReD: Research and eData

Theses and Dissertations

3-10-2019

\title{
Social Emotional Learning Through Depression Education In A High School Setting
}

Antonette Minniti

Illinois State University, antonetteminniti@gmail.com

Follow this and additional works at: https://ir.library.illinoisstate.edu/etd

Part of the Educational Psychology Commons, Elementary and Middle and Secondary Education Administration Commons, Public Health Education and Promotion Commons, School Psychology Commons, Secondary Education and Teaching Commons, and the Student Counseling and Personnel Services Commons

\section{Recommended Citation}

Minniti, Antonette, "Social Emotional Learning Through Depression Education In A High School Setting" (2019). Theses and Dissertations. 1043.

https://ir.library.illinoisstate.edu/etd/1043

This Dissertation is brought to you for free and open access by ISU ReD: Research and eData. It has been accepted for inclusion in Theses and Dissertations by an authorized administrator of ISU ReD: Research and eData. For more information, please contact ISUReD@ilstu.edu. 


\title{
SOCIAL EMOTIONAL LEARNING THROUGH DEPRESSION EDUCATION IN A HIGH SCHOOL SETTING
}

\author{
Antonette Minniti
}

\section{Pages}

Education on depression is an important part of social emotional learning. Lacking emotion regulation skills tend to lead to larger problems, such as academic struggles, disconnect from peers, strife at home and trouble in interpersonal relationships. Research in depression education or educational programs connected to mental health literacy are minimal, especially at the high school level. The purpose of this research focused on examining the impact of one depression education program, John Hopkins Hospital's Adolescent Depression Awareness Program (ADAP). The ADAP is a three-day program that informs students about the facts of depression, how it is treated, and what to do if the individual students or someone they know needs help with depression. The program involves administering the Adolescent Depression Knowledge Questionnaire before the program begins, and again six weeks later as a post-test. This study is a non-experimental quantitative study using secondary data from a sample population of approximately 250 students, ages 15-18, who attend a high school in the Midwest and are enrolled in a health education class (required for graduation). Research questions focus on the levels of understanding that students retain of depression and resources to cope with depression after participating in the ADAP curriculum. The findings of this study revealed that students were able to retain information about depression and ways to reach out for help following the ADAP curriculum. Some items on the questionnaire came up as statistically 
significant while other items did not show significance. Overall, the benefit of incorporating an effective mental health literacy program into a high school can make a difference in a student's life if they can identify symptoms of the medical illness of depression and seek help.

KEYWORDS: Social Emotional Learning, Depression Education, Mental Health Literacy, Adolescent Depression Awareness Program, High School, Health Education 
SOCIAL EMOTIONAL LEARNING THROUGH DEPRESSION EDUCATION

IN A HIGH SCHOOL SETTING

ANTONETTE MINNITI

A Dissertation Submitted in Partial

Fulfillment of the Requirements

for the Degree of

DOCTOR OF EDUCATION

School of Teaching and Learning

ILLINOIS STATE UNIVERSITY

2019 
(C) 2019 Antonette Minniti 
SOCIAL EMOTIONAL LEARNING THROUGH DEPRESSION EDUCATION

IN A HIGH SCHOOL SETTING

ANTONETTE MINNITI

COMMITTEE MEMBERS:

Douglas Hatch, Chair

Steven B. Mertens

Gary Weilbacher 


\section{ACKNOWLEDGMENTS}

Upon reflection of this whole experience, I will attempt to put into words how grateful and blessed I feel. From the beginning, after reading about how many doctoral candidates remain as $\mathrm{ABD}$ (All But Dissertation) in my first class, I knew that completing a doctorate degree would take the efforts of many people. To begin, I would like to sincerely thank my committee, Dr. Hatch, Dr. Mertens and Dr. Weilbacher. It was truly an honor to learn from all of you; this was the most valuable part of my doctoral process. Dr. Hatch, your patience, guidance and encouragement were critical to my completion of the whole process. Dr. Mertens, your attention to detail and ability to get me through my most challenging part of my dissertation was critical in getting me to the end. Dr. Weilbacher, thank you for bringing a different perspective that allowed my writing to have better clarity and depth.

As a first generation student, I am truly here because of the value that my parents placed on education from the time I was born. They moved to this country with a dream of better opportunities for their future family. Their love, support and encouragement helped me tremendously in this process. I am truly grateful and blessed to have my parents and could not have done it without them. I imagined this dream even when I married my husband 13 years ago and decided to keep my last name. I wanted the title of "Dr." to be attached to my family name "Minniti" as a recognition and honor to all that has come before me to get me to this point. I hope that any student, who is also first generation or raised in a place like Berwyn/Cicero like me, believes that we can achieve what we believe in our minds and our hearts.

I want to also thank my husband, Andrew Kostelancik, who helped push me, edited for me and encouraged me in the most stressful moments. Andrew invested in the process to support me, but also because we both knew the message that we wanted to send to our boys. 
JonPaulo and Stefano: Value your education and your opportunities, and turn them into the future you dream for yourself. After this process is complete, I look forward to focusing my time and energy more completely on both of you.

Finally, I would like to thank my district for this opportunity and assembling such a great cohort to experience this program. I feel incredibly supported by my department, colleagues and friends; each word of encouragement was much appreciated. A special thank you to Jason Spoor-Harvey, who has read my dissertation so many times and provided honest and insightful feedback. Your encouragement was a critical part in helping build my confidence in moving forward each step. Another special thank you to Dr. Kerri Largo and Dr. Lori Anne Frieri, who were the voices of experience and encouragement. Kerri, thank you for your advice and editing skills... I could always count on you to answer late night messages on Facebook with helpful insight and positivity. Lori Anne, your encouragement was so helpful...I could always count on you to answer my random texts and make things seem achievable.

Ultimately, I hope that my work will benefit students and bring to light the need for a comprehensive social emotional learning approach. An approach that solely focuses on suicide prevention is not enough. I hope my work speaks to educators who are looking to educate the whole child and really want an education for them that goes beyond academics, and also prepares them with social emotional learning skills to achieve their future goals as I have mine. As they say in Italian, "Mille Grazie!" to everyone. A million thanks to everyone.

A.M. 


\section{CONTENTS}

Page

ACKNOWLEDGMENTS

$\begin{array}{lc}\text { CONTENTS } & \text { iii }\end{array}$

FIGURES vii

TABLES

CHAPTER I: INTRODUCTION 1

Statement of the Problem 3

$\begin{array}{ll}\text { Background } & 6\end{array}$

$\begin{array}{ll}\text { Theoretical Framework } & 10\end{array}$

Purpose and Scope of the Study 11

$\begin{array}{ll}\text { Research Questions } & 13\end{array}$

$\begin{array}{ll}\text { Proposed Study } & 13\end{array}$

$\begin{array}{ll}\text { Significance of the Study } & 14\end{array}$

$\begin{array}{ll}\text { Definitions } & 15\end{array}$

$\begin{array}{ll}\text { Summary } & 17\end{array}$

CHAPTER II: REVIEW OF LITERATURE 19

$\begin{array}{ll}\text { Social Emotional Background } & 20\end{array}$

SEL and Mental Health Literacy 23

Importance of Mental Health Literacy $\quad 27$

Knowledge Acquisition $\quad 29$

$\begin{array}{ll}\text { Stigmatizing Attitudes } & 30\end{array}$

Help-seeking Behavior 31 
Effective Mental Health Literacy Programs

Timing of Adolescence and Role of the School

Important Elements in Maintaining Strong Programs 40

Administrative Support $\quad 41$

$\begin{array}{ll}\text { Professional Development } & 41\end{array}$

$\begin{array}{ll}\text { Skill Development } & 42\end{array}$

$\begin{array}{ll}\text { Student Connectedness } & 43\end{array}$

$\begin{array}{ll}\text { Evaluation } & 44\end{array}$

$\begin{array}{ll}\text { Summary } & 45\end{array}$

CHAPTER III: RESEARCH METHODOLOGY 47

Statement of the Problem $\quad 48$

Rationale for Quantitative Research $\quad 49$

$\begin{array}{ll}\text { Research Questions } & 50\end{array}$

$\begin{array}{ll}\text { Hypotheses } & 50\end{array}$

$\begin{array}{ll}\text { Research Design } & 52\end{array}$

Research Setting $\quad 53$

$\begin{array}{ll}\text { Study Sample } & 54\end{array}$

$\begin{array}{ll}\text { Data Collection } & 55\end{array}$

$\begin{array}{ll}\text { Instrumentation } & 56\end{array}$

$\begin{array}{ll}\text { Variables } & 60\end{array}$

$\begin{array}{ll}\text { Reliability and Validity } & 61\end{array}$

$\begin{array}{ll}\text { Data Collection Procedures } & 63\end{array}$

$\begin{array}{ll}\text { Data Analyses Procedures } & 64\end{array}$ 
$\begin{array}{ll}\text { Data Analyses } & 65\end{array}$

Research Question $1 \quad 65$

Research Question $2 \quad 66$

$\begin{array}{ll}\text { Limitations } & 67\end{array}$

$\begin{array}{ll}\text { Ethical Considerations } & 68\end{array}$

$\begin{array}{lr}\text { Summary } & 69\end{array}$

CHAPTER IV: RESEARCH RESULTS 70

$\begin{array}{ll}\text { Findings } & 70\end{array}$

$\begin{array}{ll}\text { Participants } & 71\end{array}$

$\begin{array}{ll}\text { Research Questions } & 72\end{array}$

$\begin{array}{ll}\text { Research Question } 1 & 73\end{array}$

$\begin{array}{ll}\text { Research Question } 2 & 79\end{array}$

$\begin{array}{ll}\text { Summary } & 87\end{array}$

CHAPTER V: ANALYSIS, RECOMMENDATIONS, AND CONCLUSION 88

$\begin{array}{lr}\text { Analysis of Findings } & 89\end{array}$

$\begin{array}{ll}\text { Research Question } 1 & 89\end{array}$

$\begin{array}{ll}\text { Research Question } 2 & 92\end{array}$

$\begin{array}{ll}\text { Limitations } & 95\end{array}$

Implications and Recommendations $\quad 96$

$\begin{array}{ll}\text { Future Studies } & 99\end{array}$

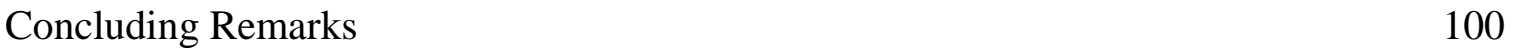

$\begin{array}{ll}\text { REFERENCES } & 102\end{array}$

APPENDIX A: JOHNS HOPKINS ADAP COORDINATOR EMAIL 118 
APPENDIX B: SAMPLE ADAP CLASS SIGN IN SHEET

APPENDIX C: ADOLESCENT DEPRESSION KNOWLEDGE QUESTIONNAIRE 


\section{FIGURES}

Figure $\quad$ Page

1. Graphic representation of two general types of SEL programs 8 


\section{TABLES}

Table

Page

1. Participant Demographics 72

2. McNemar Test Results from ADKQ Pre-/Post-survey from 3 Semesters 74 with Significant $p$-values (Questions 1-20)

3. McNemar Test Results from ADKQ Pre-/Post-survey from 3 Semesters 76 without Significant $p$-values (Questions 1-20)

4. Chi-square Test Results from ADKQ Pre-/Post-survey from 3 Semesters (Questions 21-24)

5. McNemar Test Results from ADKQ Pre-/Post-survey from 3 Semesters (Question 25)

6. Frequency Count \& Percentage from ADKQ Pre-/Post-survey from 3 Semesters (Question 26)

7. Frequency Count $\&$ Percentage from ADKQ Pre-/Post-survey from 3 Semesters (Question 27)

8. Chi-square Test Results from ADKQ Pre-/Post-survey from 3 Semesters 86 (Question 28) 


\section{CHAPTER I: INTRODUCTION}

A beautiful, spunky, 17-year-old student, named Klaira, walks into her counselor's office in tears. Her multicolor headband gives the false impression that her life is all sunshine and rainbows. To her friends, she is a cool girl with incredible singing talent; they perceive her problems to be that of a normal teenager. To her parents, she is worth all of their sacrifices and will fulfill all their dreams of moving to America if she succeeds in becoming a famous singing star. To her teachers, she is well respected and liked for her dynamic, enthusiastic personality, but they also recognize her tenacious spirit. When this student struggles with issues at home or school, she experiences an extreme range of emotions. She can be laughing in the hallway one minute and in a ball of tears in the next. There is not one person who completely understands what Klaira is going through, and sometimes it feels like she is living in a different world. She asks those around her to pinch her to make sure life is real. Her emotions are make her experience anxiety, which include physical symptoms like dizziness and shortness of breath, and she does not know how to handle any of it. Besides needing to see a medical and mental health professional, she needs to increase her social emotional skills in order to successfully function on a daily basis and recognize when she needs help. The good news is that Klaira was accepted to her dream school for next year; yet, she frequently sees her counselor to express feelings of anxiety, fear, low self-esteem and not feeling like herself. She has lost her appetite and rarely sleeps more than a few hours at a time, but feels like sleeping all the time. She questions whether it is all worth it and recently came to school with small cuts on her leg. Klaira does not recognize these symptoms of depression and suicidal ideation. In her family culture, they do not seek professional help, but rather try to treat any ailment homeopathically. Yet, each day, her emotional roller coaster impacts her education, sense-of-self, responsible decision-making, and 
relationships. How can her high school help her build the skills necessary to succeed in life beyond strong academics when she graduates? Does her high school provide any type of depression education? How can this benefit the student in helping her regulate her emotions? The answers may be complex, but it is clear that academics alone are not enough in building a successful future for students. Building students' social emotional skills should also be an integral part of education, so students can recognize what may ail them and they seek the help they need to care for themselves.

President Franklin D. Roosevelt (1940, para. 30) once said, "We cannot always build the future of our youth, but we can build our youth for the future." While there may be many components to preparing for the future, one's emotional intelligence should be a critical part of that landscape. Specifically, students need education on mental health just as they do physical health. Depression education and mental health literacy should be a part of core educational experience, so that they can be prepared for their future. This preparation is even more critical when they are not in daily contact with so many adults who are actively always trying to be aware of their state of being and who want what is best for them. On a daily basis, students talk to their counselors, teachers, and coaches about issues that they are experiencing in school or at home, which is a healthy part of growing up. Adolescents seek guidance in exercising skills connected to emotion regulation because they may be unsure how to recognize, manage and express what they are experiencing (Conley, 2015; Durlak, Weissberg, Dymnicki, Taylor \& Schellinger, 2011). If these social emotional needs are not met, inevitably they impact a student's functioning in some way (Brackett, Rivers, \& Salovey, 2011). Poor social emotional skills can create barriers to learning, to creating trustworthy relationships, and to one's contentment (Mayer \& Salovey, 2004; Salovey \& Mayer, 2004). Emotional intelligence (EI) 
helps to prepare students for the future and is the foundation for social and emotional learning programs (Brigman \& Campbell, 2003; Collaborative for Academic, Social, and Emotional Learning, 2005; Durlak et al., 2011). The recognition of the importance of SEL in education helps to understand the emergence of SEL programs in schools. In particular, one type of SEL programming in schools is education connected to mental health literacy (MHL), which includes programs connected to depression education and suicide prevention (Naylor, Cowie, Walters, Talamelli, \& Dawkins, 2009; Skre et al., 2013; Swartz, et al., 2010). Research in depression education or educational programs connected to mental health literacy are minimal and that research has not been assessed for their effectiveness; thus, the purpose of this research focuses on examining the impact of one depression education program, the John Hopkins Hospital's Adolescent Depression Awareness Program (ADAP).

\section{Statement of the Problem}

As educators strive to meet the needs of students and focus on closing the achievement gap, many are questioning what yet remains within our locus of control. One specific way is for schools to develop the SEL approaches in school to specifically include depression education, such as the ADAP. As the pendulum swung strongly in the direction of standardized tests with No Child Left Behind (NCLB), educators knew that this would not paint the complete picture of what is needed in our schools (Lee \& Reeves, 2012). Since NCLB was focused on reading and math improvement, social emotional learning (SEL) seemed to be less valued because measuring these skills does not appear on standardized tests. The reality remains that not building these skills creates a barrier for many students' learning and achievement of academics and life goals (Durlak et al., 2011; Mayer \& Salovey, 2004). Poor management of emotions can lead to depression, which left untreated can lead to suicide (McCarthy, Bruno \& Fernandes, 2011). 
High school aged adolescents are a prime target group as $8 \%$ meet the diagnostic criteria for depression (Birmaher, Brent, AACAP Work Group on Quality Issues, 2007). According to Burns and Rapee (2006), " $80 \%$ of youth ages $6-18$ years with a mental disorder fail to receive treatment" (p. 225). Moreover, when depression is untreated, the worst can happen: death by suicide, which is the third leading cause of death among people ages 10-24 (Centers for Disease Control and Prevention, 2007). Since depression can develop for the first time in adolescence, it is an ideal time for education and prevention efforts within the schools (Nock et al., 2013).

Even though SEL programs have been developed in the last 60 years, the number of ways by which schools can approach SEL is overwhelming and the most effective programming depends on student needs. Sometimes SEL programs are referred to as social, emotional and/or behavioral (SEB) programs (Sklad, Diekstra, Ritter, Ben, \& Gravesteijn, 2012) or life skills programs (Botivin \& Griffin, 2002), which all include building a student's level of emotional intelligence to cope with life (recognize/manage emotions, solve problems, make responsible decisions, and build positive relationships) (Collaborative for Academic, Social, and Emotional Learning, 2005; Goleman, 1995; Sklad et al., 2012; Zins \& Elias, 2007). Another type of SEL program focuses more on mental health literacy, which focuses on building knowledge, recognition and treatment of mental health illnesses (Ball, et al., 2016; Kelly, Jorm \& Wright, 2007). According to Cooper, Clements, and Holt (2011), "high school prevention programs have been and continue to be how social scientists and educators have chosen to address this problem" (p. 696). At the same time, Adelman and Taylor (2000) warned that:

If schools are to work effectively on mental health and psychosocial concerns, great efforts must be made to develop comprehensive, multifaceted, and integrated intervention approaches. For greater efforts to be realized, initiatives for mental health in schools must 
be developed, coordinated, and fully integrated with each school site's school reform policy. (p. 171)

Any type of SEL program within a school can work hand-in-hand with mental health literacy programs, such as depression education, because they can benefit each other. For instance, Sklad et al. (2012) shared the viewpoint of SEL programs to be preventative: "They follow the assumption that the enhancement of universal skills will lead to a reduction in undesirable or (self-) harmful behavior, attitudes, and characteristics" (p. 893). For instance, Durlak et al. (2011) shared many significant indirect effects through their meta-analysis of schools' interventions of SEL, such as less anxiety and depression, reduction in drug use, more prosocial behavior, and increased positive attitudes toward school. There are many programs that have positive results, but there may not be one perfect fit for every school. There are many different school environments and factors to consider in implementing any type of SEL program.

Even though there are many elements to consider when making the decision on which SEL programs to implement, social emotional skill building needs to be addressed as these skills help people to care for themselves (Mayer \& Salovey, 2004; Williamson, Modecki, \& Guerra, 2015). One such way to address SEL needs is through mental health literacy or depression education. Jorm (2000) defines mental health literacy:

Mental health literacy consists of several components, including: (a) the ability to recognise [sic] specific disorders or different types of psychological distress; (b) knowledge and beliefs about risk factors and causes; (c) knowledge and beliefs about self-help interventions; (d) knowledge and beliefs about professional help available; (e) attitudes which facilitate recognition and appropriate help-seeking; and (f) knowledge of how to seek mental health information. (p. 396) 
Building a student's mental health literacy is skill building in order to prevent poor care of themselves. It is important to consider the bigger picture of SEL when putting in place components such as programs to address mental health literacy. For this literature review, the focus was on approaches connected to depression education or mental health literacy in adolescence. More specifically, this study will focus on one type of mental health literacy program, the Johns Hopkins Adolescent Depression Awareness Program (ADAP), which falls under the category of depression education (Swartz, 2016). The ADAP educates students about the symptoms of both unipolar and bipolar depression, and how to get help for either medical illness (Swartz, 2016). Lastly, one other important issue to recognize in this research is the lack of information or studies conducted at the high school level (Williamson et al., 2015). Even though, social emotional skills are built over a lifetime, the adolescent years can have an impact on the adult years.

\section{Background}

Researchers recognize the possible impact of emotional intelligence (EI) on future success, but also acknowledge the areas in which further research is needed to strengthen the field. EI has caused educators to take emotional education more seriously (Darling-Hammond, Friedlaender, \& Snyder, 2014; Denham, 2015; Durlak, Domitrovich, Weissberg, \& Gullotta, 2015; Elias et al., 1997). Even though the work of Daniel Goleman popularized and exposed the concept of emotional intelligence, a German psychoanalyst, Barbara Leuner, first coined the term in 1966 and later, Jack Mayer and Peter Salovey formally researched EI for the first time (Zeidner, Matthews, \& Roberts, 2009). Also, James Comer from the Yale Child Study Center began some SEL work in the late 1960s by designing his own school program, which produced positive results at two schools where the program was implemented and thus, began the 
movement of SEL in school programming (Durlak et al., 2015). Slowly, EI began to gain ground as a type of intelligence with a rich history of various fields connecting to the concept. According to Durlak et al. (2015), Comer reflected that he did not realize how slow the development of social emotional learning would be at the time, but that we need to take our current progress and "make a big leap forward in the preparation of all students, particularly those that have been left behind" (p. 591). While the concept of emotional intelligence is still developing as a science, applications of the concept are prevalent through SEL programs in schools. Another major player in the history of SEL is the Chicago-based Collaborative for Academic, Social, and Emotional Learning (CASEL). Their mission is to weave evidence-based SEL into every school with the focus on five core competencies: self-awareness, social awareness, self-management, relationship skills, and responsible decision-making (CASEL, 2017; Durlak et al., 2015). Evidence-based SEL has been researched and found to have effective practices for children in building SEL skills (CASEL, 2005; Durlak et al., 2011). These SEL skills include the five core competencies.

To briefly review the five core competency terms; (a) self-awareness "involves understanding one's emotions, personal goals, and values;" (b) self-management "requires skills and attitudes that facilitate the ability to regulate emotions and behaviors;" (c) social awareness "involves the ability to take the perspective of those with different backgrounds or cultures and to empathize and feel compassion;" (d) relationship skills "provide children with the tools they need to establish and maintain healthy and rewarding relationships and to act in accordance with social norms;" and (e) responsible decision making "requires the knowledge, skills, and attitudes needed to make constructive choices about personal behavior and social interactions across diverse settings" (Durlak et al., 2015, p. 6-7). Even with a set of core competencies (CASEL, 
2017), SEL programs manifest themselves in diverse ways, in practice, with variations of grade level, foci, implementation, design and costs. Some programs focus solely on depression education, suicide prevention, emotion regulation, academic connections, or transitional programs just to name some of the common types; while others may combine some of these foci (Burns \& Rapee, 2006; CASEL, 2005, Durlak et al., 2011; Garmy, Berg, \& Clausson, 2015).

Programs have been created to meet many different needs in a school, but they still fall under the larger umbrella category of social emotional learning as (Figure 1). Some programs will fill the purpose of emotional regulation skills, while some will fit the category of mental health literacy. For the purpose of this research, the focus was under mental health literacy as the ADAP is a depression education program.

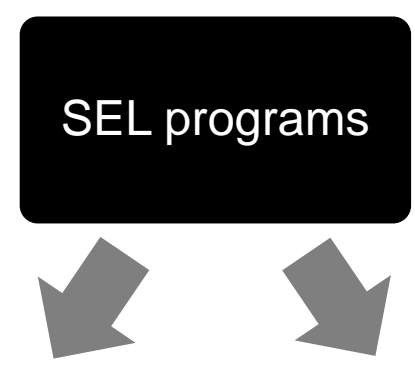

Emotional Regulation Skills

-Mindfulness

-Mediation Program

- Character Education
Mental Health Literacy

-Depression Education

- Suicide Prevention

-Mental Health Conditions

Figure 1. Graphic representation of two general types of SEL programs

The advantage of multiple types of SEL programs in a school is meeting different student needs, but the disadvantage is possibly a disjointed social emotional approach altogether. For instance, the ADAP encompasses all five CASEL (Collaborative for Academic, Social, and Emotional Learning) competencies to some degree, but it is focused on depression education. Depression education falls under the category of mental health literacy programs and is one type 
of SEL approach. The ADAP is a program that can be considered when building an overall SEL approach in a school, but it is not a comprehensive SEL approach that would, for example, encompass the whole student body during all four years of high school. Regardless, incorporating education on depression is an important part of SEL because deficits in emotion regulation skills tend to lead to larger problems, such as academic struggles, disconnect from peers, strife at home and trouble in interpersonal relationships. Therefore, helping students to manage their feelings can potentially help them cope with depression.

While the literature review will present some of the research around social emotional learning programs, this study will focus on one type of SEL program: depression education. Specifically, the study focuses on depression education, such as the ADAP. As psychological and educational professionals have tried to create interventions and programs aimed toward social emotional learning, one focus can be a mental health perspective, which for example can be depression education in order to gain knowledge about what leads to the possibility of suicide (Katz et al., 2013). For instance, the ADAP intends to teach students, teachers, and parents about the illness of depression through a three-day curriculum. The mental health approach of depression education has also been referred to as mental health literacy, a term invented by Jorm et al. (1997), in which their research concluded that if mental disorders are going to be recognized early and interventions sought, then mental health literacy needs to be raised. Hart et al. (2014) agreed that "Mental health literacy appears to be an important target for intervention" (p. 214). Mental health literacy values informing adolescents about helpful resources, so they can help themselves or others. Of course, in the end, coping with depression or any mental disorder and being able to effectively regulate their emotions allows students to remove this barrier to their learning and to their lives. 


\section{Theoretical Framework}

In considering a theoretical framework for this study, social learning theory (SLT) and the social development model (SDM) fit well. According to Brackett, Elbertson, and Rivers (2015), "Theory should inform how an approach is designed and implemented in ways that will lead to a specified set of outcomes" (p. 20). Even though theories of systems, learning, child development, brain science, information processing, and behavior can shape SEL, the focus was SLT and the SDM. These theories provide the foundation of understanding how children learn to behave and what shapes their behavioral choices.

In social learning theory, "people learn by observing the behavior of others.

Environmental and cognitive factors can influence the process as well” (Kretchmar, 2013, para.

1). Bandura blended behaviorism and cognitive theories of learning to develop his social learning theory, which he and others continued to develop from 1977 to the early 2000s (Kretchmar, 2013). According to Bandura (1977):

Learning would be exceedingly laborious, not to mention hazardous, if people had to rely solely on the effects of their own actions to inform them what to do. Fortunately, most human behavior is learned observationally through modeling: from observing others one forms an idea of how new behaviors are performed, and on later occasions this coded information serves as a guide for action. (p. 22)

A component that developed later in Bandura's social learning theory is the consideration of a person's motivation in learning anything, which impacts someone's self-efficacy in that they do better if they feel they are good at a task.

SDM is a theory that is used to explain harmful behavior in a young person. According to Hawkins, Smith, and Catalano (2004): 
The theory of social development...integrates propositions from three theories of human behavior and development: social learning (Bandura, 1977; Burgess \& Akers, 1966;

Krohn, Lanza-Kaduce, Radosevich \& Akers, 1980), social control (Hindelang, 1973;

Hirschi, 1969; Kornhauser, 1978), and differential association theories (Cressey, 1953;

Matsueda, 1988; Sutherland, 1973). (p. 136)

Hawkins et al. (2004) state that a part of this "theory is modeling, reinforcement, and rewards along with the social bonds that shape behavior" (p. 136). Therefore, it is important to build an environment of opportunities for prosocial behavior and bonding. In other words, students need time and space to practice their social and emotional learning skills, a place that is safe and allows them to work on recognizing, managing and expressing their emotions. Hawkins et al. (2004) write that "the creation of opportunities for prosocial interaction and involvement throughout school, community, and family life allows children to use their social and emotional competencies while developing powerful protective attachments to positive social influences" ( $p$. 137). With these experiences, students can develop a positive sense of self along with positive behaviors, which can impact their individual contentment and academic success. Also, social cognitive theory adds that self-efficacy or one's confidence in prosocial behaviors is important for "skill mastery of promoting clear connections between the concepts and skills being taught and students' actual experiences in order to make explicit the relevance to their lives" (Payton et al., 2000, p. 183). Understanding these important elements of SEL is essential to the success and impact of SEL programs.

\section{Purpose and Scope of the Study}

The Adolescent Depression Awareness Program (ADAP) is taught to students enrolled in health courses during the academic school year at a large suburban public high school 
in the Midwest. According to Hart et al. (2014), "School health education classes are an ideal forum to enhance depression literacy before the peak age of onset of mood disorders" (p. 221). All of the health teachers have been trained through an online course from the Johns Hopkins Mood Disorders Center to teach the program. The ADAP takes place three days during the students' stress unit in the health class, which also includes the topic of mental wellness and suicide. The ADAP includes a pre-test and a post-test, known as the Adolescent Depression Knowledge Questionnaire (ADKQ), which is designed to reveal the levels of students' understandings of depression and resources to help before the ADAP curriculum and again six weeks after the program. According to Hart et al. (2014), "ADKQ was developed to measure changes in depression knowledge and attitudes, the primary targets of the ADAP intervention" (p. 215). Therefore, the purpose of this quantitative study is to explore the impact of ADAP's curriculum on students' knowledge of depression and help-seeking behavior in coping with depression. This study will also examine students' knowledge of seeking help when recognizing the symptoms of depression in themselves and/or others. The purpose of this study is to determine the impact of the ADAP. This was accomplished through analyzing students' answers on the Adolescent Depression Knowledge Questionnaire (ADKQ) as there is a pre-test and posttest to the ADAP designed at the Johns Hopkins Hospital. The ADKQ was designed and evaluated by a team of psychiatrists, psychiatric nurses and medical students (Hart et al., 2014). Hart et al., (2014) share that "The ADKQ was designed in conjunction with the Adolescent Depression Awareness Program (ADAP), a school-based, universal program designed to educate high school students about mood disorders (i.e., increase "depression literacy" while reducing mental health stigma)" (p. 215). Hess et al. (2004) initially examined the ADAP and its effectiveness through analyzing the ADKQ. There was one previous study on the ADAP in its 
early stages by Hess et al. (2004) in which the ADKQ was developed. A similar study has yet to be replicated after the ADKQ and the ADAP have been changed and revised. Since both the ADAP and the ADKQ have been further developed, there have been no similar studies to examine the effectiveness of the program. Furthermore, this study will provide recommendations for future educators who are considering making this program a part of their curricula and how it can fit in with other SEL approaches in their schools.

\section{Research Questions}

This quantitative study was guided by the following research questions:

- What levels of understanding do students retain of depression after participating in the ADAP curriculum?

- What levels of understanding do students retain about the resources to cope with depression after participating in the ADAP curriculum?

\section{Proposed Study}

This study is a non-experimental quantitative study using secondary data from a sample population of approximately 250 students, ages $15-18$, who attend a high school in the Midwest and are enrolled in a health education class (required for graduation). The health class is a semester long course that includes a stress unit toward the beginning of each semester. The Adolescent Depression Awareness Program is included as part of the stress unit. The ADAP is a three-day program that informs students about the facts of depression, how it is treated, and what to do if individual students or someone they know needs help with depression. The program involves administering the ADKQ before the program begins as a pre-test, which is then administered again six weeks later as a post-test. The students are assigned random identification numbers through the ADAP coordinators at the Johns Hopkins Hospital, so their responses on 
both the pre-test and post-test are anonymous to their teacher or anyone else at their own high school. Data was collected from the ADKQ pre-tests and post-tests. To evaluate the significance of the ADAP on the student population, data analysis will include a McNemar test

for questions 1-20 \& 25, which "is the most appropriate tool for analyzing pre-post differences in dichotomous items (e.g., "yes" or "no", "correct" or "incorrect”, etc.)” (Adedokun \& Burgess, 2012, p. 125). The McNemar test is similar to the paired-samples $t$ test, which is used with a continuous dependent variable instead of dichotomous (e.g., "yes" or "no", "correct" or “incorrect”) (McNemar's test using SPSS Statistics, n.d.). The McNemar test is similar to the paired-samples $t$-test or a chi-square test that uses related dichotomous items instead (Adedokun \& Burgess, 2012). The advantage in using the McNemar test is that the same population is being tested twice, which increases the chance to detect a statistical significance. Since the sample population is the same, it increases the power of the test. For questions $21-24 \& 28$, the chisquare analyses was used to analyze frequency distribution of categorical data. "Any test between frequencies or proportions of mutually exclusive categories...requires the use of chisquare" (Salkind, 2011, p.288). Finally, a comparison table was used for questions 26 and 27 to more easily compare pre-/post-survey results for all three semesters.

\section{Significance of the Study}

The significance of this study lies in the urgency with which educators must help students recognize depression and how to seek help for depression in order to increase the possibility of students seeking treatment for mental illness. Furthermore, even though not all people who have the mental illness of depression experience the symptom of suicidal ideation, the ability to recognize depression and seek help can also prevent suicide. This study will contribute to the field because it will focus on a high school program, which is not widely found in the literature 
on social emotional learning. The target audience are high school educators and administrators who are considering the implementation of any depression education or suicide prevention program, or considering any SEL program that addresses the larger scope of mental illness. The goal is for them to understand whether or not this program meets their needs.

\section{Definitions}

In this section, key terms are defined to help with the understanding of this research. Terms will also be defined that are currently used in education and connect to social emotional learning in schools.

Achievement Gap: This term refers to the disproportion in achievement levels between large groups of students usually separated by socioeconomic status, race/ethnicity, and/or gender. The achievement gap is also referred to as the opportunity gap or more recently, the education debt. Ladson-Billings (2006) argues that "we need to look at the "education debt" that has accumulated over time. This debt comprises historical, economic, sociopolitical, and moral components" (p. 3).

Adolescent Depression Awareness Program (ADAP): A depression education program designed by the Johns Hopkins Hospital aimed to educate students, teachers, and parents how to identify the symptoms of depression and how to get help.

Adolescent Depression Knowledge Questionnaire (ADKQ): This questionnaire is part of the ADAP and contains 28 questions to assess an adolescent's depression knowledge and how they would seek help before exposure to the curriculum. Then the questionnaire is given 6 weeks later to assess the retention of the depression knowledge gained in the ADAP curriculum. 
CASEL: Collaborative for Academic, Social, and Emotional Learning (2017) is a Chicago-based organization that is the leading organization in developing academic, social and emotional learning for all students.

CASEL's 5 Core Competencies: CASEL has identified a core set of five competencies, including self-awareness, self-management, social-awareness, relationship skills and responsible decision-making, for social and emotional learning. Not only are these competencies important to social emotional learning, but they are elements that are used to evaluate SEL programs. Depression Education: A type of SEL program that aims to educate about identifying the symptoms of the mental illness of depression, in order to recognize the symptoms in oneself or in others. With this knowledge, one can seek appropriate help to change the way they are feeling, and also in some cases prevent suicide.

Emotional Intelligence (EI): A term coined in 1966 by a German psychoanalyst, Barbara Leuner, and used interchangeably with social emotional learning at times. Jack Mayer, Peter Salovey and James Comer were among the first to research the concept (Zeidner et al., 2009). Emotional intelligence refers to the ability of one being able to identify their emotions, label how they are feeling and then being able to regulate their emotions in order to guide their thinking and behavior.

No Child Left Behind (NCLB): A legislative act signed into law by George W. Bush in 2002 to control Title I funding to schools based on their achievement scores on standardized tests. The law included many regulations for schools who are not meeting standards.

Social Emotional Learning: CASEL (2005, p. 1) defines social and emotional learning as the process of developing the ability to recognize and manage emotions, develop caring and concern for others, make responsible decisions, establish positive relationships, and handle challenging 
situations effectively. Social emotional learning centers on teaching students the skills of emotional intelligence in order to ensure good decision-making, as well as physical and mental well-being as a person and as a learner.

Social Development Model: SDM is a theory of behavior change that suggests that children learn from their social surroundings, which include both prosocial and antisocial behavior, but can be influenced by experiences of skill development (Catalano \& Hawkins, 1996).

Social Learning Theory: SLT suggests that there are various social interactions that impact how a person learns new behavior, such as modeled interactions between others, verbal guidance in interactions, and feedback on interactions (Bandura, 1977).

Suicide Prevention: A type of SEL approach that focuses on reducing the incidents of suicide. This approach emphasizes knowing the risk factors and who is at risk to reduce suicide. Also, increasing knowledge on these risk factors can hopefully decrease the shame that some feel from talking about suicide and asking for help.

\section{Summary}

The important factor in creating successful SEL programs in schools is the relationship between teachers and students. According to Matthews, Zeidner and Roberts (2002), students' relationships with their teachers and their peers makes school a place that naturally factors into a child's development of emotion and intelligence. School is a place where educators not only spend time teaching students, but also socializing students as to behavior that adheres to

prevailing cultural norms. Harris (2008) wrote,

It is inevitable that schools find themselves at the interface between the relentless modernization $[s i c]$ and marketisation $[s i c]$ of the educational system on the one hand and 
the social, emotional and behavioural [sic] fallout of pervasive human stress and distress on the other. (p. 367)

Of course, there needs to be a balance between academic preparation and social-emotional learning. Zins and Elias (2007) emphasized that:

Genuinely effective schools - those that prepare students not only to pass tests at school but also to pass the tests of life- are finding that social-emotional competence and academic achievement are interwoven and that integrated, coordinated instruction in both areas maximizes students' potential to succeed in school and throughout their lives. (p. 233)

Social and emotional learning has a broad range of accepted qualities and facets; thus, many different types of SEL programs have been created for different schools. To build the best SEL approach for one's school, it is important to build it with the elements that meet the students' needs in that school. This might involve implementing an overall SEL approach or building a program unique to one's school. Therefore, this study will focus on examining one program that can be implemented in building an overall comprehensive SEL approach in a school. 


\section{CHAPTER II: REVIEW OF LITERATURE}

In this chapter, literature pertaining to mental health literacy (MHL), specifically depression education, was reviewed. This review focuses on social emotional learning (SEL) in schools, which is a large umbrella term for many different types of education connected to how students understand and regulate their mental health and emotions. Understanding the background and development of social emotional learning is important in understanding the development of depression education. Some SEL programs focus on skills that support emotional regulation, while some focus more on the identification and treatment of mental health disorders. The development of SEL has laid a foundation for the emergence of different SEL programs; depression education or mental health literacy are examples of these approaches.

Among the research, the approach of depression education was often encompassed in the broader term of mental health literacy. A part of choosing the best fit for any school is considering an approach that also develops students' mental health literacy; therefore, implementation of depression education is a significant piece of developing a comprehensive SEL program at any school. Social cognitive theory as described by Bandura (1998) stressed that building knowledge and skills is necessary for change and high self-efficacy beliefs are crucial for there to be changes in behavior. Therefore, the literature review coverd the context of social emotional learning and the connection to depression education. The literature review includes the importance of mental health literacy and effective mental health literacy programs. The importance of the school's role in developing this literacy and the timing of instruction in adolescence was also reviewed. Lastly, to maintain strong SEL or MHL programs, the elements of administrative support, professional development, skill development, student connectedness, and evaluation are important. 


\section{Social Emotional Background}

To understand the emergence and proliferation of Social and Emotional Learning (SEL) programs in American PK-12 schools, it is helpful to understand the development of emotional intelligence, as well as how students' mental health literacy can be developed.

According to CASEL (2005):

Social emotional learning is the process of developing the ability to recognize and manage emotions, develop caring and concern for others, make responsible decisions, establish positive relationships, and handle challenging situations effectively. SEL provides schools with a framework for preventing problems and promoting students' well-being and success. (p. 1)

While this combination of abilities and behaviors can be, by nature, difficult for schools to specifically target and develop, literature supports the positive impact on students' lives and learning from SEL programs (CASEL, 2005; Durlak et al., 2011). One of the goals of American public schools is to provide students with the opportunity and tools for future success and wellbeing. It is not just academic success but a strong foundation in emotional and mental health that all contribute to future success (Adelman \& Taylor, 2006; Brackett, et al., 2011; Brigman \& Campbell, 2003; Harris, 2008). The difficulty in pinpointing these abilities and behaviors cannot prevent efforts to cultivate them in our students.

Through their research, Mayer and Salovey (1993) renamed social emotional intelligence as Emotional Intelligence (EI), connected emotion to a type of intelligence, and indicated that there are skills with emotional intelligence. Mayer and Salovey (1993) addressed criticisms by providing a historical perspective on intelligence and differentiating emotional intelligence. Mayer and Salovey (1993) also shared their research on connecting emotions to abilities and in 
particular, mental operations. Social emotional learning has been in development since researchers began focusing on emotional intelligence in the 1960s. In 1966, Barbara Leuner, a German psychoanalyst, coined the term emotional intelligence but initial key researchers also included James Comer, Jack Mayer and Peter Salovey. Emotional intelligence refers to a person's ability to recognize and manage their emotions in connection to their decision making, relationship building and care of others (CASEL, 2005). Social emotional learning refers more to the process of how schools can play a role in helping students to develop their SEL skills. While there is much research to support these concepts, two key pieces that examined the effectiveness of multiple programs are CASEL's publication, Safe and Sound (2005) and a meta-analysis by Durlak et al. (2011). Both determined the effectiveness of programs based on specific criteria. CASEL's criteria included the following characteristics; grounded in theory and research, application of SEL skills, connection to school, helps unify school programs, involves family and community, staff development and continued evaluation. Durlak et al. (2011) delineated criteria such as emphasis on one or more SEL skills; for children aged 5 to 18, and included a control group and sufficient effect sizes. Even though both included high school age students, the percentage of research studies is much lower than the other age groups (elementary and middle school). Only a handful of the 22 programs identified by CASEL (2005) are intended for high schools and are classified as excellent, having met their criteria of excellence in all three areas: outstanding SEL instruction, evidence of effectiveness, and outstanding professional development (p. 12). Both studies also included measurement results of the program's effectiveness through pre/post assessments. 
The effectiveness of SEL programs can have positive a short and long term impact on students. Students' connection to school can aid in the effectiveness of SEL programs too. According to Zins and Elias (2007):

Developing social-emotional competence is a key to success in school and in life. We know that emotions affect how and what we learn, that caring relationships provide the foundation for lasting learning, and that important SEL skills and knowledge can be taught. Research shows that SEL has positive effects on academic performance, benefits physical health, improves citizenship, is demanded by employers, is essential for lifelong success, and reduces the risk of maladjustment, failed relationships, interpersonal violence, substance abuse, and unhappiness. (p. 237)

The importance of social and emotional learning lies, not only with the short-term impact on individual students and their learning, but also the long-term benefits, which can build a framework to support critical thinking, resiliency, and effective emotional management (Brackett, et al., 2015; CASEL, 2005; Durlak et al., 2011; King, 2006; Merrell, 2010; Payton et al., 2000; Shochet et al., 2001; Zins, Weissberg, Wang, \& Walberg, 2004). If students are less connected in school, they may be less connected to work and life in the future. This has the potential to impact them negatively in many ways.

The wide variety of SEL programs available to schools makes it difficult to narrow down just a single best approach, and there is much research that demonstrates positive results from various SEL programs implemented in different schools. Durlak et al. (2011) also wrote that a student lacking in social emotional skills may not be connected to school, which causes them negative consequences with academics, behavior and relationships. The "multiplier effect" on the student further contributes to what the research shows as the widening of the achievement 
gap as students navigate the educational environment (Stinson, 2011). Of course, there are services to help students, but the goal of SEL programs is to impact every student instead of a small number of students that have already demonstrated negative outcomes which identify them as needing intervention or are able to access structural services. The goal of SEL is to expand these services in a manageable and beneficial way to all students. There is always and will always be a need for social and emotional learning to support students as they process what is happening in the world both locally and globally. Beyond the school walls, there are events that may impact students on a deeper emotional level, and they need to know how to be resilient in the face of these often complex and difficult issues.

Dealing with stress is a reality of life. If adolescents can handle stress and regulate their emotions, they can impact their short and long term health (Greenberg, Katz \& Klein, 2015). According to a study by Garmy et al. (2015), which included 12 focus groups of 89 adolescents aged 13-15, "The school-based mental health program was perceived as beneficial and meaningful on both individual and group levels, but students expressed a desire for a more health-promoting approach" (p. 1). Furthermore, social and emotional learning also prevents other troubling behaviors that frequently manifest in schools and impact the learning environment. In order to understand the impact and effectiveness of various programs in American schools, this literature review explores some of the research underpinnings of social and emotional learning, specifically mental health literacy.

\section{SEL and Mental Health Literacy}

In the era of NCLB, which relied primarily on the results of standardized achievement tests, American schools grappled to find ways to close the achievement gap. Could implementing effective, research-based SEL programs impact learning for students? Some educators may only 
associate NCLB with standardized testing, sub-groups, and increased priority placed on data collection and analysis. Therefore, some educators may feel that implementing an SEL program may not be supported in their schools as some may feel it distracts from the focus on standardized testing and academic achievement; however, programs that increase social emotional learning skills can make a positive impact on student behaviors and learning (Garmy et al., 2015; Sklad et al., 2012). This is also relevant with increasing students' mental health literacy, which can identify students at-risk for depression and positively impact the academic success of their student participants (Cooper, 2008). Of course, understanding the importance of social emotional learning and mental health literacy is critical to incorporating their tenets in a school's vision and curriculum. Durlak et al. (2011) wrote that school plays a significant role in developing the cognitive, as well as social and emotional, development of a healthy child. To foster social and emotional development in students, these programs require a strong foundation, dedicated leadership and continued support.

Research on social emotional learning programs provided an informative lens to mental health literacy approaches. For instance, a study by Midford et al. (2017) showed that even brief social and emotional programs can have positive effects, but a program with more direct skill development could produce greater positive effects. The significant result of students participating in any type of SEL program, including mental health literacy approaches, is that it impacts one's awareness of emotions, management of emotions, and ability to reach out for help when needed. Blair and Raver (2015) shared that SEL is about "recognizing and managing our emotions, developing caring and concern for others, establishing positive relationships, making responsible decisions, and handling challenging situations constructively and ethically" (p. 65); moreover, self-regulation helps learning and executive function behavior. Similarly, Wei, 
Hayden, Kutcher, Zygmunt, and McGrath (2013) stated that mental health literacy includes skills to connect young people with mental health care, which include "the biological, psychological and social aspects of mental health to increase the understanding of mental health and mental disorders, reduce stigma, help recognize and prevent mental disorders, and facilitate help-seeking behaviours [sic]" (p. 110). Since MHL is a subcategory of SEL, it makes sense that MHL still involves recognizing and managing emotions. Blair and Raver (2015) believed that:

Effective SEL programming, is understood to influence the pattern of connections between brain areas, leading the individual toward a more reactive or more reflective behavioral profile, or phenotype, in response to stimulation...As such, experientially induced neural activity can be understood to shape the relative strength of developing connections between brain areas in ways that lead to difference in cognitive and emotional profiles of self-regulation. (p. 66-67)

Therefore, SEL and MHL programs stimulate neural activity, which helps shape the brain's cognitive development to regulate emotion. Even though one regulates their emotions on a daily basis, these skills can be further developed allowing positive effects.

There are additional positive effects to developing SEL skills, which can include MHL skills. For instance, in one study, Garmy et al. (2015) found that in their program that focused on intrapersonal strategies (directed thinking, improved self-confidence, stress management, and positive activities), students made more connections between their thoughts, feelings and actions, which led to an impact on their way of thinking about themselves, their behavior and others. In addition to positive individual effects, they also felt that the program increased interpersonal awareness, which allowed them to trust and show consideration for others in the group (Garmy et al., 2015). In another study, Sklad et al. (2012) examined 75 studies that taught social and 
emotional skills to examine if these programs had enough positive effects on students to be considered effective for the school environment. In the long terms, "These outcomes include enhancement of social and emotional skills; positive self-image; prosocial behavior; reduction or prevention of antisocial behavior, mental problems, and disorders; and promotion of academic achievement" (Sklad et al., 2012, p. 905). More immediately, "the largest effects were found for social-emotional skills, attitudes toward self, and prosocial behavior, followed by academic achievement and reduction of antisocial behavior" (Sklad et al., 2012, p. 905). This group of studies not only supported the positive impact of teaching SEL skills, but also the connection to the benefits of increased mental health literacy. Another example is a study by Shochet et al. (2001) where students participating in an SEL program had a reduction in depressive symptoms according to three depression measures. An encouraging piece of this study is that even during a follow-up with participants, students that were part of SEL programs were still showing lower levels of depressive symptoms.

Another positive effect is that these programs teach adolescents the necessary information about how to seek help when facing depression personally or seeing symptoms among their friends. Wei, et al. (2013) shared that mental health literacy programs enable adolescents' access to care for mental health concerns. Well supported, multi-year, goal-oriented SEL programs can help reduce risky behaviors (Battistich, Schaps, Watson, \& Solomon, 1996; Stan \& Beldean, 2014; Stoiber, 2011; Weissberg \& Cascarino, 2013). For example, Miller, Eckert and Mazza (2009) found that:

There is some evidence that prevention programs that include providing information to students regarding suicide awareness and intervention, teaching them coping and problem-solving skills, and teaching and strengths and protective factors while 
addressing risk-taking behaviors may lead to improvements in students' problem-solving skills and self-efficacy as well as reductions in self-reported suicide vulnerability. As such, incorporating informational and skill-building elements in prevention programs appears to be a potentially useful strategy. (p. 181)

Clearly, SEL and MHL go hand-in-hand. Knowledge helps individuals builds the necessary skills to help themselves or those around them. A person's self-efficacy plays a huge role in cognitive development and functioning (Bandura, 1993) and that is why it is imperative to build a comprehensive SEL program which includes depression education. In essence, preventing a problem before it becomes a serious issue can help young adults.

\section{Importance of Mental Health Literacy}

This section will discuss the importance of addressing mental health concerns with mental health literacy or depression education programs. Jorm et al., (1997) shared that mental health literacy is "knowledge and beliefs about mental disorders, which aid their recognition, management, or prevention (p. 182). Study results around mental health literacy tend to revolve around three key benefits: knowledge acquisition, stigmatizing attitudes, and developing help-seeking behavior (Wei, et al. 2013). Mental illness is an important issue in our society. According to Perou et al. (2013),

A total of $13 \%-20 \%$ of children living in the United States experience a mental disorder in a given year, and surveillance during 1994-2011 has shown the prevalence of these conditions to be increasing. Suicide, which can result from the interaction of mental disorders and other factors, was the second leading cause of death among children aged 12-17 years in 2010. (p. 21) 
Without treatment, the impact can be negative in many ways to an individual and the larger society, and the act of suicide is definitely one of the most severe of these negative outcomes. Miller and Eckert (2009) agreed and shared that teens experiencing depression are more likely to attempt suicide than teens not experiencing depression. Merritt, Price, Mollison and Geddes (2007) shared that many people experience depression before adulthood and emphasized that this is why depressed people need to know the signs: "Depression can be treated successfully in most patients. However, for treatment to be successful, depressed people need to recognize their symptoms as illness, present to medical care, and be aware that effective treatment is available" (p. 363). Therefore, even though SEL programs provide the overarching goals for a school, any school should consider depression education to be included to help build mental health literacy. Wei, Kutcher, and Szumilas (2011) further explained that mental health literacy programs in schools not only increases the mental health literacy education of students, but also for educators, parents, and the community. Some of the strongest advocates for mental health literacy in schools are parents. Parents play a huge role in any facet of a child's education, but especially in the arena of social emotional learning. For example, Fox, Eisenberg, McMorris, Pettingell, and Borowsky (2013) found parents support schools implementing education for depression and suicide. Fox et al. (2013) found through a survey that Minnesota parents also supported schools establishing depression and suicide programs. The follow up care of accessing mental health care is critical and parents are a key component in making this happen in most cases. To review, there are three areas that are beneficial to programs promoting mental health literacy. Those areas are knowledge acquisition, decreasing stigmatizing attitudes and developing help-seeking behaviors. 


\section{Knowledge Acquisition}

The key to mental health literacy programs is that one gains the knowledge to recognize mental illness in themselves or others. Mental health literacy programs have been successful in improving knowledge and impacting youth's attitudes (Kelly et al., 2007). For instance, depression literacy is a great example of knowledge acquisition with mental health literacy programs.

Depression affects a significant number of students; according to Birmaher et al. (2007), eight percent of adolescents meet the diagnostic criteria for depression. Youth who experience depression are at an increased risk for legal problems, physical illness, early pregnancy, and poor work, academic, and social functioning (Fergusson \& Woodward, 2002; Lewinsohn, Rohde, Seeley, Klein, Gotlib, 2003). Depression is difficult to handle whether or not one recognizes the symptoms, which can lead to dealing with this ill state of being in negative ways. Depression and the suicidal behavior that sometimes accompanies it are a significant issue that need to be addressed because it is a matter of life or death (Miller \& Eckert, 2009; Miller, Eckert \& Mazza, 2009). Depression can also make a return appearance later on in life. According to Fergusson and Woodward (2002), "Young people having early depression were at increased risk of later adverse psychosocial outcomes. There was a direct linkage in which early depression was associated with increased risk of later major depression and anxiety disorders" (p. 225). If young people do not learn the skills to cope with their depression, they could possibly continue to struggle throughout their adult lives. King and Vidourek (2012) agreed that teens will exhibit warning signs of depression, and these warning signs are also similar to warning signs of suicide; therefore, developing an awareness of these signs can provide early interventions. Even though depression literacy is a good idea for young people, many feel that there is a lack of mental 
health literacy. McCarthy et al. (2011) shared that one reasons adolescents are not receiving treatment for their depressions is the lack of education about what they are experiencing and what supports are available. Lack of information on depression or any mental health issue prevents treatment, which can cause troubling issues in any person's life.

\section{Stigmatizing Attitudes}

An additional factor to preventing treatment for those who suffer with mental illness is a perceived stigma around mental illness. According to Hart et al. (2014), improving knowledge about mental health decreases stigma connected to mental health concerns and also increases help-seeking behaviors. In examining barriers Gulliver, Griffiths and Christensen (2010) found:

Young people perceived stigma and embarrassment, problems recognizing [sic]

symptoms (poor mental health literacy), and a preference for self-reliance as the most important barriers to help-seeking. However, there was evidence that young people perceived positive past experiences, and social support and encouragement from others as aids to the help-seeking process. (p. 113).

To support the idea that mental health literacy programs can reduce the stigmatizing attitudes around mental illness, two studies also supported this notion. For example, after a systemic review of school based interventions to reduce mental health stigma, Schachter et al. (2008) found that implementing a structured curriculum may be the intervention demonstrating the most promising outcomes in impacting the negative stigma associated with mental health. Also, a study by $\mathrm{Ng}$ and Chan (2002) revealed significant positive changes, which could last a longer period of time, in specific attitudes on separatism and stigmatization of people with mental illness among students after the training program. Ultimately, the importance of reducing stigmatizing attitudes is to promote help-seeking behaviors. 


\section{Help-seeking Behavior}

Lack of knowledge is a barrier to treatment when one lacks the understanding of what is happening to themselves or those close to them. Gulliver et al. (2010) found that lacking mental health literacy is a barrier in adolescents seeking help. A benefit to knowledge acquisition is the access to mental health care. In a two-year follow-up, Fox et al. (2013) found in their study that:

Two-thirds of those referred had accessed mental health care.... the barriers to follow-up were related to poor knowledge of depression. These findings reiterate the value of depression education to improve knowledge and subsequent help-seeking behavior for both adults and youth. (p. 461)

If students do not understand how they are hindering themselves, it is difficult for them to understand the criticalness of treatment and the means necessary to access it. Also, Kelly et al. (2007) found that students tend to turn to their own peers, but their own peers are not equipped to help with mental illness; only about $25 \%$ of teens said they would talk to an adult for help and about $50 \%$ shared that they would help their friend on their own through positivity. Therefore, increasing students' mental health literacy could also increase seeking help for not only themselves, but for others around them. Lastly, the other risk in teens not recognizing these signs and not seeking help is the risk of suicide. "Suicide is the second leading cause of death among persons aged 10-24 years in the United States" (Sullivan, Annest, Simon, Feijun, \& Dahlberg, 2015, p. 201). King (2006) emphasized that it is critical that young people know what the warning signs are of depression and suicide, so they know what to do to get help. The benefit of knowledge extends beyond one individual person as seen in these examples in which help-seeking behaviors can make a tremendous impact. 
Knowledge acquisition, decreasing stigmatizing attitudes and increasing help-seeking behaviors seem to make a positive impact on students. Thus, the next section will detail examples of effective mental health literacy programs.

\section{Effective Mental Health Literacy Programs}

Many of the following studies and evaluations demonstrate positive effects with knowledge acquisition, decreasing stigmatizing attitudes and increasing help seeking behaviors. Mental health literacy programs seem to follow two common approaches. One approach is that the program focuses on specific mental health conditions like depression (Merritt et al., 2007; Naylor et al., 2009; Strunk, King, Vidourek, \& Sorter, 2014; Swartz et al., 2016); this would include depression education. The other approach focuses on a general mental health understanding of other mental disorders (Ng \& Chan, 2002; Skre et al., 2013). This section will include examples of both.

The following studies are examples of a program that focuses on specific mental health conditions. For example, Mcluckie, Kutcher, Wei and Weaver (2014) analyzed the impact on mental health literacy of a high-school mental health curriculum (The Guide) in Canadian schools. They conducted a secondary analysis from pre/post-survey information from 265 students, who had experienced The Guide. "The Guide is a manualized mental health literacy resource consisting of six modules that are delivered in 10-12 hours of class time through a mix of didactic instruction, group discussion, group activities, self-directed learning and video presentations" (p. 91). This study showed that a high school mental health curriculum can improve students' knowledge of mental health and attitudes, as well as reduce the stigma associated with mental health disorders (Mcluckie et al., 2014). The study also showed that a mental health curriculum can be delivered in the usual school curriculum with its own teachers 
and does not require outside interventions to make a difference (Mcluckie et al., 2014).

Mcluckie et al. (2014) found "student knowledge scores following exposure to The Guide is significantly and substantively higher than baseline student knowledge scores” (p. 94). Mcluckie et al. (2014) also found "no significant differences identified between post-test and 2 month follow-up ( $p>0.05)$, suggesting attitudes maintained overtime" (p. 95). The impact of enhancing knowledge and reducing stigmatizing attitudes increased the likelihood of helpseeking behaviors; whether this approach actually increases help-seeking behaviors is an area for further examination (Mcluckie et al., 2014). Overall, Mcluckie et al. (2014) advocated for a foundation of mental health literacy for students in order to build other mental health interventions.

Another mental health literacy approach is a depression education program, the Johns Hopkins Hospital's Adolescent Depression Awareness Program (ADAP), the focus of this study. After discovering that the majority of suicide prevention programs did not hold mental illness at the forefront of why people contemplate or complete suicide, the team at the Johns Hopkins Hospital created a program to address this need (Swartz et al., 2010, p. 2). The ADAP intends to teach students, teachers, and parents about the illness of depression. According to Swartz et al. (2010),

In all cases, the resounding message is that suicide is not a normal part of adolescence and a trusted adult should always be informed when an adolescent has thoughts of suicide. This approach was chosen to put suicide in the context of an illness needing treatment, rather than a normal response to a stressful event. (p. 4)

This perspective on suicide is important as some people unfortunately think that suicide happens in response to a negative event in someone's life rather than mental illness. This approach is also 
evident in their training and on their website where their core message is shared: "depression and bipolar disorder are treatable medical illnesses and that concerned individuals should seek help. Through this work, the ADAP aims to increase awareness about mood disorders in young people while stressing the need for evaluation and treatment" (Swartz, 2016, para.1). The creators of the ADAP believe: "Education, identification, and treatment of psychiatric disorders, particularly depression, are alternative strategies for suicide prevention. Major depression, frequently the diagnosis determined on psychological autopsy following a completed suicide, is one of most common illnesses affecting teenagers" (Swartz et al., 2010, p. 2).

The ADAP, the focus of this study, is an example of depression education, which falls under the umbrella of a mental health literacy approach. The program can be implemented in any high school classroom and many times is incorporated in health classrooms. After approximately a five hour training, teachers can teach the ADAP curriculum, which is a three hour curriculum. The ADAP uses the Adolescent Depression Knowledge Questionnaire (ADKQ) as an anonymous pre-survey and post-survey element that assess students' understanding of depression and resources to help those who exhibit signs of depression (Swartz, 2016). In one study, the ADAP was used to determine the connection between school climate, depression literacy and mental health stigma (Townsend et al., 2017). In this study, positive school climate was connected to greater depression literacy and fewer stigmatizing beliefs connected to students. Also, in another study, Swartz et al. (2010) found that students scoring $80 \%$ or higher on the ADKQ tripled from pre-test to post-test. Both studies show a positive side to using the ADAP in a high school curriculum.

Another study that focuses on specific mental health concerns by Strunk et al. (2014) found that most school programs have not been evaluated rigorously for their effectiveness, but 
they believed that school-based prevention programs can be an effective method in increasing students' ability to seek help. To evaluate the direct impact of the Surviving the Teens ${ }^{\circledR}$ Suicide Prevention and Depression Awareness Program, Strunk et al. (2014) used a comparison group to examine any differences from group participants on pre-test and post-test measures. Surviving the Teens ${ }^{\circledR}$ Suicide Prevention and Depression Awareness Program is delivered in health classes in four 50-minute sessions over 4 consecutive days (Strunk et al., 2014). Students from nine high schools were surveyed one day prior to the program and again directly after the program; 966 participated in the program group and 581 were in the control group (Strunk et al., 2014). The outcomes of this study showed many positive outcomes. First, "the program group had a greater increase in knowledge of suicide risk factors, myths, facts, and perceived importance in knowing suicidal warning signs and steps to take with suicidal friends than the comparison group from pretest to posttest" (Strunk et al., 2014, p. 609). From pre-test to post-test, the study also reported a drop in stigma toward suicide, depression, and counseling for mental health concerns (Strunk et al., 2014). Finally, students in the program showed an increase in confidence in helping a suicidal friend, which may also contribute to students' increasing ability in seeking help in the posttest (Strunk et al., 2014). Strunk et al. (2014) also shared that "two final important outcomes of the program are that the program group showed a greater increase in selfesteem and frequency in communicating/handling problems from pretest to posttest than the comparison group" (p. 611). The program tried to reinforce the program's s aims through specific steps, additional building activities, and encouraging outreach to surrounding adults.

Another study that highlights mental health conditions is by Naylor et al. (2009), which encompassed a two group pre-post-test control group design; one school received a teaching intervention on mental health issues; another group was given access to the materials on 
completion of research. Naylor et al. (2009) found that "there were a number of positive effects of the six lessons on pupils' understanding of mental health difficulties. Both boys and girls showed increased empathy in understanding: why some people become depressed, why some people think life is not worth living; how bullied people are affected" (p. 368). Also, increasing knowledge about mental illnesses helped reduce stigma among teens (Naylor et al., 2009). Further research is needed for the impact on help-seeking behaviors.

Another study that focused on more general mental health literacy development is by Skre, et al. (2013) and investigated the impact of a mental health literacy program called "Mental Health for Everyone," which is a three-day universal education program for adolescents. The study included 1,070 adolescents from three Norwegian schools, one school receiving the intervention and two schools being the control group. There was a pre-test of 66 questions and a follow-up three months later. Skre, et al. (2013) found that the results were improved mental health literacy based on this school program and more openness to receiving help in a primary health care facility. They concluded that a mental health literacy program in schools does not cost much and improves mental health literacy for adolescents (Skre et al., 2013). Students gained knowledge about anxiety, depression, schizophrenia, and anorexia; and more specifically, "this study demonstrated that adolescents prejudiced beliefs about mental health problems can be changed" (Skre et al., 2013, p. 885). Furthermore, there is was a difference between age groups; for example, " $10^{\text {th }}$ graders (mean age 15 years) knew more than $8^{\text {th }}$ graders (mean age 13 ) and the age difference in knowledge increased after the intervention" (Skre et al., 2013, p. 885). Skre et al. (2013) also found that the older students were more receptive to using their primary health care place for help. Overall, this study showed positive results after implementing a three-day program for students on mental health literacy. 
In another example, Kelly et al. (2007) found that mental health literacy interventions were poorly researched. They focused their evaluation on four different types of mental health literacy programs in the areas of whole-of-community, community, school-based and individual training programs. Kelly et al. (2007) were not able to discern common components that would be effective in teaching young people about mental health, but they suggested that it is important to know your audience in order to tailor messages to various groups. Mental Health Literacy can make an impact on students in school, but one must consider their school culture and what program best serves the needs of the community. King (2006) emphasized that "adolescents who felt positively connected to their family and school were significantly less likely than adolescents who did not feel positively connected to have seriously considered or attempted suicide in the past year" (p. 9). It is also important to note that the idea that a combination of programs may work better in conjunction with one another than just one alone (Katz et al., 2013), especially because mental health literacy is part of the larger umbrella of social and emotional learning.

\section{Timing of Adolescence and Role of the School}

A significant part of the literature connected to mental health literacy is the importance of mental health literacy during adolescent years and the role of schools in that education. Schools are identified as a time and place for students to learn about mental health needs (Wei et al., 2011) and promoting social emotional learning (Durlak et al., 2011). Sanders, Shaw, Guez, Baur, and Rudd (2009) believed that "the educational system has a vested interest in building each child's health-literacy skills" (p. S310). Furthermore, Wei et al. (2013) shared that school and health professionals, as well as policy makers, recognize the importance of addressing the mental health needs of adolescents and fully support the implementation of mental health literacy 
programs in schools. Wei et al. (2011) highlighted that "the average teen spends over thirty hours per week in the classroom. Not only does the school offer a relatively focused and potentially cost-effective opportunity to reach youth, it is also a convenient place where mental health can be linked with other curricula" (p. 216). Timing and location make the adolescent years in school a prime target for mental health literacy.

Since many mental health disorders can first display symptoms and begin to manifest in adolescence, this provides another reason that secondary schools providing mental health literacy education is prevalent in the literature (Kessler, Bergland, Demler, Jin \& Walters, 2005; Sanders et al., 2009). Many substantive mental disorders first appear during adolescence (American Psychiatric Association, 2014; Kessler et al., 2005). The impact that mental health literacy can have on early identification, treatment and success of an adolescent and into adulthood emphasizes the importance of the timing of MHL. Wei et al. (2011) emphasized that "the earlier that mental health problems are identified and addressed through appropriate and effective intervention, the more likely beneficial effects may be achieved in both the short- and long-term" (p. 216). Furthermore, Wei et al. (2011) stated that teaching mental health literacy is critical during adolescence in order to increase their understanding of mental health and mental health illnesses, which will benefit them for their whole life. Sanders et al. (2009) agreed that "health literacy may be a critical and modifiable factor for improving preventive care and reducing health disparities" (p. S306). Untreated mental disorders can impact adolescents in many negative ways, which can include poor internalizing and externalizing behaviors. According to Bhatia and Bhatia (2007), "Major depression affects 3 to 5 percent of children and adolescents. Depression negatively impacts growth and development, school performance, and peer or family relationships and may lead to suicide" (p. 73). In addition, mental disorders can negatively 
impact a student's learning if the condition leads to chronic absenteeism (McEwan, Waddell, \& Barker, 2007). Students may also have difficulty making good grades or meeting academic standards (Adelman \& Taylor, 2006). Therefore, the lack of attention to mental health needs can have many negative effects on a person's life.

Furthermore, according to Kendal, Keeley and Callery (2011), "intervening early to address an emotional difficulty can prevent a clinical problem and may be more successful than waiting until it has become enmeshed in the personality of the individual" (p. 245). If a problem does become worse, students could consider other means of escaping their problems. For instance, Durlak et al. (2011) shared that many teens hinder their life success by engaging in high-risk behavior, such as substance abuse, sex, violence, attempted suicide, which impacts their academic performance negatively. Surmounting these problems can take much time and cause much stress and heartache to a student and his/her family. Schools have resources and community connections to help students and their families. Ball et al. (2016) stated:

School mental health (SMH) systems are integral to address children's mental health needs and increase access to these services. SMH systems often include a broad range of programs and services that include the prevention, early intervention, and treatment of students' emotional and behavioral problems, as well as strategies that enhance the learning environment and promote social and emotional development for all students (p. $313)$.

Of course, there is always room for improvement as Ball et al. (2016) mentioned that even though teachers are given the task of supporting students' mental health needs and teaching standards reflect the competencies of SMH, there is still not enough professional development in this area for teachers. Regardless, if SEL and MHL can help prevent some of these issues, the 
benefit to students' lives is motivation to implement a quality program or approach in every school.

Lastly, even though a handful of high school programs have been reviewed in this literature review, an important issue to recognize in this research is the lack of information or studies conducted at the high school level (Williamson et al., 2015). There seem to be many programs, but most of them are designed for elementary through middle school age students. Part of the philosophy is that if you can get students early enough, then they will have these skills later on in life. The truth is that people continue to build these skills over their lifetimes, but schools are an excellent opportunity for foundational social emotional skill-building to take place. Building SEL skills or mental health literacy skills to recognize depression during high school is a critical time period for an adolescent considering how much a student changes during this time personally, socially, and emotionally (Williamson et al., 2015). For example, in a meta-analysis by Durlak et al. (2011), only $13 \%$ of studies were at the high school level, and even then "these studies rarely are replicated, leaving few high school-specific or high schooltested programs that have been evaluated more than once" (Williamson et al., 2015, p. 185). Therefore, there is a pressing need to examine what type of programs work at the high school level with the focus being on mental health literacy.

\section{Important Elements in Maintaining Strong Programs}

The supportive components that are needed for building and maintaining any type of strong SEL program, including mental health programs, is administrative support, professional development, skill development, student connectedness, and evaluation. To have positive outcomes, programs need to incorporate certain components. In general, researchers advocated for administrative support, systemic programming, support and professional development, skill 
development, and student connectedness (Harris, 2008; Kress \& Elias, 2006; Payton et al., 2000; Velsor, 2009; Zins et al., 2004).

\section{Administrative Support}

Support from administration communicates much to students and staff about the value of an approach or a program. Administrative supports sets a tone in any school culture about what is valued and what is important. Saying something is important is not as powerful as backing the concept or movement with resources and support. Another important point is addressed by Wanless, Groark and Hatfield (2015) in that administrative support also indicates organizational readiness, which can critically impact implementation of any initiative. Leadership support is critical because it impacts every aspect of the organization and its vision for program implementation. "Beyond supportive relationships with direct service providers, a strong commitment to the importance of SEL may be the most essential leader characteristic for successful implementation of SEL interventions" (Wanless et al., 2015, p. 365). In drawing from the literature of education reform and organizational change, Mart, Weissberg, and Kendziora (2015) advocated to work with district leaders as they control the resources and access to a larger number of schools.

\section{Professional Development}

Another aspect to helping develop or maintain successful SEL curriculum is to support the educators implementing the program with one-on-one guidance, professional development, and sufficient training or education as they begin to understand the goals and practices of the curriculum. Kress and Elias (2006) suggested that a learning community be created to provide time and structure for collaboration, so that decisions can be made involving input from multiple stakeholders. With multiple stakeholders investing time into the development of the program, 
there can be more buy-in and a better product. Developing these types of communities also built confidence in program delivery and engagement among both students and educators. DuFour (2004) supported the power of educators collaborating to improve student learning, and he shares, "Educators who are building a professional learning community recognize that they must work together to achieve their collective purpose of learning for all. Therefore, they created structures to promote a collaborative culture" (p. 9). Even though his research supports improved student learning, DuFour (2007) warned that professional learning communities succeed "on the most important element in the improvement of any school - the collective capacity, commitment, and persistence of the educators within it" (p. 7). For instance, some studies show that teachers with some structured training, support and background knowledge successfully implemented SEL lessons with students with much more regularity than their colleagues that lack this scaffolding (Linares et al., 2005; Payton et al., 2000). Just like academic interventions, it is not enough to have great lessons on a page; what is needed is an overall plan for implementation with a process for reflection, evaluation, and improvement.

\section{Skill Development}

Specific focus on skill development can provide sound structure for building or implementing any SEL program. The evidence that research provided regarding skill development and practical applications is widespread in the literature of effective SEL programs (Durlak et al., 2011; Elias, Bruene-Butler, Blum, \& Schuyler, 1997; Matthews et al., 2002;

Weissber and Cascarino, 2013; Zins et al., 2004). For skill development to be effective, students must be able to connect to the lessons, topics, and activities. Payton et al. (2000) also emphasized not only skill development, but establishing a clear order in which skills and concepts should be introduced. 
In education, the necessity of a general level of preparedness in the success of desired program outcomes can never be underestimated. As such, another important aspect of a successfully integrated SEL program includes general, organizational preparedness. For instance, Durlak et al. (2011) shared that their research has surfaced several recommendations for skill development, which includes a step-by-step training approach that use active learning with specific learning goals. A school that commits to implementing an SEL program needs to commit to providing the environmental supports that ensure this preparedness among the teaching staff.

\section{Student Connectedness}

By providing opportunity to prepare for the implementation of the program, teachers can ensure that it meets the cultural needs of the academic community. Student satisfaction and connection with any SEL program can make a huge difference in the receptiveness of what it has to offer. Sometimes in designing and laying out the most elaborate of plans, the voices of those the plans affect the most can be left out. Therefore, it is important to consider what students think and gather their feedback at multiple points throughout the process of implementation. According to Kendal et al. (2011), students will participate if they feel they have influence in the process, and they feel genuine empathy and trustworthiness from people with real experience. Two other preferences that surfaced in this study were confidentiality of information and discontinuing the use of peer mentoring. Another way to gather information on the effectiveness on students is from students themselves, such as through formative assessments and other opportunities to provide feedback. For instance, Marzano (2015) shared a system of formative assessments to help students form SEL goals and get meaningful feedback on those goals. Formative assessments can help students "with an understanding of why humans make decisions, 
and the power of making decisions that are based on well-reasoned beliefs as opposed to beliefs they have inherited from their past or their immediate surroundings" (Marzano, 2015, p. 346). Furthermore, Durlak et al. (2011) included that quality SEL instruction allows students to impact their school and community, which allows them a sense of belonging and increases their motivation. Students' ability to connect these skills beyond themselves only reinforces the skills gained in SEL programs and their application beyond the school environment.

\section{Evaluation}

Not only is a systemic approach important with SEL curriculum, but so is the continued evaluation of any program (Redding \& Walberg, 2015). Zins and Elias (2007) advised to “engage in program monitoring and evaluation services. Assess the extent and quality of SEL program implementation using identified benchmarks, and evaluate formatively and summatively whether goals are attained" (p. 245). Evaluating a program is a healthy process for all initiatives in schools and unfortunately is also a process that is often neglected. A quality evaluation of the SEL program will facilitate the implementation of needed improvements and building of a more successful program (Redding \& Walberg, 2015).

In order to avoid the dismissal of important programs, it is important to adhere to these elements of administrative support, professional development, skill development, student connectedness, and evaluation. Programs that are introduced without preparedness are often considered initiatives that are quickly forgotten by stakeholders essential to successful implementation. Without serious thought to implementation, structure, time, and evaluation it is more difficult to achieve the positive results that will continue to fuel the growth of these programs and as a result the greater opportunities we wish to afford our students. 


\section{Summary}

One aspect that is clear in the literature is that social and emotional learning and mental health literacy have a place in our education system, especially at the secondary level. Schools must build comprehensive programs to ensure the greatest potential for the positive impact on the largest number of students. Future research should include studies that help to strengthen SEL and MHL programs, as well as efforts to discover reliable and valid ways to assess social and emotional learning skills. There is also room for more quantitative information on these programs along with further examination of the impact on high school and post-secondary students. More specifically, Taylor and Dymnicki (2007) suggested:

Researchers have offered little information about how to (a) infuse SEL interventions into the regular academic curriculum; (b) include informal SEL practices outside of classroom lessons; (c) strengthen SEL by facilitating cooperation between parents and teachers; or

(d) create opportunities for students to learn through authentic experiences" (p. 228).

As with the implementation of any program, there is always room for growth. Weissberg, Durlak, Domitrovich and Gullotta (2015) shared that "numerous studies from implementation science have confirmed that a critical factor affecting outcomes of interventions is the quality of program implementation that is obtained" (p. 3). Programs must be evaluated and tailored to meet the needs of students in any particular school. Educators must continue to always keep in mind a vision for successful education for every student; they must monitor every aspect of that education, including the academic and the social and emotional. All three areas can be transformative in the lives of students. To ignore this type of learning neglects an important part of a student's education. Furthermore, waiting on this type of development to "just happen" in individuals can be detrimental to society. Ultimately, mental health literacy programs benefit 
students' academic and social and emotional well-being; schools must take the time to assess their needs and build programs according to student needs. 


\section{CHAPTER III: RESEARCH METHODOLOGY}

In this chapter, the research design and methodology are described and discussed. After reviewing the statement of the problem and research questions, a quantitative research design, exploring the statistical significance of a high school-level depression education program known as the Adolescent Depression Awareness Program (ADAP), is described. Given that various types of SEL programs can have an impact on students, this non-experimental research study investigated the impact of the ADAP on students' knowledge of depression and available resources. The quantitative design structure involved focusing on approximately 250 high school students, who have been taught the ADAP depression education curriculum and assessing their knowledge of depression and coping resources for depression by using the Adolescent Depression Knowledge Questionnaire (ADKQ) as a pre-test and post-test. The convenience sample of 250 students are enrolled in a Midwest suburban high school's health course, which is a graduation requirement and also includes the ADAP in their semester course. The structure of having a common measurement as a pre-/post-test lends itself to a quantitative design because it allowed for comparing that measurement and whether there was a change. This study included using the McNemar test to compare the dichotomous items in questions 1-20 \& 25 (Adedokun \& Burgess, 2012), as well as a chi-square analyses for questions 21-24 and comparison tables for questions 26-27. This chapter also includes ethical considerations and limitations to the study. Overall, the purpose of this non-experimental quantitative study was to gather data about the effectiveness of a depression education program on students' knowledge of depression and ways to cope with depression. 


\section{Statement of the Problem}

In education, barriers to student success are continuously explored with the intention to remove or overcome barriers in order for students to be more successful and increase their learning abilities. As human beings, the ability to manage difficulties in life are not necessarily a result of intellectual intelligence, but rather emotional intelligence (Brackett, et al., 2011; CASEL, 2005; Goleman, 1995). There are a variety of reasons that social emotional learning is needed in school, and high school age students are a prime group. For instance, childhood to adolescence is the time when children begin to display symptoms of mental disorders, so it is important that young people know about the symptoms and how to get help (Jorm, 2000).

Overall, building social emotional learning skills for students can be significant to their academic and personal success (Durlak et al., 2011; Mayer \& Salovey, 2004; Weissberg \& Cascarino, 2013). Including mental health literacy as part of an SEL approach is critical because if students lack understanding this component, they may not reach out for help or know how to help others if impacted by depression. Even though the information could be beneficial much earlier, high school is a necessary time to incorporate education about mental health literacy. Often students are required to have some type of health education as a part of their graduation requirements, and mental health education is an important part of health education. Specifically, depression education includes suicidal thoughts as a major symptom of a depression, and suicide is a leading cause of death of young people (King, 2013). Therefore, educating high school students about depression can help them recognize symptoms of depression in themselves or others, which can help them to seek appropriate resources for treatment of depression. 


\section{Rationale for Quantitative Research}

This study was quantitative in design to highlight specific details about how teens may or may not learn information about depression. Since the ADAP already existed in this high school's health classes and teachers administered a pre/post-questionnaire as part of the program, the researcher decided to collect these data on a secondary basis. The ADAP related to the type of social emotional learning the research indicated as important. Therefore, data were collected that were quantitative in this case and these data were instructive about the program being reviewed, which is also of value to the high school.

The rationale for a quantitative design for this study consists of the following points. First, while assessing the social emotional field in a qualitative way can provide particular insight, the power in attempting to study the relationships quantitatively can provide a different scope of the impact of SEL. In current trends, many people examine and analyze data to make decisions, which is very true in the field of education. Therefore, being able to examine the ADAP quantitatively may be more persuasive to an audience of educators. Second, the ADAP curriculum has an established pre-survey and post-survey known as the ADKQ, so it lends itself well to a quantitative design. The ADKQ assesses students' knowledge of depression along with their knowledge of resources to cope with depression. Therefore, the research was quantitative in that data were collected to see if the ADAP impacted students' retention about depression and resources to help depression. Lastly, survey research provides a "quantitative or numeric description of trends, attitudes, or opinions of a population" (Creswell, 2014, p. 13) or a way to "summarize the characteristics of different groups or to measure their attitudes and opinions toward some issue" (Ary, Jacobs, Razavieh, \& Sorensen, 2006, p. 31). There are many advantages to the survey design, which include using a valid and reliable survey designed by the 
Johns Hopkins Hospital, results within two months of the program administration, and also being able to assess the impact of the ADAP on a larger number of students. In deciding whether a program is effective, this design gave tangible numeric data to help make a decision for the continuation of the program.

\section{Research Questions}

This quantitative study examines the students' levels of understandings about depression and knowledge about resources to cope with depression. The following research questions guide this study:

1. What levels of understanding do students retain about depression after participating in the ADAP curriculum?

2. What levels of understanding do students retain about the resources to cope with depression after participating in the ADAP curriculum?

The hypotheses below are designed to explore if the ADAP curriculum made an impact on student knowledge about depression and resources to help themselves or others. For each of the research questions, there is a testable null and research hypotheses.

\section{Hypotheses}

Null Hypothesis 1

$\mathrm{H}_{01}=$ There is no difference in students' levels of understanding of depression after experiencing the ADAP.

\section{Research Hypothesis 1}

$\mathrm{H}_{1}=$ There is a difference in students' levels of understanding of depression after experiencing the ADAP.

Null Hypothesis 2 
$\mathrm{H}_{02}=$ There is no difference in students' levels of understanding of resources to cope with depression after experiencing the ADAP.

\section{Research Hypothesis 2}

$\mathrm{H}_{2}=$ There is a difference in students' levels of understanding of resources to cope with depression after experiencing the ADAP.

The first research question of this study focuses on what levels of understanding students retain about depression after the ADAP. The null hypothesis for RQ 1 is that there is no difference in the students' levels of understanding about depression after experiencing the ADAP. The research hypothesis for RQ 1 is that there is a difference in students' levels of understanding of depression after experiencing the ADAP. The McNemar test for dichotomous items was conducted to evaluate the students' levels of understanding depression after the ADAP. The McNemar test "is one of the very few statistical procedures available for pretestposttest analysis of related dichotomous variables" (Adedekun \& Burgess, 2012, p. 125). The $\mathrm{McNemar}$ test is a non-parametric statistical test that is described as a $2 \mathrm{X} 2$ cross classification of paired responses (Adedokun \& Burgess, 2012). Comparing the mean group differences between these paired responses is the crux of this research because it will indicate whether or not students have retained knowledge about depression. For Questions 21-24, since all are categorical variables at a nominal level, a chi-square test statistic was used to check for any statistical significance in the pre-/post-test responses.

The second research question focuses on students' levels of understandings of resources to help cope with depression for themselves or someone they know. The null hypothesis for RQ 2 is that there is no difference in students' levels of understandings of resources to cope with depression after experiencing the ADAP. The research hypothesis for RQ 2 is that there is a 
difference in students' levels of understandings of resources to cope with depression after experiencing the ADAP. The McNemar test for dichotomous items was conducted to evaluate the students' levels of understanding resources to cope with depression after the ADAP for question 25, whereas the chi-square test was used for questions 21-24 and a comparison table for questions 26 and 27. The pre-/post-test results were examined using these three methods to see the differences from pre-/post-survey results. This procedure of comparing the differences between paired responses helps the researcher to determine the difference in students' knowledge of depression after the ADAP curriculum is taught.

\section{Research Design}

This quantitative research study is a non-experimental survey design (Ary et al., 2006; Creswell, 2014). The ADAP includes a pre-survey called the Adolescent Depression Knowledge Questionnaire (ADKQ) that is administered before the three-day program designed to increase student awareness of symptoms of depression and resources to help with depression. The postsurvey is administered six weeks after the program to assess whether students have retained information and resources from the program.

According to Johnson (2001), there is a two-dimensional classification of nonexperimental quantitative research. "The first dimension is based on the primary "research objective" (i.e., description, prediction, and explanation), and the second dimension is called the "time" dimension (i.e., cross-sectional, longitudinal, and retrospective)" (Johnson, 2001, p. 3). This study would be considered descriptive, non-experimental research because the researcher is primarily describing the phenomenon" or "documenting the characteristics of the phenomenon" (Johnson, 2001, p. 9). This non-experimental design was chosen because there is no manipulation of the independent variable. The independent variable is the ADAP curriculum, 
which has been designed and evaluated by the Johns Hopkins Hospital for many years. The dependent variables are: students' knowledge of depression and their knowledge of resources to help depression.

The purpose of this non-experimental, study is to inform educators about the retention of student knowledge concerning depression and how to seek resources to help treat depression after participating in the ADAP curriculum. Possible threats to the internal and external validity of this research design can include students' perceptions of the importance of the topic, their honesty while taking the questionnaire, and their attendance in all three days of the program. At the start of the ADAP, if the instructor follows the instructions and shares that their responses are anonymous, then this can potentially address these threats. Since one of the instructors of the ADAP curriculum is delivered by their own health teacher, this can benefit the students' responsiveness to the information about depression given that they have established, hopefully, a positive relationship with the health teacher. The other benefit of the program is that the pre/post-questionnaire is anonymous for students. Those who teach the ADAP receive training that includes an instructional slide that covers the pre-/post-survey anonymity. Being assigned an identification number also helps in this way rather than asking for participants' names on the survey. Clarity about the anonymity of the instrument helps address the threat of students' honesty on the instrument. Ultimately, this analysis will enhance the ability of educators to make informed decisions about the continuation of the ADAP.

\section{Research Setting}

This study was conducted in a large high school located in the suburbs of a large Midwestern city. According to the Illinois State Report Card (Illinois State Board of Education, 2016), the enrollment in this school is 2,759 students. The student population is also described 
as $14 \%$ low income students, $8 \%$ students with disabilities, $3 \%$ English learners, and 1\% homeless. The student population has a similar number of students per grade level, which ranges from 660-700 students per grade level (ISBE, 2016). The racial/ethnic diversity is described as 61.9\% White, 23.6\% Asian, 8.9\% Hispanic, 2.8\% Black, 2.6\% two or more races, $0.1 \%$ American Indian, and $0.1 \%$ Pacific Islander. The school is nationally recognized by the U.S. Department of Education as a Blue Ribbon School of Excellence (ISBE, 2016). All teachers are highly qualified based on the guidelines set forth by the Illinois Board of Education. The health teachers are certified to teach health and physical education classes. The ADAP instructors at this high school include all health teachers and a member of the Student Services department (school counselor, social worker, or psychologist). All the ADAP instructors are trained in the ADAP curriculum by attending a one-day workshop or five hours of online training. The ADAP curriculum takes place during the semester-long health course as part of the unit focusing on stress. The course also covers other topics connected to nutrition, drug education, obesity, eating disorders, diseases, pregnancy, date rape, cardiopulmonary resuscitation (CPR), and fitness. Further student supports at this high school include a mentoring program for freshmen, reading specialists, special education program, as well as 12 school counselors, two social workers, two psychologists and a nurse.

\section{Study Sample}

The study will include a convenience sampling based on the students currently enrolled in health classes. Each of the health classes at this high school includes the ADAP in their curriculum for the academic school year. Each semester, there are approximately 120-150 students enrolled in health classes and experience the ADAP curriculum on depression education during their stress unit. This study will include data collected for three semesters (spring 2015, 
spring $2016 \&$ fall 2016), so the total number of students could include approximately $360-450$ students. Spring 2015 was the first time that the ADAP took place in all health courses that semester. The health course is a high school graduation requirement, therefore the students in the class could be in grades 10,11 or 12 .

\section{Data Collection}

Data collected for this study include two sources: the Illinois Report Card (2016) data and the Adolescent Depression Knowledge Questionnaire (ADKQ). The Illinois Report Card data provides information about the school and district. Illinois Report Cards are available online for all Illinois public schools; the information is updated every year according to the academic calendar. The second data source comes from the ADKQ, which was designed by the Johns Hopkins Hospital. The Illinois Report Card data was accessed in 2016; the pre-/post-ADKQ data was accessed in the Spring 2015, Spring 2016 and Fall 2016. More detailed information about the ADKQ is included in the next section.

It is important to note that data analyzed for this study come from previously collected data and the analyses of these data for the purposes of this study were secondary in nature. The $\mathrm{ADKQ}$ is administered prior to the ADAP curriculum (pre-questionnaire), and then the same questionnaire is administered a second time (post-questionnaire) six weeks later to determine if students have retained knowledge about depression symptoms and resources to help with depression. Students are assigned a unique identification number before taking the online version of the ADKQ. The unique identification numbers are only accessible by the health teachers and students. The researcher assisted in bringing this program to this particular high school and also helped to teach the ADAP curriculum to one section of the health class each semester. Health teachers administer the pre- and post-questionnaire on their own, the researcher 
was not present in the classroom at those times. Students take the questionnaire online each time and the results are sent directly to the Johns Hopkins Hospital with only their identification numbers and no other identifying information. Unique identification numbers are assigned in order to match up the pre-survey with the post-survey results, as well as to maintain anonymity and confidentiality. Results are then be returned to a school administrator when requested. Since the data have been collected as secondary data and the results are anonymous, informed consent is not required. The ADAP is an existing program within each health class at this high school, so the information is being accessed from already existing data. Students who participated in ADAP during the spring of 2015, spring of 2016 and fall of 2016 were not made aware of this study at the time as it was not yet an established or approved study. However, they were informed that the pre-/post-questionnaire would be sent anonymously to the Johns Hopkins Hospital. The purpose of this study is to analyze data collected to evaluate the impact on students' knowledge of depression and resources.

\section{Instrumentation}

This section will share the origins, the background and the contents of the ADKQ to understand why certain statistical tests were chosen to analyze the results. To begin, the ADKQ was used in its entirety without any modifications. The ADAP team at the Johns Hopkins Hospital has granted permission (Appendix D) to use the instrument, which was granted based on the approval of Illinois State University's Institutional Review Board. The purpose of using a survey design is to gather information about a particular topic in order to understand how a sample population may feel or think about that topic (Creswell, 2014). A survey method produces statistics that are numerical descriptions of the way a population responds (Creswell, 2014). One benefit of a survey method design is that it permits the researcher to gather 
information from a larger group of subjects (Jackson, 2009). Administration of the ADKQ survey will gather data from multiple health classes with over 250 high school students, which will serve as a convenience sample of students enrolled in the health classes. Ary et al. (2006) noted that administering a survey via the internet saves time and money, which usually means a higher sample population. The ADKQ survey is administered online, and more importantly, allows for anonymity of the respondents. The fact that the pre-test and post-test can be connected via an identification number without any identifying information protects each subject and hopefully allows for honest answers in responding to the survey.

The ADKQ was developed as part of the ADAP, which was designed to increase mental health literacy for adolescents. In 1999, two psychiatrists and a psychiatric nurse developed and began teaching the ADAP to 530 students in eight schools (Swartz et al., 2010). In the following six years, the program grew and developed in many ways. The developers recognized a lack of assessment tools in the area of depression knowledge and help-seeking attitudes, and therefore, developed the ADKQ in conjunction with the ADAP (Hart et al., 2014). Also, "the pre-test and post-test ADKQ comparisons demonstrated that teaching the curriculum in multiple sessions (intervention group) compared to a limited one-session curriculum (control group) effected a greater improvement in ADKQ scores" (Swartz et al., 2010, p. 13). The next steps included revising the curriculum and training additional psychiatric clinicians along with medical and nursing students to teach the ADAP. Later, the team also expanded the teaching of the curriculum to using the students' own teachers, which allowed for more outreach of the program.

To understand the instrumentation more fully, it is important to know what the ADKQ assesses and the content of its questions. The ADKQ was developed to assess students' knowledge and attitudes about depression, which is the main goal of the ADAP (Hart et al., 
2014). The instrument contains a total of 28 items, which vary in style of questioning (Appendix C). The first 20 questions in the ADKQ are yes-no questions, which "were designed to test factual knowledge about depression" (Swartz et al., 2010, p. 4). The remaining questions fall in the Attitudes section, which include four questions (\#21-24) that present different scenarios about people in difficult situations. Students read the descriptions and are provided with three choices: (a) he/she is having a rough time, (b) he/she has the medical illness of Depression, or (c) he/she has the medical illness of Bipolar Disorder. For each question, students are asked to select how confident they are about their choice: (a) not at all sure, (b) somewhat sure, (c) almost sure, or (d) very sure. The last four questions (\#25-28) gather additional information concerning the respondents' attitudes in regards to seeking help for depression. Question 25, "If you thought that you or a friend was depressed would you encourage him/her to ask for help?" is a yes/no questions. Question 26 asks students which three people they would be most likely to ask for help and provides 14 possible responses including "no one" and "I don't know." Question 27 asks students to identify the response that describes what would make it difficult to get help for themselves or for a friend. There are 13 possible responses including being judged by others, denying having an illness, not wanting to lose a friendship, having too much pride to ask for help, feeling embarrassment, being afraid of getting treatment, worrying about what friends would think, not knowing who to ask for help, feeling too depressed to ask for help, fearing the reaction of parents/adults, worrying other will find out, feeling that no one will understand, and nothing would stop me. The last question (\#28) asks what the student would do if a friend asked them to keep their depression a secret: responses include keep it a secret, keep it a secret unless it gets serious, tell someone, or I don't know. 
According to Hart et al. (2014), "to the best of our knowledge, there are no validated measures to assess the construct of depression literacy" (p. 215). The items for ADKQ were designed by professionals in treating or researching mood disorders. Hart et al. (2014) state, "The core ADAP team, consisting of psychiatrists, psychiatric nurses, and medical students, evaluated the items. The scale developed over time through feedback from facilitators of, students receiving, and evaluators of ADAP" (p. 215). Therefore, the ADKQ has undergone many revisions since its beginning stages and some small modifications since 2014 .

The ADKQ is the online pre-test and post-test survey designed to gather information on the topic of depression, in order to provide a clearer understanding of students' knowledge of depression and resources to help depression. In the study, approximately 250 students will participate in the survey before and after the curriculum in their health class. Research has indicated that the ADKQ is a reliable and valid instrument for the purpose of assessing students' knowledge and attitudes about depression (Hart et al., 2014). The research underpinnings for the development of the ADAP are connected to helping the treatment of depression, decreasing suicide and other negative consequences, as well as decreasing high-risk behaviors in young people. In helping the treatment of depression, Hart et al., (2014) shared that "there appears to be an inverse relationship between age at diagnosis and treatment initiation for these mood disorders" (p. 213). Since adolescents do not know as much about depression, they tend not to seek help as often as adults do. An adolescent is more likely to seek help if knowledgeable about mental disorders (Olsson \& Kennedy, 2010). Of course, the lack of treatment can have many consequences, the worst being suicide (Hart et al., 2014). In addition, a program, like the ADAP, explains that possible symptoms of depression include suicidal thoughts and behaviors, which are connected with both unipolar and bipolar depression (Hart et al., 2014). Lastly, 
research on adolescent risky behaviors during depression led the ADAP team in developing the ADAP and the ADKQ. These risky behaviors can include lack of education, sex, drugs, criminal behavior, and overall, lack of treatment. For instance, adolescent depression can have a significant impact on education in that the onset of mental health disorders is associated with early discontinuation of education (Lee et al., 2009; Quiroga, Janosz, Bisset, \& Morin, 2013). In addition to poor educational attainment, these depressive symptoms can also be associated with risky behaviors, such as multiple sex partners, criminal history, and substance abuse (Wickrama \& Wickrama, 2010). Essentially, the lack of treatment during the adolescent years seemed to indicate continued mental health problems in the adult years (Jonsson et al., 2011; Yaroslavsky, Pettit, Lewinsohn, Seeley, \& Roberts, 2013). Therefore, prevention and intervention strategies are suggested to cope with adolescent depression to improve decision making skills in adulthood (Yaroslavsky et al., 2013).

\section{Variables}

Since this is a descriptive, non-experimental design, there is no manipulation of the independent variable, the ADAP curriculum. The three-day program is taught to the students in health class over a three-day period. Each class is co-taught by the health teacher assigned to that class all semester along with a guest teacher, who is either a counselor or psychologist. Each of the staff members teaching the curriculum received training in the ADAP through a workshop or online modules. The instructors delivering the ADAP curriculum do not vary the curriculum from the original the ADAP design. Part of the ADAP training requires the ADAP instructors to sign a contract agreeing to deliver the curriculum as designed. Therefore, there was no manipulation of the independent variable as this is a descriptive, non-experimental design (Johnson, 2001). 
The two dependent variables are (a) students' knowledge of depression literacy, and (b) students' knowledge of resources to help someone with depression. The dependent variables were measured through the change in aggregate and group responses from the pre-test to posttest ADKQ. The first set of dependent variables connected to students' knowledge of depression are the first 24 items on the ADKQ. In the first 20 statements, students must identify whether or not the statement is true (Appendix C). The next set of dependent variables were assessed using responses from questions 21-24 and whether or not a student can identify someone who is having a rough time (ie., experiencing less than five depressive symptoms) versus someone who has the illness of depression or bipolar disorder (Appendix C). Lastly, the dependent variable of assessing a students' knowledge of resources to help depression was assessed through questions 25-28. Question 25 asks if a student would encourage a friend to ask for help if depressed and who they may go to for help. Therefore, the dependent variables of students' knowledge of depression and knowledge of resources to help depression will contribute to the assessment of the effectiveness of the independent variable, the ADAP curriculum.

\section{Reliability and Validity}

Creswell (2014) shared that examining the "validity and reliability of scores on instruments lead to meaningful interpretations of data" (p. 155). Reliability examines how consistently the instrument measures what it is supposed to measure (Ary et al., 2006). In order to understand the meaningfulness or genuineness of the scores, it is important to examine validity (Ary et al., 2006; Jackson, 2009). In other words, does the ADKQ provide truthful feedback about students' knowledge of depression? In this case, construct-related evidence of validity is important because the $\mathrm{ADKQ}$ "focuses on test scores as a measure of a psychological construct," which is depression literacy (Ary et al., 2006, p. 249). Creswell (2014) also shares 
that measuring hypothetical constructs has become more important recently in order to help find an instrument that might be good for future survey research.

Since the ADKQ is an existing instrument and there are no other known assessments of depression literacy, it is important to examine the existing literature on the reliability and validity of the ADKQ. In the study by Hart et al. (2014), the knowledge section of the ADKQ is evaluated for both validity and reliability. In examining validity, Hart et al. (2014) shared that figuring out "the internal, or latent, structure of the measure" is important and it would be evaluated through factor analysis (p. 217). Specifically, this analysis found that there were high correlations between the gender results, which was positive as the curriculum is taught to both male and female students. (Hart et al., 2014). Also, there were high correlations whether or not the program was taught by a school-based or outside facilitator (Hart et al., 2014). Therefore, the significance was that teachers within schools could be trained to teach the curriculum rather than the ADAP only being delivered by outside facilitators that are psychiatric professionals. Next, in regards to reliability, the authors examined internal consistency. The findings by Hart et al. (2014) included improvement from ADKQ pre-test to post-test results along with good reliability. The results reinforced previous research showing improvement from pre-test to posttest results in depression literacy after the ADAP based on student responses (Hart et al., 2014). The internal consistency was considered reliable at 0.89 (Hart et al., 2014). Hart et al. (2014) also shared that "As the latent structure remains the same over time, performance can thus be compared. Further, establishing measurement invariance within groups of interest (e.g., sex, facilitator) allows for future analyses to compare these groups" (p. 220). Consistent latent structure establishes the knowledge section of the ADKQ to be a valid and reliable instrument that is beneficial to the mental health field. 


\section{Data Collection Procedures}

Administration of the ADAP is an established program at this high school. Data utilized for this study will therefore be secondary data and, as such, do not require any type of informed consent procedure by the researcher. Students were notified that their pre- and postquestionnaire answers are collected anonymously and sent to the Johns Hopkins Hospital. Therefore, the researcher contacted the program coordinator at the Johns Hopkins Hospital to request data from the spring of 2015, spring of 2016 and the fall of 2016. Prior to receiving data for analyses, the ADKQ data was sent directly to the dissertation committee chair, who ensured that there were no identifying student information aspects in the data set.

Each semester, at the study high school site, the ADAP takes place during the first month (September and February) of health classes during a stress unit. Currently, the three-day program is co-taught by a health teacher and a school counselor or psychologist. At the start of each semester, the ADAP coordinator from the Johns Hopkins Hospital emails a high school staff member to inquire how many classes participate in the ADAP that semester and then will follow up with an instructional email to administer the pre-/post-test (Appendix A). The email includes one sign in sheet per class with enough identification numbers for a class of 32 students (Appendix B). Before the three-day the ADAP begins, students are briefly introduced to the program and asked to complete an online questionnaire by their health teacher, known as the ADKQ. In this introduction, students are informed that the purpose of the ADKQ is to inquire about their knowledge of depression before the ADAP. It is not graded and results are anonymous. At that point, the health teacher will assign students a random identification number that students will enter online as part of the ADKQ. Aside from their gender, students are not asked for any other identifying information. Students complete the questionnaires online, which 
are directly submitted to the ADAP team at the Johns Hopkins Hospital. The health teacher maintains the students' identification numbers until six weeks later when the post-test ADKQ is administered. Without any additional review from six weeks prior, students were given the same questionnaire (post-ADKQ). Students were reminded by their health teacher of the identification number to enter online, and then the identification numbers are destroyed.

After the pre-/post-test data were completed for all three semesters, the ADAP team completed a file of the requested secondary data. Survey data did not include any student identifying information, but data was stored on an external hard drive in a locked cabinet at the high school to which the researcher will have sole access. This original was kept as a backup file under a new name before importing it into SPSS for analyses. All files and related documents are kept in a filing cabinet in the researcher's office at the high school for five years (Creswell, 2014). After five years, all paper and electronic files will be destroyed.

\section{Data Analyses Procedures}

After all the survey data were collected and cleaned, they were imported into SPSS. The research design followed Creswell's (2014) suggested six step process for data analysis. First, information was reported about the sample, which will include number of participants and their gender. In step two, a method is chosen to address response bias since the study includes only those who participate on both the pre-test and post-test. Bias could indicate different overall results because it indicates that students who did not respond may have changed the results (Creswell, 2014). One of the reasons a student may not respond is because they were absent on the day of the pre- or post-survey. One way to possibly check for respondent/non-respondent bias is to remind absent students to complete the survey on their own or to complete it before class begins the next day. According to the Illinois School Report Card (2015-2016), students at 
this particular high school have a $96 \%$ average of daily attendance, so the potential impact of an absent student is minimized. In steps three through five, a descriptive analysis of the data was provided that goes beyond descriptive statistics and identifies the best statistical methods for this study and hypotheses (specific details included in next section). In the last step, the researcher will prepare and discuss the results, as well as any conclusions.

\section{Data Analyses}

The first research question of this study centers on the impact of the ADAP on students' retention of information about depression. The main type of data analyses used for this study was inferential statistics, so that inferences can possibly be made about the larger population based on a smaller sample. Prior to running inferential analyses, the researcher also ran descriptive statistics for all the variables to check the coding and accuracy of the data. This means that data was checked for errors and cleaned to eliminate incomplete or duplicated entries. Descriptive statistics were used to analyze and address each of the research questions.

\section{Research Question 1}

What levels of understanding do students retain about depression after participating in the ADAP curriculum? Research Question 1 focuses on what levels of understanding students retain about depression after the ADAP. The null hypothesis for RQ 1 is that there is no difference in the students' levels of understanding about depression after experiencing the ADAP. The research hypothesis for RQ 1 is that there is a difference in students' levels of understanding of depression after experiencing the ADAP. The McNemar test was used to evaluate the students' levels of knowledge about depression after the ADAP. Specifically, data from questions 1-24 will help in analyzing RQ1 (students' levels of understanding of depression). Since questions 120 are yes/no answers, the levels of measurement is nominal for the dependent variable of 
students' knowledge of depression. The independent variable is the ADAP curriculum. The McNemar test will examine differences on dependent variables that are dichotomous for two related groups (Adedokun \& Burgess, 2012). In this study, the pre-test and post-test were given to the same group of students. The McNemar test is one of the few statistical procedures that can be used for analyzing pre-test and post-test with related dichotomous variables (Adedokun \& Burgess, 2012). Comparing the difference between these paired responses is the crux of this research because it communicates whether or not students have retained knowledge about depression.

\section{Research Question 2}

What levels of understanding do students retain about the resources to cope with depression after participating in the ADAP curriculum? The secondary Research Question 2 focuses on the retention level of students' understanding of resources to help cope with depression for themselves or someone they know. The null hypothesis for RQ 2 is that there is no difference in students' levels of understandings of resources to cope with depression after experiencing the ADAP. The research hypothesis for RQ 2 is that there is a difference in students' levels of understandings of resources to cope with depression after experiencing the ADAP. Specifically, data from questions 25-28 in the questionnaire was analyzed to understand students' levels of understanding resources to help cope with depression (RQ2). Again, the independent variable is the ADAP curriculum. Data for both RQ 1 and 2 were entered into SPSS for measurement in order to analyze the data. Three different methods that were used to compare data for RQ2: McNemar test, chi-square tests, and a comparison table. For question 25, the McNemar test for dichotomous dependent variables were also conducted to evaluate the students' levels of understandings of resources to cope with depression. The pre-/post-test 
results are examples of paired responses that were analyzed by the McNemar test, which measures the difference between the paired responses for dichotomous responses (Adedokun \& Burgess, 2012). For questions 26 and 27, a comparison table containing count totals for each category was created to compare pre-/post-survey results. For question 28, a chi-square test was used to assess the significance before and after the ADAP curriculum in students response of what to do if experiencing depression or knowing someone who is experiencing depression. This procedure of comparing differences between paired responses helps the researcher to determine the difference in students' knowledge of depression resources after the ADAP curriculum is taught.

\section{Limitations}

Limitations in this study include survey methods, sample size, type of study and focusing on one aspect of SEL. In survey research, there is a limitation of available participants. The pretest is given before the ADAP, and the post-test is given six weeks later. Data are limited to students who complete both surveys before and after the ADAP; students who are absent one of those days will not be a part of the survey results. There is also a limitation on any demographic information about the student as the only information gathered is gender. It is assumed teachers followed the curriculum accurately and data were collected with integrity and complete anonymity by the Johns Hopkins Hospital. There are also no other known measurements of depression literacy and can be considered as a limitation since there is a lack of comparison. The study is limited to students who are enrolled in health class during these three semesters in one high school only, and may not be generalizable to other grade levels or schools. Also, this quantitative study is limited by the scope of two research questions and connecting hypotheses. It is assumed that the researcher maintained the trustworthiness and reliability of the study by 
following the guidelines of the Institutional Review Board. Finally, the study does not cover all aspects of social emotional learning, but rather focuses on depression education, which may not be generalizable to other SEL approaches.

\section{Ethical Considerations}

Ethical considerations in research can be organized into these categories: obligation to subjects, obligation to the profession, and legal obligations (Ary et al., 2009). The American Educational Research Association created a Code of Ethics (2011) to help guide researchers. The five main principles from the American Educational Research Association (2011) include professional competence, integrity, professional, scientific, and scholarly responsibility, respect for people's rights, dignity, and diversity, and lastly, social responsibility. These ethics guided the collection, analysis and reporting of these data without revealing any information that would compromise the teachers' or students' identities. As a school counselor and doctoral candidate, the researcher understands the impact of this level of ethics when research involves human subjects.

Typically, when research involves human subjects, informed consent is provided prior to the study. In this case, since the ADAP takes place every semester as an existing program in this particular high school, data was collected on a secondary basis. Even though there was no informed consent, confidentiality is of the utmost importance. Therefore, there are no identifying or linking information items from students to the results of the survey. When the information is received by the Johns Hopkins Hospital, it only has a randomly assigned identification number. Then data reports are generated without any information linking them back to a student or class. 
Even though data are collected anonymously, an effort is made to ensure that data does not have any identifying information by having someone else receive and check the data first. The Institutional Review Board application and protocols were followed to conduct this study, which also adds a level of protection to the participants.

\section{Summary}

In contemplating barriers to student success, the importance of social emotional learning emerges. While there are various ways to approach SEL, the focus for this study narrowed to mental health literacy. Depression education is a common way that mental health literacy is incorporated in school for adolescence. This study has been designed with the purpose of exploring the impact of Johns Hopkins Hospital's ADAP curriculum with the focus on what depression knowledge students retain from the program, as well as if students retain ways to cope with depression from the program. The research methodology was designed by taking into consideration the ADAP, the research questions and the instrumentation. This chapter included details on research design, data collection, instrumentation, data collection procedures, data analyses procedures, data analyses, limitation, and ethical considerations. The next chapter will include details of the research results from the collected data. 


\section{CHAPTER IV: RESEARCH RESULTS}

Social emotional learning programs can have a positive impact on students in various ways (Brackett, et al., 2011; Burns \& Rapee, 2006; CASEL, 2005; Durlak, et al., 2011; Harris, 2008; Hart et al., 2014; Shochet et al., 2001; Sklad et al., 2012, Zins et al., 2004). There are different approaches to social emotional learning, and one approach focuses on mental health literacy, specifically depression education prevention (Naylor, Cowie, Walters, Talamelli, \& Dawkins, 2009; Skre et al., 2013; Swartz, et al., 2010). In exploring the impact of social emotional learning, this study examines the impact of the Johns Hopkins Hospital's Adolescent Depression Awareness Program (ADAP). Through a non-experimental, quantitative method, this study uses secondary data from a high school that has implemented the ADAP in their health classes. The secondary data consists of information derived from the ADAP's 28 question pre/post-survey, known as the Adolescent Depression Knowledge Questionnaire (ADKQ), which students take anonymously.

\section{Findings}

The ADKQ is an online pre-/post-test designed by the team at the Johns Hopkins Hospital to be implemented with the ADAP. The questionnaire is given to all the students prior to the program beginning, and the post-test is given six weeks after the three-day ADAP curriculum is complete. To inform this study, data from three semesters of implementing the ADAP at a large Midwestern suburban high school was used to inform this study. At this high school, the ADAP takes place in all health classes, and there are 4-5 sections of this class that typically run during each semester of the school year. Specifically, the secondary data from Spring 2015, Spring 2016 and Fall 2016 were used. The ADAP is still incorporated into this high school's health classes currently, but data were approved initially for these three semesters. 


\section{Participants}

During these three semesters, there were 4-5 sections of health classes each semester. Each class can include up to 32 students per class, which is the contractual cap for health teachers at this school. The students are given identification numbers prior to taking the pre-test, so that their answers can be matched with their post-test answers and remain anonymous when submitted to the Johns Hopkins Hospital's ADAP team. No identifying information is collected from students in terms of name, background, age, etc. The only question that is included is a gender question of female or male. At this high school, sophomores, juniors or seniors can take the Health course, so the age range is from 15-18. Prior to taking the pre-test, the teacher shares the purpose of the program and that their responses will remain anonymous when submitted to the Johns Hopkins Hospital.

To be included in this study, each student's results needed to include both the pre-/posttest information. During the spring semester of 2015 (Semester 1), out of the initial 67 students, $43(64 \%)$ of the students completed the pre-/post-test. During the spring semester of 2016 (Semester 2), $111(66 \%)$ of students completed the pre-/post-test. During the fall semester of 2016 (Semester 3), 84 (42\%) completed the pre-/post-test of the ADKQ. The percentages are shared to understand how each semester compared, but it also brings to light the lower percentage of completed surveys in semester 3. After further evaluation of the lower percentage of respondents in Semester 3, there seems to be a whole class that did not complete the postsurvey. This is important to note as there was not a technical issue or a possible cause like absenteeism, but also because the sample size is smaller than originally expected. It seems that one teacher may have forgotten to give the post-test to their class. In the analysis of the data in the next chapter, the impact of sample size was considered. 
The only demographic information gathered in the collection of the pre-/postquestionnaire data is the gender of the respondents, which is represented in the Table 1 . The only choices given for this question was male or female.

Table 1

Participant Demographics

\begin{tabular}{|c|c|c|c|c|c|c|}
\hline \multirow[t]{2}{*}{ Demographic } & \multicolumn{2}{|c|}{ Semester 1} & \multicolumn{2}{|c|}{ Semester 2} & \multicolumn{2}{|c|}{ Semester 3} \\
\hline & \multicolumn{2}{|c|}{ Spring 2015} & \multicolumn{2}{|c|}{ Spring 2016} & \multicolumn{2}{|c|}{ Fall 2016} \\
\hline Gender & $\mathrm{N}$ & $\%$ & $\mathrm{~N}$ & $\%$ & $\mathrm{~N}$ & $\%$ \\
\hline Male & 21 & 49 & 48 & 43 & 40 & 48 \\
\hline Female & 22 & 51 & 63 & 63 & 44 & 52 \\
\hline
\end{tabular}

Semesters 1 and 3 is very close to having equal representation from both genders. Semester 2 includes more female respondents $(63 \%)$ than male respondents $(43 \%)$.

\section{Research Questions}

This study examines the students' levels of understanding about depression and knowledge about resources to cope with depression. The following research questions guide this study:

1. What levels of understanding do students retain about depression after participating in the ADAP curriculum?

2. What levels of understanding do students retain about the resources to cope with depression after participating in the ADAP curriculum?

The hypotheses below are designed to explore if the ADAP made an impact on student knowledge about depression and resources to help themselves or others. 


\section{Research Question 1}

What levels of understanding do students retain about depression after participating in the ADAP curriculum? To begin to examine the research question about students' retention of depression after interaction with the ADAP curriculum, questions 1-24 were examined in this section. Questions 1-20 are twenty statements about depression that the students must answer yes or no, while questions 21-24 ask students to identify if a person is having a rough time or suffers from a type of depression. For Questions 1-20, the McNemar test for dichotomous items was conducted to evaluate students' understandings of depression. For Questions 21-24, the chisquare test checks for statistical significance since they are all nominal-level categorical variables. In order to focus on the information that was statistically significant, data were first organized into two table formats, Tables 2 and 3. Then each component that had a significant $p$ value was given an asterisk. If the data were significant at the $p$-value less than .05 , it was given one asterisk; the data that were significant at the $p$-value of .01 was given two asterisks, and finally three asterisks were given if data was significant at the $p$-value of .001 . Finally, the statements that were not significant are separated into Table 3 in order to clearly distinguish those that were significant versus not significant. In running the pre-/post-survey results in SPSS, data were kept separate by semesters to be able to isolate or identify significant information and trends more clearly. The results for questions 1-20 in Table 2 are discussed by how many semesters a question shows a significant $\mathrm{p}$-value. 
Table 2

McNemar Test Results from ADKQ Pre-/Post-survey from 3 Semesters with Significant p-values (Questions 1-20)

\begin{tabular}{|c|c|c|c|c|c|c|c|}
\hline & \multirow{2}{*}{ Question } & \multicolumn{2}{|c|}{ Semester 1} & \multicolumn{2}{|c|}{ Semester 2} & \multicolumn{2}{|c|}{ Semester 3} \\
\hline & & \# & $p$-value & $\#$ & $p$-value & $\#$ & $p$-value \\
\hline 2) & $\begin{array}{l}\text { Major depression is a normal part of } \\
\text { adolescence. }\end{array}$ & 43 & .125 & 111 & $.004^{* *}$ & 84 & .093 \\
\hline 3) & Depression runs in some families. & 43 & 1.000 & 111 & $.007^{* *}$ & 83 & 1.000 \\
\hline 4) & $\begin{array}{l}\text { Depression can be controlled through } \\
\text { willpower. }\end{array}$ & 43 & $.035^{*}$ & 111 & $.007^{* *}$ & 84 & $.027^{*}$ \\
\hline 8) & $\begin{array}{l}\text { Major depression is a treatable medical } \\
\text { illness. }\end{array}$ & 43 & $.006^{* *}$ & 111 & $.000^{* * *}$ & 84 & $.000^{* * *}$ \\
\hline 9) & A person with depression always feels sad. & 43 & .219 & 111 & .523 & 84 & $.021^{*}$ \\
\hline 13) & $\begin{array}{l}\text { Someone who has a major stress (like } \\
\text { having parents get a divorce) always } \\
\text { develops a depressive illness. }\end{array}$ & 43 & .453 & 111 & .189 & 84 & $.013^{*}$ \\
\hline 17) & $\begin{array}{l}\text { The process for diagnosing major } \\
\text { depression is similar to other medical } \\
\text { conditions because you look for a cluster of } \\
\text { symptoms. }\end{array}$ & 43 & .065 & 110 & $.000^{* * *}$ & 84 & $.007^{* *}$ \\
\hline 18) & $\begin{array}{l}\text { There is a test that can diagnose major } \\
\text { depression. }\end{array}$ & 43 & .210 & 111 & .868 & 84 & $.019^{*}$ \\
\hline 19) & Not needing sleep is a symptom of mania. & 43 & .289 & 111 & $.001^{* *}$ & 84 & $.001^{* *}$ \\
\hline
\end{tabular}

To begin, this section will show which questions had significant $p$-values for all 3 semesters. In examining the pre-/post-survey results from three different semesters, there are two survey questions that had significant $p$-values for all three semesters to varying degrees. In general, the lower the $p$-value, the stronger the significance. Statement number 4 states that "Depression can be controlled through willpower," which is one of the myths of Depression that 
the program attempts to prove is false. For Semesters 1 and 3, the statement is significant at the $\mathrm{p}<.05$ (Semester 1: $\mathrm{p}=.035$; Semester 2: $\mathrm{p}=.027)$, and for Semester 2 it is significant at $\mathrm{p}=.007$. The other statement that is a core piece of information to the ADAP and is significant across all three semesters is statement 8: "Major depression is a treatable medical illness," which is true. For Semester 1 , it is significant at the $p<.01$ level at $p=.006$. Semester 2 and 3 were both significant at the $p$-value of .001 ; in both cases, $p=.000$. Since $p<.001$, both statements show a stronger change from one semester to another.

There were also two statements that were significant in two out of the three semesters examined. Survey question number 17 states that "The process for diagnosing major depression is similar to other medical conditions because you look for a cluster of symptoms." This true statement is significant at $\mathrm{p}=.000$ for Semester 2 and $\mathrm{p}=.007$ for Semester 3. The other statement was number 19 , which states that "Not needing sleep is a symptom of mania." In Semesters 2 and 3, this statement was significant at $p=.001$. Both of these statements are true of depression.

There were a number of statements that were significant for only one semester. For instance, the second statement of the survey is false and significant at $\mathrm{p}=.004$ for Semester 2 : "Major depression is a normal part of adolescence." The next statement was number 3 and is also true: "Depression runs in some families" and was significant at $p=.007$ during Semester 2 as well. The next three statements were significant during Semester 3. Number 9 states that "A person with depression always feels sad," which is false and significant at $p=.021$. Another false statement is number 13, which states that "Someone who has a major stress (like having parents get a divorce) always develops a depressive illness" and was significant at $p=.013$. Finally, another false statement is number 18 , which states that "There is a test that can diagnose major 
depression." This was significant at $p=.019$. All five statements were significant with the two semesters that had larger sample sizes.

In assessing the program as a whole, it may also be valuable to evaluate the statements that did not generate significant $p$-values. Table 3 reveals eleven statements that did not have significant $p$-values for any of the three semesters, which approximately $39 \%$ of the total number of questions on the ADKQ.

Table 3

McNemar Test Results from ADKQ Pre-/Post-survey from 3 Semesters without Significant pvalues (Questions 1-20)

Semester $1 \quad$ Semester $2 \quad$ Semester 3

Question

\# $p$-value \# $p$-value \# $p$-value

1) Five percent of all teenagers will suffer a $\quad \begin{array}{lllllll}43 & 1.000 & 111 & 1.000 & 84 & .096\end{array}$ major depression.

5) The cause of major depression is well known.

$\begin{array}{llllll}43 & .453 & 111 & .424 & 84 & .832\end{array}$

6) A change in behavior is a symptom of depression.

$\begin{array}{llllll}43 & .125 & 111 & 1.000 & 84 & 1.000\end{array}$

$\begin{array}{llllllll}7) & \text { There are certain groups of people who are } & 42 & .063 & 111 & .077 & 84 & .581\end{array}$ immune to depression.

10) The abuse of alcohol and drugs can be a sign of depression.

11) Bipolar disorder is more common than major depression.

12) Major depression is a curable illness.

14) Behaviors such as eating disorders or substance abuse can worsen mood

$\begin{array}{llllll}43 & 1.000 & 111 & .219 & 84 & .727\end{array}$

$\begin{array}{llllll}43 & .143 & 111 & 1.000 & 84 & .430\end{array}$

$\begin{array}{llllll}43 & .143 & 111 & .597 & 84 & 1.000\end{array}$

$\begin{array}{llllll}43 & 1.000 & 111 & 1.000 & 83 & .727\end{array}$ disorders.

15) There are effective treatments for depression.

$\begin{array}{llllll}43 & 1.000 & 111 & .774 & 84 & 1.000\end{array}$

(Table Continues) 


\begin{tabular}{llllllll}
\hline & Question & Semester 1 & \multicolumn{2}{l}{ Semester 2 } & \multicolumn{2}{l}{ Semester 3 } \\
& $\#$ & $p$-value & $\#$ & $p$-value & $\#$ & $p$-value \\
\hline 16) & $\begin{array}{l}\text { A person with bipolar disorder always has a } \\
\text { high mood. }\end{array}$ & 43 & 1.000 & 111 & .267 & 84 & .109 \\
20) & $\begin{array}{l}\text { Irritable mood can be a symptom of major } \\
\text { depression. }\end{array}$ & 43 & 1.000 & 111 & 1.000 & 84 & 1.000 \\
$* \mathrm{p}<.05, * * \mathrm{p}<.01, * * * \mathrm{p}<.001$ & & & & & &
\end{tabular}

Therefore, the statements did not have a significant change in the means for any of the semesters. Either students already knew the information and initially performed very well, or they did not retain this information from their ADAP experience.

The next section of questions on the ADKQ were numbers 21-24; each question contains two parts: $a$ and $b$. For each question, there is a scenario presented to the student in which they must identify whether the person is "having a rough time," "has the medical illness of Depression," or "has the medical illness of Bipolar Disorder." Part b requires them to select their level of confidence by choosing one of the following: not at all sure, somewhat sure, almost sure or very sure. In Table 4, only the statistically significant question parts remain and have an asterisk next to the $p$-value to show which ones are significant at $p<.05, \mathrm{p}<.01$, or $\mathrm{p}<.001$. Table 4

Chi-square Test Results from ADKQ Pre-/Post-survey from 3 Semesters (Questions 21-24)

\begin{tabular}{|c|c|c|c|c|c|c|c|c|c|c|c|c|}
\hline \multirow[t]{2}{*}{ Question } & \multicolumn{4}{|c|}{ Semester 1} & \multicolumn{4}{|c|}{ Semester 2} & \multicolumn{4}{|c|}{ Semester 3} \\
\hline & \# & Value & df & $p$-value & \# & Value & $\mathrm{df}$ & $p$-value & $\#$ & Value & $\mathrm{df}$ & $p$-value \\
\hline $\begin{array}{l}21 \text { a) He is } \\
\text { having a rough } \\
\text { time } \\
\text { He has the } \\
\text { medical illness } \\
\text { of Depression. }\end{array}$ & 42 & 4.06 & 2 & .131 & 110 & 3.00 & 4 & .557 & 81 & 33.81 & 4 & $.000 * * *$ \\
\hline
\end{tabular}

(Table Continues) 


\begin{tabular}{|c|c|c|c|c|c|c|c|c|c|c|c|c|}
\hline \multirow[t]{2}{*}{ Question } & \multicolumn{4}{|c|}{ Semester 1} & \multicolumn{4}{|c|}{ Semester 2} & \multicolumn{4}{|c|}{ Semester 3} \\
\hline & $\#$ & Value & $\mathrm{df}$ & $p$-value & \# & Value & $\mathrm{df}$ & $p$-value & \# & Value & $\mathrm{df}$ & $p$-value \\
\hline $\begin{array}{l}\text { He has the } \\
\text { medical illness } \\
\text { of Bipolar } \\
\text { Disorder. }\end{array}$ & & & & & & & & & & & & \\
\hline $\begin{array}{l}21 b) \text { Not at all } \\
\text { sure } \\
\text { Somewhat sure } \\
\text { Almost sure } \\
\text { Very sure }\end{array}$ & 40 & 12.33 & 6 & .055 & 110 & 25.53 & 9 & $.002 *$ & 82 & 11.78 & 6 & .067 \\
\hline $\begin{array}{l}22 \text { a) He is } \\
\text { having a rough } \\
\text { time } \\
\text { He has the } \\
\text { medical illness } \\
\text { of Depression. } \\
\text { He has the } \\
\text { medical illness } \\
\text { of Bipolar } \\
\text { Disorder. }\end{array}$ & 43 & 20.44 & 4 & $.000 * * *$ & 110 & 1.44 & 4 & .836 & 84 & 23.37 & 4 & $.000 * * *$ \\
\hline $\begin{array}{l}23 \text { a) He is } \\
\text { having a rough } \\
\text { time } \\
\text { He has the } \\
\text { medical illness } \\
\text { of Depression. } \\
\text { He has the } \\
\text { medical illness } \\
\text { of Bipolar } \\
\text { Disorder. }\end{array}$ & 43 & 1.73 & 4 & .785 & 110 & 19.12 & 4 & $.001 * * *$ & 84 & 19.03 & 4 & $.001 * * *$ \\
\hline $\begin{array}{l}24 \text { a) He is } \\
\text { having a rough } \\
\text { time } \\
\text { He has the } \\
\text { medical illness } \\
\text { of Depression. } \\
\text { He has the } \\
\text { medical illness } \\
\text { of Bipolar } \\
\text { Disorder. }\end{array}$ & 43 & 29.01 & 4 & $.000 * * *$ & 109 & 3.57 & 4 & .466 & 84 & 12.21 & 4 & $.016^{*}$ \\
\hline $\begin{array}{l}24 b) \text { Not at all } \\
\text { sure } \\
\text { Somewhat sure } \\
\text { Almost sure } \\
\text { Very sure }\end{array}$ & 43 & 32.03 & 9 & $.000 * * *$ & 107 & 30.08 & 9 & $.000 * * *$ & 83 & 19.77 & 9 & $.019 *$ \\
\hline
\end{tabular}


In each of the questions for 21-24, students read an anecdote about 4 separate people and are asked to apply their knowledge of depression by identifying who is having a rough time versus having the mental illness of depression or bipolar depression in part a. In part b of 21-24, students are asked to identify how sure they feel about their answer in part a by selecting "Not sure at all, "Somewhat sure," "Almost sure," or "Very Sure." In general, all the "a" parts were significant for at least one of the three semesters. For Question 21a, only semester three contained a significant $p$-value of .000 , which demonstrates an impact on knowledge. Part b of question 21 is only significant in the second semester with $\mathrm{p}=.002$, which signifies a change there. It could be possible that there was not a change in how students felt about their responses despite whether or not their response to part "a" or b" is right or wrong. They may have felt initially very sure and not realize the accurate information. For questions 22 and 23, each has two significant semesters in part a, but not part b. For question 22a, Semesters 1 and 3 are significant with the $p$-value of .000 . For question 23a, Semesters 2 and 3 are significant at $\mathrm{p}=.001$. This communicates that students have changed their answer on the post-test after learning the ADAP information. Same in question 24, both parts "a" and "b" have semesters with significant values. For 24a, Semester 1 is significant at .000 and Semester 3 is significant at .016. Finally, question $24 \mathrm{~b}$ is significant for all three semesters.

\section{Research Question 2}

What levels of understanding do students retain about the resources to cope with depression after participating in the ADAP curriculum? For research question 2, questions 2528 have been examined because each explores students' responses to coping with depression. Each of these questions did require a different way to examine the significance of the question. For instance, for question 25, the question was examined with the McNemar test, whereas 
questions 26 and 27 were tallied separately for pre-/post-test results and compared. Finally, in question 28, a chi-square cross-tabulation was used to compare pre-/post-test results.

Question 25 is included under Research Question 2 because encouraging a friend to ask for help could be one way to cope with depression. For Question 25 (Table 5), the null hypothesis cannot be rejected or accepted as a superscript of "a" appears, which indicates that it was "computed only for a PXP table, where P must be greater than 1." Therefore, too few cases responded to calculate the McNemar value for Semesters 1 and 2. Semester 3 did not produce a significant McNemar value.

Table 5

McNemar Test Results from ADKQ Pre-/Post-survey from 3 semesters (Question 25)

Question
$\begin{aligned} & \text { If you thought that you or a friend } \\ & \text { was depressed would you encourage }\end{aligned}$
him/her to ask for help?


Table 6

Frequency Count \& Percentage from ADKQ Pre-/Post-survey from 3 Semesters (Question 26)

26) Fill in the $\quad$ Semester $1 \quad$ Semester $2 \quad$ Semester 3

bubble next to the

THREE people you

would be likely to Pre Pre Post Post Pre Pre Post Post Pre Pre Post Post \begin{tabular}{lcccccccccccc} 
ask for help: & $\#$ & $\%$ & $\#$ & $\%$ & $\#$ & $\%$ & $\#$ & $\%$ & $\#$ & $\%$ & $\#$ & $\%$ \\
\hline
\end{tabular}

$\begin{array}{lllllllllllll}\text { Adult } & 20 & 46.5 & 14 & 32.6 & 47 & 42.3 & 54 & 48.6 & 22 & 26.2 & 37 & 44.0\end{array}$

$\begin{array}{lllllllllllll}\text { Classmate } & 14 & 32.6 & 8 & 18.6 & 28 & 25.2 & 31 & 27.9 & 31 & 36.9 & 22 & 26.2\end{array}$

$\begin{array}{lllllllllllll}\text { Counselor } & 16 & 37.2 & 21 & 48.8 & 38 & 34.2 & 50 & 45 & 30 & 35.7 & 31 & 36.9\end{array}$

$\begin{array}{lllllllllllll}\text { Doctor } & 7 & 16.3 & 9 & 20.9 & 14 & 12.6 & 15 & 13.5 & 15 & 17.8 & 24 & 28.6\end{array}$

$\begin{array}{lllllllllllll}\text { Hotline } & 2 & 4.6 & 1 & 2.3 & 4 & 3.6 & 3 & .02 & 2 & 2.4 & 2 & .02\end{array}$

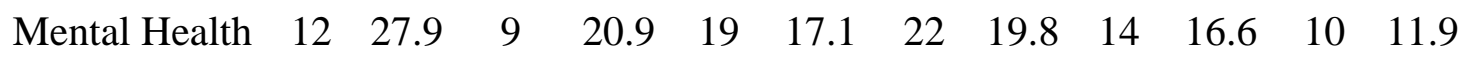
Professional

$\begin{array}{lllllllllllll}\text { Parent/Guardian } & 26 & 60.4 & 24 & 55.8 & 62 & 55.8 & 69 & 62.1 & 59 & 70.2 & 57 & 67.9\end{array}$

$\begin{array}{lllllllllllll}\text { Psychiatrist } & 5 & 11.6 & 7 & 16.2 & 21 & 18.9 & 16 & 14.4 & 13 & 15.4 & 10 & 11.9\end{array}$

$\begin{array}{lllllllllllll}\text { School Counselor } & 10 & 23.3 & 17 & 39.5 & 22 & 19.8 & 24 & 21.6 & 16 & 19.1 & 16 & 19.1\end{array}$

$\begin{array}{lllllllllllll}\text { School Nurse } & 1 & 2.3 & 4 & 9.3 & 0 & 0 & 1 & .01 & 0 & 0 & 2 & .02\end{array}$

$\begin{array}{lllllllllllll}\text { Sibling } & 13 & 30.2 & 5 & 11.6 & 32 & 28.8 & 23 & 20.7 & 26 & 30.9 & 20 & 23.8\end{array}$

$\begin{array}{lllllllllllll}\text { Teacher } & 7 & 16.2 & 6 & 13.9 & 15 & 13.5 & 18 & 16.2 & 15 & 17.9 & 19 & 22.6\end{array}$

$\begin{array}{lllllllllllll}\text { No One } & 3 & 6.9 & 1 & 2.3 & 9 & 8.1 & 3 & .02 & 6 & 7 & 3 & .04\end{array}$

$\begin{array}{lllllllllllll}\text { I don’t know } & 2 & 4.6 & 0 & 0 & 11 & 9.9 & 5 & .04 & 4 & 4.7 & 7 & .08\end{array}$ 
Since the ADAP emphasizes telling a trusted adult, it is important to examine all of these options. For this examination, all these choices were arranged into 4 groups: adults, school professionals, mental health professionals, and other. To begin, the percentages overall for the Adult option are higher than other choices in the list, such as doctor, hotline, psychiatrist, school nurse, or teacher for example. In Semester 1, the percentage decreases from 46 to $32 \%$, whereas the percentage increases in Semester 2 (42 to 48\%) and Semester 3 (26 to 44\%). Another adult option is Doctor. The percentage increased for every semester in the post-survey results. Parent/Guardian is the option on the list that received the highest response each semester with percentages ranging from 55-70\%. In Semester 1 and 3, the percentage dropped a bit, but still remain higher than other categories.

In considering school options, the percentages for School Counselor, School Nurse and Teacher can be examined. In these three options, School Counselor was chosen more frequently. The percentages increase in Semester 1 (24 to 40\%) and Semester 2 (20 to 22\%), but stay the same in Semester $3(19 \%)$. There is a slight increase each semester for the option of School Nurse, but still involves a small number of students. Lastly, the option of Teacher showed a slight decrease for semester 1, but increases for Semesters 2 and 3.

For the category of Mental Health Professionals, the following can be included: Counselor, Mental Health Professional, and Psychiatrist. For Counselor, the percentage increased for each semester from pre-/post-survey, whereas there were percentages fluctuations for mental health professional and psychiatrist. For instance, for Mental Health Professional, the percentage decreased for Semesters 1 and 3, but increased slightly for Semester 2. For Psychiatrist, the percentage increased slightly for Semester 1, but then decreased for Semesters 2 and 3. 
In the next group, classmate, sibling, hotline, no one and I don't know options were considered. For classmate, the percentage decreases from 32 to 18 in semester 1 and from 36 to $26 \%$ in semester 3 , whereas the percentage slightly increases during semester 2 from 26 to $28 \%$. For sibling, the percentages decreased every semester. For hotline, the percentages were very low in general and decreased every semester in the post-survey as well. With the option of no one, the percentage of students selecting that option decreased for each semester. Lastly, the option of I don't know also decreased every semester.

As a whole, percentages that seemed to involve some type of adult person increased more often than not. The choices that did not involve an adult seem to consistently decrease in postsurvey results as well.

Data for question 27 were examined similarly to question 26 in the following section. Question 27 asks students what they would find difficult in asking for help for themselves or a friend. Table 7 provides the choices and what students selected in the pre/post-survey each semester. Percentages have been included to more easily compare responses and pre-/postchanges from survey results.

Table 7

Frequency Count \& Percentage from ADKQ Pre-/Post-survey from 3 Semesters (Question 27)

\begin{tabular}{|c|c|c|c|c|c|c|c|c|c|c|c|c|}
\hline \multirow{2}{*}{$\begin{array}{l}\text { 27) Fill in the } \\
\text { bubble net to the } \\
\text { BEST answer that } \\
\text { describes what } \\
\text { would make it } \\
\text { difficult for you to } \\
\text { get help for yourself } \\
\text { or for a friend. }\end{array}$} & \multicolumn{4}{|c|}{ Semester 1} & \multicolumn{5}{|c|}{ Semester 2} & \multicolumn{3}{|c|}{ Semester 3} \\
\hline & $\begin{array}{c}\text { Pre } \\
\#\end{array}$ & $\begin{array}{l}\text { Pre } \\
\%\end{array}$ & $\begin{array}{c}\text { Post } \\
\#\end{array}$ & $\begin{array}{l}\text { Post } \\
\%\end{array}$ & $\begin{array}{c}\text { Pre } \\
\#\end{array}$ & $\begin{array}{c}\text { Pre } \\
\%\end{array}$ & $\begin{array}{c}\text { Post } \\
\#\end{array}$ & $\begin{array}{l}\text { Post } \\
\%\end{array}$ & $\begin{array}{c}\text { Pre } \\
\#\end{array}$ & $\begin{array}{c}\text { Pre } \\
\%\end{array}$ & $\begin{array}{c}\text { Post } \\
\#\end{array}$ & $\begin{array}{c}\text { Post } \\
\%\end{array}$ \\
\hline $\begin{array}{r}\text { Being judged by } \\
\text { others }\end{array}$ & 13 & 30.2 & 16 & 37.2 & 37 & 33.3 & 35 & 31.5 & 24 & 28.5 & 27 & 32.1 \\
\hline
\end{tabular}

(Table Continues) 


\begin{tabular}{|c|c|c|c|c|c|c|c|c|c|c|c|c|}
\hline \multirow{2}{*}{$\begin{array}{l}\text { 27) Fill in the } \\
\text { bubble net to the } \\
\text { BEST answer that } \\
\text { describes what } \\
\text { would make it } \\
\text { difficult for you to } \\
\text { get help for yourself } \\
\text { or for a friend. }\end{array}$} & \multicolumn{4}{|c|}{ Semester 1} & \multicolumn{4}{|c|}{ Semester 2} & \multicolumn{4}{|c|}{ Semester 3} \\
\hline & $\begin{array}{c}\text { Pre } \\
\#\end{array}$ & $\begin{array}{l}\text { Pre } \\
\%\end{array}$ & $\begin{array}{c}\text { Post } \\
\#\end{array}$ & $\begin{array}{c}\text { Post } \\
\%\end{array}$ & $\begin{array}{c}\text { Pre } \\
\#\end{array}$ & $\begin{array}{c}\text { Pre } \\
\%\end{array}$ & $\begin{array}{c}\text { Post } \\
\#\end{array}$ & $\begin{array}{l}\text { Post } \\
\%\end{array}$ & $\begin{array}{c}\text { Pre } \\
\#\end{array}$ & $\begin{array}{c}\text { Pre } \\
\%\end{array}$ & $\begin{array}{c}\text { Post } \\
\#\end{array}$ & $\begin{array}{c}\text { Post } \\
\%\end{array}$ \\
\hline $\begin{array}{r}\text { Denying having an } \\
\text { illness }\end{array}$ & 4 & 9.3 & 5 & 11.6 & 23 & 20.7 & 17 & 15.3 & 10 & 11.9 & 8 & 9.5 \\
\hline $\begin{array}{l}\text { Not wanting to } \\
\text { lose a friendship }\end{array}$ & 7 & 16.2 & 9 & 20.9 & 21 & 18.9 & 21 & 18.9 & 14 & 16.6 & 10 & 11.9 \\
\hline $\begin{array}{r}\text { Having too much } \\
\text { pride to ask for } \\
\text { help }\end{array}$ & 8 & 18.6 & 5 & 11.6 & 13 & 11.7 & 21 & 18.9 & 2 & 2.3 & 13 & 15.4 \\
\hline $\begin{array}{r}\text { Feeling } \\
\text { embarrassed }\end{array}$ & 8 & 18.6 & 13 & 30.2 & 31 & 27.9 & 25 & 22.5 & 18 & 21.4 & 25 & 29.7 \\
\hline $\begin{array}{l}\text { Being afraid of } \\
\text { getting treatment }\end{array}$ & 4 & 9.3 & 3 & 6.9 & 11 & 9.9 & 12 & 10.8 & 1 & 1.1 & 6 & 7.1 \\
\hline $\begin{array}{r}\text { Worrying about } \\
\text { what friends } \\
\text { would think }\end{array}$ & 4 & 9.3 & 3 & 6.9 & 19 & 17.1 & 11 & 9.9 & 12 & 14.2 & 12 & 14.2 \\
\hline $\begin{array}{r}\text { Not knowing } \\
\text { whom to ask for } \\
\text { help }\end{array}$ & 6 & 13.9 & 3 & 6.9 & 13 & 11.7 & 10 & 9.0 & 12 & 14.2 & 12 & 14.2 \\
\hline $\begin{array}{r}\text { Feeling too } \\
\text { depressed to ask } \\
\text { for help }\end{array}$ & 3 & 6.9 & 5 & 11.6 & 6 & 5.4 & 4 & 3.6 & 6 & 7.1 & 9 & 10.7 \\
\hline $\begin{array}{r}\text { Fearing the } \\
\text { reaction of parents } \\
\text { or others }\end{array}$ & 8 & 18.6 & 8 & 18.6 & 19 & 17.1 & 13 & 11.7 & 12 & 14.2 & 18 & 21.4 \\
\hline $\begin{array}{l}\text { Worrying others } \\
\text { will find out }\end{array}$ & 2 & 4.6 & 3 & 6.9 & 12 & 10.8 & 15 & 13.5 & 11 & 13.1 & 13 & 15.4 \\
\hline $\begin{array}{r}\text { Feeling that no } \\
\text { one will } \\
\text { understand }\end{array}$ & 9 & 20.9 & 7 & 16.2 & 20 & 18.0 & 22 & 19.8 & 23 & 27.3 & 11 & 13.1 \\
\hline $\begin{array}{r}\text { Nothing would } \\
\text { stop me }\end{array}$ & 6 & 13.9 & 6 & 13.9 & 11 & 9.9 & 11 & 9.9 & 9 & 10.7 & 4 & 4.7 \\
\hline
\end{tabular}

For the first choice, "being judged by others," received the most selections out of all the choices given in the list. The percentage increases in semester 1 (31 to 38\%) and semester 3 (28 
to $32 \%$ ), but decreased slightly in semester 2 (34 to $32 \%$ ). The next frequently chosen reasons are "feeling embarrassed" and "feeling that no one will understand." Students who chose "feeling embarrassed" increased in semester 1 from 18 to $31 \%$ and in semester 3 from 22 to $30 \%$. On the other hand, students who chose "feeling that no one will understand" were as high as $27 \%$ in semester 3, but decreased in all post-survey results.

The next set of reasons on the list landed in the middle in terms of frequency of being selected as a reason why asking for help when depressed is difficult. To begin, "not wanting to lose a friendship" increased in semester 1 (16 to 20\%) and stayed the same in semester 2 (18\%), but decreased in semester 3 (16 to 12\%). Another reason, "having too much pride to ask for help," decreased in semester 1 (18 to 12\%), but increased in semester 2 (12 to 18\%) and semester 3 (2 to 16\%). Another reason, "not knowing who to ask for help," decreased in semester 1 (14 to $6 \%$ ) and semester 2 (12 to $9 \%$ ), and stayed the same for semester $3(14 \%)$. The last two reasons, "fearing the reaction of parents or others" and "nothing would stop me," had varying results. "Fearing the reaction of parents or others" stayed the same in semester $1(18 \%)$, decreased in semester 2 (18 to $12 \%)$, and increased in semester 3 (14 to $22 \%)$. Selecting the reason, "Nothing would stop me," had the same results in pre-/post-survey results for semester $1(14 \%)$ and semester 2 (10\%), but decreased in semester 3 (10 to 4\%).

Choices that were overall selected the least were "worrying others will find out," "feeling too depressed to ask for help," "being afraid of treatment," "denying having an illness" and "worrying about what friends would think." "Worrying others will find out" increased each semester by a couple of percentage points. "Feeling too depressed to ask for help" increased for semester 1 (6 to $12 \%)$ and semester 3 (7 to $11 \%)$, but decreased in semester 2 (6 to $4 \%$ ). "Being afraid of getting treatment" decreased in semester 1 (10 to 6\%) and semester 3 (2 to 8\%), but 
stayed approximately the same in semester $2(10 \%)$. "Denying having an illness" decreased every semester in the post-survey results. Lastly, "worrying about what friends would think" decreased semester $1(10$ to $6 \%)$ and semester 2 (17 to $10 \%)$, and stayed the same for semester 3 $(14 \%)$.

The last piece of the survey is question 28 , which asks students what they would do if a friend asks them to keep it a secret that he or she is depressed. The choices are keep it a secret, keep it a secret unless it gets serious, tell someone or I don't know. Of course, the goal of the ADAP is to encourage students to tell someone. Table 8 shows the results from the chi-square test results for question 28 on the ADKQ. Semesters that showed significant values are signified with asterisks.

Table 8

Chi-square Test Results from ADKQ Pre-/Post-survey from 3 Semesters (Question 28)

\begin{tabular}{|c|c|c|c|c|c|c|c|c|c|c|c|c|}
\hline \multirow[t]{2}{*}{ Question } & \multicolumn{4}{|c|}{ Semester 1} & \multicolumn{4}{|c|}{ Semester 2} & \multicolumn{4}{|c|}{ Semester 3} \\
\hline & \# & Value & $\mathrm{df}$ & $p$-value & \# & Value & $\mathrm{df}$ & $p$-value & \# & Value & $\mathrm{df}$ & $p$-value \\
\hline $\begin{array}{l}\text { If your friend } \\
\text { tells you that } \\
\text { he/she is } \\
\text { depressed and } \\
\text { asks you to } \\
\text { keep it a } \\
\text { secret because } \\
\text { no one else } \\
\text { knows, what } \\
\text { would you } \\
\text { do? (Select } \\
\text { only one) } \\
\text { Keep it a } \\
\text { secret } \\
\text { Keep it a } \\
\text { secret unless } \\
\text { it gets serious } \\
\text { Tell someone } \\
\text { I don't know }\end{array}$ & 43 & 20.76 & 9 & $.014 *$ & 111 & 53.99 & 9 & $.000 * * *$ & 84 & 37.06 & 9 & $.000 * * *$ \\
\hline
\end{tabular}


All three semesters show significant $p$-values. Semester 1 is significant at $\mathrm{p}=.014$, and semesters 2 and 3 are both significant at $p=.000$. This shows a significant change in the means of the pre/post-survey results.

\section{Summary}

The ADAP was incorporated into the health classes of this suburban high school. Overall, this chapter examines secondary data of the ADKQ results from the ADAP in Spring 2015, Spring 2016 and Fall 2016. Specifically, the 28 question pre-/post-survey results help to examine the impact of depression education for high school students. In the first research question, the focus is on what levels of understanding students retain about depression after participating in the ADAP curriculum. Many of the questions on the ADKQ assess the student's levels of depression knowledge. Specifically, the first twenty-four questions of the survey help with assessing students' knowledge base of depression. The pre-/post-survey results showed some significant $\mathrm{p}$ levels on certain questions for some of the survey questions, which serves as the basis of analysis in the next chapter. The other focus in examining the results of the pre/post-ADKQ results is the second research question that is examining the levels of understanding students retain about the resources to cope with depression after participating in the ADAP curriculum. More specifically, questions 26-28 help to give a sense of students' knowledge in coping with depression. Questions 26-27 help to compare who students would go to for help and what may make it difficult for them to do so. Question 28 helps to assess that the bottom line is to tell someone if one is struggling with depression or knows someone who is struggling with depression. In summary, the ADKQ pre-/post-survey results provides much data to analyze the ADAP's effectiveness with students. 


\section{CHAPTER V: ANALYSIS, RECOMMENDATIONS, AND CONCLUSION}

Building social emotional skills through the Adolescent Depression Awareness Program (ADAP) could potentially help to serve students during their high school years and beyond. This study focuses on the Johns Hopkins' Hospital ADAP, which educates high school students about the mental illness of depression through a lens of diagnosing and treating a medical illness. The core messages of the program also include that depression is a treatable illness through therapy, medication and education, along with providing resources to get help for depression. A quantitative study design was chosen in this case for reasons including an established pre-/postsurvey in the ADAP, as well as being able to provide a numerical description of the impact of the ADAP. This descriptive, non-experimental quantitative design explored the statistical significance of depression education for high school students. The research questions centered on the impact of the ADAP on students' levels of understanding of depression and resources to cope with depression. The research setting was a large high school in a suburban setting that implemented the ADAP into their health courses. The study included secondary data collected from students' results in three semesters of health classes, which included approximately 250 students. The ADKQ, a 28-item online questionnaire, helped to anonymously assess students' knowledge before and after (six weeks later) the ADAP curriculum by assigning students the same identification numbers for their pre-/post-test. Therefore, the Johns Hopkins Hospital does not know the identities of students, nor is there any identifying information in the results. The independent variable is the ADAP curriculum while the dependent variables are students' knowledge of depression and resources to help depression. After all data were collected, the ADAP coordinator at the Johns Hopkins Hospital was contacted for the data. In this chapter, the data was analyzed to determine the effectiveness of the ADAP curriculum on students' 
knowledge of depression and resources to help depression. While the scope of the study is limited to students in health classes at one high school and also to depression literacy rather than all SEL skills, it will help to evaluate the effectiveness of the program. High school students are an appropriate age group to address these social emotional learning needs because the onset of mental illness and emotional difficulties; therefore, it is important to have effective programming for these students to raise their level of self and social awareness and helps them to manage their emotions.

\section{Analysis of Findings}

Both research questions focused on part of the ADKQ that applied to that particular research question in order to analyze and determine effectiveness of the results. Specifically, the content of questions 1-24 apply to research question 1, while the content of questions 25-28 apply to research question 2 .

\section{Research Question 1}

What Levels of Understanding do Students Retain of Depression after Participating in the ADAP Curriculum? To begin, the first 20 questions of the ADKQ are yes/no statements based on facts of depression from the ADAP. The McNemar test for dichotomous questions revealed that nine of the 20 statements showed significant $p$-values in comparing the pre-/post-survey results for Spring 2015, Spring 2016 and Fall 2016. At an initial glance, it is evident that students retained knowledge about depression since some of the statements are statistically significant from the ADKQ. A total of nine out of the initial 20 that show a significant change from the pre-test to the post-test, so it seems fair to think that students gained some knowledge of depression through the ADAP. This suggests that there was a change from what the student initially thought to what they know after three days of the ADAP. Also, it is not reflective of 
what they know the day after completing the ADAP, but rather what information they retain six weeks later. Therefore, they gained knowledge, but is it enough for them to understand depression to the point in which they would be able to identify symptoms in themselves or someone they know in order to get help? The next sections will analyze the data to get a better understanding.

To determine students' levels of understanding of depression after participating in the ADAP, questions 1-24 were examined. The statements that were significant for the first part of the survey connect with the ADAP curriculum. One of the statements that was significant for all three semesters is "major depression is a treatable medical illness," which is a true statement covered extensively in the program, so the ADAP seems to have made an impact on their knowledge base. Knowing that depression is treatable can provide hope. If students can understand that depression is a medical illness, then students may also think that someone experiencing symptoms of depression should seek help like any other medical illness. The students also seem to understand the cluster of symptoms since item 17, "the process for diagnosing major depression is similar to other medical conditions because you look for a cluster of symptoms" statement was also significant for two of the semesters. The other statement that was significant for all three semesters is "depression can be controlled through willpower." The myth that depression can be controlled by someone is one that the ADAP attempts to dispel. If students only took away these tenets, that could be positive, but it is difficult to say how well they know the symptoms to be able to identify depression on this information alone.

The other statements that showed significance involved understanding various aspects of depression. For instance, understanding that depression runs in families is important to 
understand in helping oneself or a family member. Understanding that depression can run in families may make someone more aware for themselves if a family member suffers with depression. Another part of the symptoms information in the ADAP is to point out that depression does not always appear as sad; in fact, for adolescents who are depressed, irritability is more common (Swartz, 2016). If someone is only looking for or aware of sad feelings, they may miss irritability as a symptom of depression.

The next section of the ADKQ, questions 21-24, contain two parts to each question. "Part a" presents a scenario to students, where they have to identify if the person is having a rough time, has the medical illness of depression or bipolar depression. In "part b," they are asked to evaluate how sure they feel about their response. Each of the four questions had significant $p$-values in the chi-square analyses. This suggests that students can apply what they learned to identify symptoms and recognize whether it is defined as a rough time or a type of depression. In the ADAP, major depression is defined as exhibiting five or more symptoms for two or more weeks, and that these changes in behavior are affecting academic, social or emotional parts of one's life (Hart, et al., 2014). Since the "part a" of each of these questions 2124 had a significant $p$-value for more than one semester, students demonstrated a grasp of identifying depressive symptoms along with the possibility of recognizing depression. Therefore, if they or someone they knew were experiencing depression, they could identify the symptoms to differentiate between having a rough time or experiencing depression. "Part b" was significant for three out of the four questions in this section, which signifies that students felt differently about their answers in the post-questionnaire.

On the other hand, there were also statements that were not statistically significant. These statements may be better known to students prior to the ADAP, so there is less observed 
change from pre- to post. For instance, since the ADAP takes place during a stress unit in their health class, which may already include some general information about depression, then students may have some prior knowledge and score well on the pre-test. Or perhaps students have personal experience with depression and treatment. This may also demonstrate higher scores on the pre-test and less change to the post-test. For example, if a substance unit already took place, they may already know that the "abuse of alcohol and drugs can be a sign of depression." The other possibility is that they did not retain that information six weeks after the ADAP. This would be important for the instructors of the ADAP to consider in their future teaching of the ADAP in an attempt to get students to retain more information about depression. Lastly, this is an area where the sample sizes may have impacted the results. Since the sample size is so small for the first semester and many are missing from semester 3, more of these statements could be significant with more completion of pre-/post-questionnaires or by not separating the data by semester in order to get a better idea of the data as a whole. Overall, with all of the ADKQ parts discussed in this section that demonstrated significance, the null hypothesis can be rejected.

\section{Research Question 2}

What Levels of Understanding do Students Retain about the Resources to Cope with Depression after Participating in the ADAP Curriculum? In research question 2, item numbers 25-28 were examined for significance in students' understandings of coping with depression. To begin, at first it may seem unfortunate that too few cases were recorded to calculate the McNemar value to demonstrate significance for question number 25, which asks students to answer whether or not they or a friend would ask for help. In taking a closer look at the raw pretest data for Semester 1, it became apparent that the McNemar value could not be computed 
because the students all answered in the same way, "Yes." Therefore, a $2 \mathrm{X} 2$ table to compute the value could not be created. The good new though is that the students all answer "Yes" to asking for help for themselves or a friend. This is not attributed necessarily to the impact of the ADAP.

Question number 26 more specifically asks students to choose three people on the list they would likely ask for help. For this question, the percentages for each semester allows them to be more easily compared to one another. The fact that students chose multiple people on this list is a positive sign because in essence they are choosing to tell someone. By telling someone, they have a better chance of getting the treatment that they may need. The general trend seemed to showcase high numbers for talking with some kind of adult over a classmate or sibling. Since the ADAP emphasizes talking to an adult and reviews resources in the school house at the end of each day's lesson, the ADAP seems to make an impact on how students answer question 26. For instance, over 55\% or more, depending on the semester, indicated that they would choose their parent/guardian as one of the three people they would be "likely to ask for help." This parent/guardian result alone could impact future decisions of educators planning any type of mental health literacy programming. As a part of any type of depression education, suicide prevention or mental health literacy, it would be important to plan and incorporate a parent education part to the program. If a student turns to their parent for help and the parent lacks an understanding of depression as a medical illness, then the student may not get the help that they need. Another adult example is that over $30 \%$ reported they would be likely to talk to a counselor. More specifically, percentages increased during certain semesters for particular choices. For example, reaching out to a school counselor increased in semester 1 from $24 \%$ to $40 \%$ or reaching out to an adult increased from $26 \%$ to $44 \%$ in semester 3 after the ADAP. 
Finally, even though percentages were low for the options of "No one" or "I don't know," postsurvey percentages dropped after exposure to the ADAP. Therefore, students chose an option on the list rather than not choosing anyone or simply not knowing. This seems to be the bottomline: Even telling a classmate or a sibling is better than telling no one or not knowing who to tell because it is a sign that one can reach out for help and cope with their depression.

Where question 26 explores who a student may reach out to for help, question 27 asks students to identify the "BEST answer that describes what would make it difficult" to "get help" for themselves or someone else. If a student is unable to overcome what makes it difficult to ask for help, then they would have a hard time getting the help that is needed to overcome depression. By far, the largest percentage is "being judged by others." In semesters 1 and 3 , the percentage increased, meaning that more students felt that being judged by others would make it difficult to reach out for help even after the ADAP. On the other hand, some percentages were on the lower end. For instance, students were not as worried about others finding out about their depression or worrying about what friends would think. One reason that increased after exposure to the ADAP during semesters 2 and 3 was "having too much pride to ask for help." While it is saddening to think that a student would be too prideful to reach out for help, it also serves as a reminder of how difficult it can be to ask for help even knowing the right tools. Another positive changes to note are the percentages for the reason, "feeling that no one will understand." There were decreases in percentages for this item during semesters 2 and 3, which could mean that students may better understand depression and feel that others will too. One other positive trend to notice is that there were no decreases in percentage for "not knowing who to ask for help." Perhaps, students understand who they can go to for help better after the ADAP, which is the focus of research question 2 of knowing how to cope with depression. 
Overall, each of these reasons were chosen by students to some extent, so there are many ways that students reason themselves out of asking for help. This is helpful information to the instructors of the ADAP as well, so that they can address some of these reasons in the ADAP curriculum or build lessons around it for after ADAP.

Lastly, question 28 also helps to assess whether students are better equipped to cope with depression by their response to the following question: "If your friend tells you that he/she is depressed and asks you to keep it a secret because no one else knows, what would you do?"

Students are asked to select one answer from the following choices: "Keep it a secret, Keep it a secret unless it gets serious, Tell someone or I don't know." The chi-square test results showed significance for all three semesters. For semester 1 , the $p$-value is less than .05 at $\mathrm{p}=.014$. For semester 2 and 3, the $p$-value was .000 , indicating a statistically significant change in the mean scores for this question. This also proves a positive impact from information learned through the ADAP in that students know how better to cope with depression by telling someone.

Overall, the ADAP is an effective depression education program because it has an impact on students, which is demonstrated by the knowledge retained by students. Approximately half of the items on the questionnaire were significant in this study along with the two comparison questions of 26 and 27 that also showcased helpful information from students. Significance in these questions indicate that students changed their responses to the correct response in the post, which indicates that the ADAP added to their knowledge base of depression and coping with depression.

\section{Limitations}

There are some important possible limitations to note for this study on the impact of the ADAP with classes of students experiencing the program through their health classes. Some 
potential limitations include impact of sample size, lack of student demographic information and differences in teacher delivery. For data to be used in this study, students were required to complete the pre- and post-questionnaire, which impacted how many students were used in the sample for every semester in the study. Therefore, the sample size varied more than originally expected. The sample size for Semester 1 was 43, whereas the sample size for Semester 2 was 111 and Semester 3 was 84 . In examining the data more closely to figure out why semester 1 was so much smaller in sample size than the other two semesters, it became apparent that a whole class had not completed the post-survey and therefore, there were limited cases to use for the sample size that semester for the study. There may be an impact in variability of sample size per semester. Semesters 2 and 3 both contained more questionnaire items that were statistically significant than Semester 1. From these details, the larger sample sizes produced more results. Another limitation may include not having more student demographic information in order to understand the results in more depth and to understand how various demographics influence the results. The other factor that may exist is that the instructors gained experience in teaching the curriculum from Semester 1, which improved their instruction of the ADAP and produced more significant results in the pre-/post-test for the other semesters. This is the other limitation in that teachers changed slightly from semester to semester, which could impact the delivery of lessons from familiarity of content to comfort in discussing a difficult topic.

\section{Implications and Recommendations}

In examining two research questions connected to the impact of the ADAP, this study contributes to understanding the impact of a depression education program for high school students. First, this study brings to light that a depression education program can increase a student's knowledge of depression. Second, this study also confirms that students can learn 
some ways to cope with depression, and most importantly, the step of telling someone about their or their acquaintance's depression. The study demonstrates that a three-day depression education program can increase mental health literacy for students. Imagine the impact of a more comprehensive social-emotional learning program that also incorporates SEL skills of emotional regulation. For a more comprehensive program that can impact students on a daily basis, the two approaches of emotional regulation and mental health literacy must come together.

Of course, any program may have room for improvement, so some considerations are recommended in this next section. One aspect that may be considered is the delivery or teaching of the ADAP. When reflecting on a program or lesson, educators naturally contemplate effectiveness and possible improvements. In administering the ADAP to a high school program, there are two components that teachers can impact: usage of pre-/post-ADKQ and delivery of the three-day curriculum. Since the three-day curriculum was designed, researched and evaluated by the ADAP team at the Johns Hopkins Hospital, the content cannot be altered. The Johns Hopkins Hospital's ADAP team does require instructors to sign off on maintaining the integrity of the program. However, there is not an exact prescription in delivering the content and could be more effective in some ways if teachers take the time to reflect on pre-/post-test results. As a result, instructors delivering the ADAP may benefit from meeting ahead of time to help the effectiveness of the lessons, especially since these three semesters of the ADAP were co-taught by a health teacher and school counselor/psychologist. In this set-up, the teachers could also come together after teaching the ADAP to discuss their experiences and reflect on the pre-/posttest data. This process could improve instruction, clarity and emphasis in the curriculum. This process of reflection and examining data to inform instruction is the basis of any professional learning team. An opportunity to reflect on the three-day program could also help instructors 
improve delivery and organization. More importantly, hopefully it will inform them of how to improve the larger unit on stress, which could help students to make more connections and better retain information about depression. This process could also help these teachers focus their whole semester of Health more on the idea of Wellness rather than individual units on health topics. Ultimately, this could raise greater awareness of depression, which is the goal of the program. In an ideal situation, this process may also give teachers a voice to advocate for a more comprehensive social emotional learning approach that would go beyond just their course. Another suggestion would be to build the unit plan around the ADAP, so that teachers can scaffold student knowledge about other mental health conditions and expand on treatment information. One other expansion would be to help students understand what their role and responsibilities are in maintaining their own mental health whether or not they have depression. If they do suffer from depression, they need to understand that there are things they will need to follow up on from therapy or things they need to figure out that make themselves feel better in addition to treatment for their illness.

Another suggestion is that the ADAP curriculum at this high school could benefit from someone coordinating the efforts of the program. A coordinator/teacher lead could organize the pre-/post-survey process, so that this information can be used later for program evaluation and instruction. Since it appears that a whole class did not take the post-survey in one particular semester, a coordinator/teacher lead could help ensure this does not occur. This person could work with the Johns Hopkins Hospital to get the student survey identification numbers and also build in reminders to do the post-survey six weeks later. This position could also bring any ADAP instructors together to examine pre-/post-test data in order to reflect and improve the teaching of program's curriculum. 


\section{Future Studies}

There are many ways that this study could further the information on depression literacy or mental health literacy. This study itself could be developed into various extensions. For instance, including more semesters of data to gain a larger sample size could potentially show more significant results. Another study could extend to follow up with these same students the next year to assess the impact later. Perhaps even developing focus groups of students and/or teachers for a qualitative study could gather their insight into the program. If other high schools are incorporating the program, it could useful to compare data across schools to assess effectiveness in the program or compare how teachers approach the ADAP and the stress unit in general. Since the ADAP has been incorporated since 2015, it would be also beneficial to compare data to more recent semesters because there could be an impact on student knowledge as teacher have increased familiarity with the program. These later semesters would have teachers who have more experience in teaching the program, which could indicate an improved delivery of the ADAP. Another focal point to examine would be the background and experience level of the teachers with teaching this type of material, and whether or not there is any impact there. Lastly, if further demographic information was collected on the students, the results could help inform the impact of the ADAP on specific groups. More demographic results could help the instructors understand the needs of the students as well.

Further examining the non-significant findings in the study could also help to inform the program. Other research studies could examine the level of development of concepts from the questions that were not significant. For instance, a future study could compare how many times the concept appears in the three-day curriculum or whether or not students are required to engage with that concept. Some students may remember certain concepts more than others based on 
repetition, student involvement or reinforcement. For instance, the concept that depression is a medical illness is repeated daily and more than once each day while the fact that depression runs in families is only mentioned once.

Another way to add dimensions to this study that would help inform the practice of the program is knowing how it impacts different populations of students. It would be beneficial if the ADKQ collected some additional information about the students (e.g., race, ethnicity, sexuality) while still keeping their responses anonymous. Data could then be examined by subgroups to see if there are different trends or implications in the data. For instance, this data could be run only by gender at this point, which could be another extension of the study. Lastly, it would be informative to incorporate different mental health literacy programs within the same high school with different groups of students and compare programs for effectiveness. Gaining students' perspectives on the various approaches through focus groups or a survey could be beneficial, especially if a school is considering what approach would fit their school.

\section{Concluding Remarks}

Mental health literacy includes important knowledge for any young adult, and its significance becomes increasingly relevant as news headlines continue to reveal horrifying stories about increased adolescent depression, anxiety, suicides and school shootings to name a few. The literature around social emotional learning and mental health literacy advocated these approaches as important for any school environment, but with so many programs and approaches available, the selection process can be overwhelming and difficult. Yet, the hope remains to find a program that will impact students.

One of these paths of improvement could be to further develop this approach of mental health literacy beyond a three-day program. Examining a larger unit around the ADAP could 
help students deepen their understandings, which could help them in managing their emotions in daily activities and choices. It is possible to imagine developing the ADAP to fit within the larger context of social emotional learning. For example, coping with stress and depression can be a much larger unit than three days. Even thinking about all the important topics that are covered in a one semester health class does not seem like enough time. Perhaps this is why many schools are developing more of a wellness approach rather than keeping physical education and health separate. Depression education programs could make more of an impact if taught within the context of social emotional learning. Students are human, who regulate their emotions every day to allow themselves to navigate their daily lives. Helping students to be more self-aware and more socially-aware allows them to build skills to build positive relationship and make better decisions. If they can understand and build on their social emotional skills, they could have an easier time recognizing symptoms of depression and be better equipped in doing their part of maintaining mental wellness.

Overall, the benefit of incorporating an effective mental health literacy program into a high school can make a difference in a student's life. It is difficult to isolate one's needs into separate compartments of social, emotional, physical, academic, and other needs. These needs impact each other, so if someone has knowledge of depression literacy and can take better care of their emotional needs, then logically it would impact all the other need areas. A student's emotional needs cannot just be shoveled off to the side because it impacts each compartment. Ultimately, as educators search for ways to close the achievement gap and ways to improve the lives of their students, mental health literacy and social emotional learning components should be explored, planned and implemented to improve the lives and success of students. 


\section{REFERENCES}

Adedokun, O., \& Burgess, W. (2012). Analysis of paired dichotomous data: A gentle introduction to the McNemar test in SPSS. Journal of MultiDisciplinary Evaluation, 8(17), 125-131. Retrieved from http://journals.sfu.ca/jmde/index.php/jmde_1/article/view/336

Adelman, H. S., \& Taylor, L. (2000). Promoting mental health in schools in the midst of school reform. Journal of School Health, 70(5), 171.

Adelman, H. S., \& Taylor, L. (2006). Mental Health in Schools and Public Health. Public Health Reports (1974-), 121(3), 294-298. Retrieved from http://www.jstor.org/stable/20056960

American Educational Research Association (2011). Code of ethics. Educational Researcher, 3, 145-156.

American Psychiatric Association (2014). Diagnostic and statistical manual of mental disorders ( $5^{\text {th }}$ ed). Arlington, VA: American Psychiatric Association.

Ary, D., Jacobs, L. C., Razavieh, A., \& Sorensen, C. (2006). Introduction to research in education $\left(6^{\text {th }}\right.$ ed). Belmont, CA: Wadsworth.

Ball, A., Iachini, A. L., Bohnenkamp, J. H., Togno, N. M., Brown, E. L., Hoffman, J. A., \& George, M. W. (2016). School mental health content in state in-service K-12 teaching standards in the United States. Teaching and Teacher Education, 60(3), 12-320. doi:10.1016/j.tate.2016.08.020

Bandura, A. (1977). Social learning theory. Englewood Cliffs, NJ: Prentice-Hall, Inc.

Bandura, A. (1993). Perceived self-efficacy in cognitive development and functioning. Educational Psychologist, 28(2), 117-148. doi:10.1207/s15326985ep2802_3 
Bandura, A. (1998). Health promotion from the perspective of social cognitive theory. Psychology \& Health, 13(4), 623-649. doi:10.1080/08870449808407422

Battistich, V., Schaps, E., Watson, M., \& Solomon, D. (1996). Prevention effects of the child development project: Early findings from an ongoing multisite demonstration trial. Journal of Adolescent Research, 11(1), 12-35.

Bhatia, S. K. \& Bhatia, S. C. (2007). Childhood and adolescent depression. American Family Physician, 75(1), 73-80.

Birmaher, B., Brent, D., AACAP Work Group on Quality Issues (2007). Practice parameter for the assessment and treatment of children and adolescents with depressive disorders. Journal of the American Academy of Child and Adolescent Psychiatry, 46(11), 15031526.

Blair, C., \& Raver, C. C. (2015). The neuroscience of SEL. In J. A. Durlak, C. E. Domitrovich, R. P. Weissberg, \& T. P. Gullotta (Eds.), Handbook of social and emotional learning: Research and practice (pp. 65-80). New York, NY: Guilford Press.

Brackett, M. A., Elbertson, N. A., \& Rivers, S. E. (2015). Applying theory to the development of approaches to SEL. In J. A. Durlak, C. E. Domitrovich, R. P. Weissberg, \& T. P. Gullotta (Eds.), Handbook of social and emotional learning: Research and practice (pp. 20-32). New York, NY: Guilford Press.

Brackett, M. A., Rivers, S. E., \& Salovey, P. (2011). Emotional intelligence: Implications for personal, social, academic, and workplace success. Social and Personality Psychology Compass, 5(1), 88-103. doi:10.1111/j.1751-9004.2010.00334

Brigman, G., \& Campbell, C. (2003). Helping students improve academic achievement and school success behavior. Professional School Counseling,7(2), 91-98. 
Burns, J. R., \& Rapee, R. M. (2006). Adolescent mental health literacy: Young people's knowledge of depression and help seeking. Journal of Adolescence, 29(2), 225-239.

Catalano, R. F., \& Hawkins, J. D. (1996). The social development model: A theory of antisocial behavior. In J. D. Hawkins (Ed.), Delinquency and crime: Current theories (pp. 149197). New York, NY: Cambridge University Press.

Collaborative for Academic, Social, and Emotional Learning. (2005). Safe and sound: An educational leader's guide to evidence-based social and emotional learning (SEL) programs. Illinois Edition. Chicago, IL: Author. Retrieved from https://casel.org/wpcontent/uploads/2016/06/safe-and-sound-il-edition.pdf

Collaborative for Academic, Social, and Emotional Learning. (2017). Core SEL competencies. Chicago, IL: Author. Retrieved from https://casel.org/core-competencies/

Cooper, J. L. (2008). The federal case for school-based mental health services and supports. Journal of the American Academy of Child and Adolescent Psychiatry, 47(1), 4-8.

Cooper, G. D., Clements, P. T., \& Holt, K. (2011). A review and application of suicide prevention programs in high school settings. Issues in Mental Health Nursing, 32(11), 696-702. doi:10.3109/01612840.2011.597911

Conley, C. S. (2015). SEL in higher education. In J. A. Durlak, C. E. Domitrovich, R. P. Weissberg, \& T. P. Gullotta (Eds.), Handbook of social and emotional learning: Research and practice (pp. 197-212). New York, NY: Guilford Press. 
Darling-Hammond, L., Friedlaender, D., \& Snyder, J. (2014). Student-centered schools: Policy supports for closing opportunity gap. Policy Brief from Stanford Center for Opportunity Policy in Education. Stanford, CA: Stanford Center for Opportunity Policy in Education. Retrieved from https://edpolicy.stanford.edu/sites/default/files/scope-pub-studentcentered-policy.pdf

Denham, S. A. (2015). Assessment of SEL in educational contexts. In J. A. Durlak, C. E. Domitrovich, R. P. Weissberg, \& T. P. Gullotta (Eds.), Handbook of social and emotional learning: Research and practice (pp. 285-300). New York, NY: Guilford Press.

DuFour, R. (2004). What is a "professional learning community?" Educational Leadership, 61(8), 6-11.

DuFour, R. (2007). Professional learning communities: A bandwagon, an idea worth considering, or our best hope for high levels of learning?. Middle School Journal, 39(1), 4-8.

Durlak, J. A., Domitrovich, C. E., Weissberg, R. P., \& Gullotta, T. P. (Eds.). (2015). Handbook of social and emotional learning: Research and practice. New York, NY: Guilford Press.

Durlak, J. A., Weissberg, R. P., Dymnicki, A. B., Taylor, R. D., \& Schellinger, K. B. (2011). The impact of enhancing students' social and emotional learning: A meta-analysis of schoolbased universal interventions. Child Development, 82(1), 405-432. doi:10.1111/j.14678624.2010.01564.

Elias, M. J., Bruene-Butler, L., Blum, L., \& Schuyler, T. (1997). How to launch a social and emotional learning program. Educational Leadership, 54(8), 15-19. 
Elias, M. J., Zins, J. E., Weissberg, R. P., Frey, K. S., Greenberg, M. T., Haynes, N. M., Shriver, T. P. (1997). Promoting social and emotional learning: Guidelines for educators. Alexandria, VA: Association for Supervision and Curriculum Development.

Fergusson, D. M. \& Woodward, L. J. (2002). Mental health, educational, and social role outcomes of adolescents with depression. Archives of General Psychiatry, 59(3), 225231.

Fox, C., Eisenberg, M., McMorris, B., Pettingell, S., \& Borowsky, I. (2013). Survey of Minnesota parent attitudes regarding school-based depression and suicide screening and education. Maternal \& Child Health Journal, 17(3), 456-462. doi:10.1007/s10995-0121017-8

Garmy, P., Berg, A., \& Clausson, E. K. (2015). A qualitative study exploring adolescents' experiences with a school-based mental health program. BMC Public Health, 151-159. doi:10.1186/s12889-015-2368-z

Goleman, D. (1995). Emotional intelligence. New York, NY: Bantam Books.

Greenberg, M. T., Katz, D. A., \& Klein, L. C. (2015). The potential effects of SEL on biomarkers and health outcomes: A promissory note. In J. A. Durlak, C. E. Domitrovich, R. P. Weissberg, \& T. P. Gullotta (Eds.), Handbook of social and emotional learning: Research and practice (pp. 81-96). New York, NY: Guilford Press.

Gulliver, A., Griffiths, K. M., \& Christensen, H. (2010). Perceived barriers and facilitators to mental health help-seeking in young people: a systematic review. BMC Psychiatry, 10, $113-121$. 
Harris, B. (2008). Befriending the two-headed monster: personal, social and emotional development in schools in challenging times. British Journal of Guidance \& Counselling, 36(4), 367-383. doi:10.1080/03069880802364494

Hart, S., Kastelic, E., Wilcox, H., Beaudry, M., Musci, R., Heley, K., \& ... Swartz, K. (2014). Achieving depression literacy: The Adolescent Depression Knowledge Questionnaire (ADKQ). School Mental Health, 6(3), 213. doi:10.1007/s12310-014-9120-1

Hawkins, J. D., Smith, B. H., \& Catalano, R. F. (2004). Social development and social and emotional learning. In J. E. Zins, R. P. Weissberg, M. C. Wang, \& H. J. Walberg (Eds.), Building academic success on social and emotional learning (pp. 135-150). New York, NY: Teachers College Press.

Hess, S. G., Cox, T. S., Gonzales, L. C., Kastelic, E. A., Mink, S. P., Rose, L. E., \& Swartz, K. L. (2004). A survey of adolescents' knowledge about depression. Archives of Psychiatric Nursing, 18(6), 228-234. doi:10.1016/j.apnu.2004.09.005

Illinois State Board of Education. (2016). Township District 211 school report card. Retrieved from https://illinoisreportcard.com/District.aspx?DistrictID=05016211017.

Johnson, B. (2001). Toward a new classification of nonexperimental quantitative research. Educational Researcher, 30(2), 3-13.

Jonsson, U., Bohman, H., von Knorring, L., Olsson, G., Paaren, A., \& von Knorring, A. (2011). Research report: Mental health outcome of long-term and episodic adolescent depression: 15-year follow-up of a community sample. Journal of Affective Disorders, 130(3), 395404. doi:10.1016/j.jad.2010.10.046

Jorm, A. F. (2000). Mental health literacy - Public knowledge and beliefs about mental disorders. British Journal of Psychiatry, 177, 396-401. 
Jorm, A. F., Korten, A. E., Jacomb, P. A., Christensen, H., Rodgers, B., \& Pollitt, P. (1997). 'Mental health literacy': A survey of the public's ability to recognise [sic] mental disorders and their beliefs about the effectiveness of treatment. Medical Journal of Australia, 166(4), 182-186.

Kann, L., Telljohann, S. K., \& Wooley, S. F. (2007). Health education: Results from the school health policies and programs study 2006. Journal of School Health, 77(8), 408-434.

Katz, C., Bolton, S., Katz, L. Y., Isaak, C., Tilston-Jones, T., \& Sareen, J. (2013). A systematic review of school-based suicide prevention programs. Depression \& Anxiety, 30(10), 1030-1045. doi:10.1002/da.22114

Kelly, C. M., Jorm, A. F. \& Wright, A. (2007). Improving mental health literacy as a strategy to facilitate early intervention for mental disorders. Medical Journal of Australia, 187(7), S26-S30.

Kendal, S., Keeley, P., \& Callery, P. (2011). Young people's preferences for emotional wellbeing support in high school—a focus group study. Journal of Child \& Adolescent Psychiatric Nursing, 24(4), 245-253. doi:10.1111/j.1744-6171.2011.00303

Kessler, R. C., Berglund, P., Demler, O., Jin, R., \& Walters, E. E. (2005). Lifetime prevalence and age-of-onset distributions of DSM-IV disorders in the National Comorbidity Survey Replication. Archives of General Psychiatry, 62(6), 593-602.

King, K. A. (2006). Practical strategies for preventing adolescent suicide. Prevention Researcher, 13(3), 8-11.

King, K. A., \& Vidourek, R. A. (2012). Teen depression and suicide: Effective prevention and intervention strategies. Prevention Researcher, 19(4), 15-17. 
Kress, J. S., \& Elias, M. J. (2006). Building learning communities through social and emotional learning: Navigating the rough seas of implementation. Professional School Counseling, 10(1), 102-107.

Kretchmar, J. (2013). Social learning theory. Research Starters: Education (Online Edition). Retrieved from http://connection.ebscohost.com/c/essays/27577934/social-learningtheory

Ladson-Billings, G. (2006). From the achievement gap to the education debt: Understanding achievement in U.S. Schools. Educational Researcher, 35(7), 3-12.

Lee, J., \& Reeves, T. (2012). Revisiting the impact of NCLB high-stakes school accountability, capacity, and resources: State NAEP 1990-2009 reading and math achievement gaps and trends. Educational Evaluation and Policy Analysis, 34(2). 209-231.

Lee, S., Tsang, A., Breslau, J., Aguilar-Gaxiola, S., Angermeyer, M., Borges, G., ...Kessler, R. C. (2009). Mental disorders and termination of education in high-income and low- and middle-income countries: Epidemiological study. The British Journal of Psychiatry, 194(5), 411-417. doi:10.1192/bjp.bp.108.054841

Linares, L., Rosbruch, N., Stern, M. B., Edwards, M. E., Walker, G., Abikoff, H. B., \& Alvir, J.J. (2005). Developing cognitive-social-emotional competencies to enhance academic learning. Psychology in the Schools, 42(4), 405-417.

Mart, A. K., Weissberg, R. P., \& Kendziora, K. (2015). Systemic support for SEL in school districts. In J. A. Durlak, C. E. Domitrovich, R. P. Weissberg, \& T. P. Gullotta (Eds.), Handbook of social and emotional learning: Research and practice (pp. 482-499). New York, NY: Guilford Press. 
Marzano, R. J. (2015). Using formative assessment with SEL skills. In J. A. Durlak, C. E. Domitrovich, R. P. Weissberg, \& T. P. Gullotta (Eds.), Handbook of social and emotional learning: Research and practice (pp. 336-347). New York, NY: Guilford Press.

Matthews, G., Zeidner, M., \& Roberts, R. D. (2002). Emotional intelligence: Science and myth. Cambridge, MA: MIT Press.

Mayer, J.D., \& Salovey, P. (1993). The intelligence of emotional intelligence. Intelligence, 17, 433-442.

Mayer, J. D., \& Salovey, P. (2004). What is emotional intelligence?. In P. Salovey, M. A. Brackett, \& J. D. Mayer (Eds.), Emotional intelligence: Key readings on the Mayer and Salovey model (pp. 29-59). Port Chester, NY: Dude Publishing.

McCarthy, J., Bruno, M., \& Fernandes, T. E. (2011). Evaluating mental health literacy and adolescent depression: What do teenagers “know?” Professional Counselor, 1(2), 133142.

McEwan, K., Waddell, C., \& Barker, J. (2007). Bringing children's mental health "out of the shadows.” Canadian Medical Association Journal, 176(4), 471-472. doi:10.1503/cmaj.061028

Mcluckie, A., Kutcher, S., Yifeng, W., \& Weaver, C. (2014). Sustained improvements in students' mental health literacy with use of a mental health curriculum in Canadian schools. BMC Psychiatry, 14(1), 90-103. doi:10.1186/s12888-014-0379-4

McNemar's test using SPSS statistics. Laerd Statistics. Retrieved from https://statistics.laerd.com/spss-tutorials/mcnemars-test-using-spss-statistics.php 
Merrell, K. W. (2010). Linking prevention science and social and emotional learning: The Oregon Resiliency Project. Psychology in the Schools, 47(1), 55-70.

Merritt, R. K., Price, J. R., Mollison, J., \& Geddes, J. R. (2007). A cluster randomized controlled trial to assess the effectiveness of an intervention to educate students about depression. Psychological Medicine, 37(3), 363-372. doi:10.1017/S0033291706009056

Midford, R., Cahill, H., Geng, G., Leckning, B., Robinson, G., \& Te Ava, A. (2017). Social and emotional education with Australian Year 7 and 8 middle school students: A pilot study. Health Education Journal, 76(3), 362-372.

Miller, D., \& Eckert, T. (2009). Youth suicidal behavior: An introduction and overview. School Psychology Review, 38(2), 153-167.

Miller, D., Eckert, T., \& Mazza, J. (2009). Suicide prevention programs in the schools: A review and public health perspective. School Psychology Review, 38(2), 168-188.

Naylor, P. B., Cowie, H. A., Walters, S. J., Talamelli, L. \& Dawkins, J. (2009). Impact of a mental health teaching programme on adolescents. The British Journal of Psychiatry, 194, 365-370.

Nemeroff, R., Levitt, J. M., Faul, L., Wonpat-Borja, A., Bufferd, S., Setterberg, S., \& Jensen, P. S. (2008). Establishing ongoing, early identification programs for mental health problems in our schools: A feasibility study. Journal of the American Academy of Child and Adolescent Psychiatry, 47(3), 328-338. 12. doi:10.1097/CHI.0b013e318160c5b1

Ng, P., \& Chan, K. (2002). Attitudes towards people with mental illness: Effects of a training program for secondary school students. International Journal of Adolescent Medicine and Health, 14(3), 215-224. doi:10.1515/IJAMH.2002.14.3.215 
Nock, M. K., Green, J. G., Hwang, I., McLaughlin, K. A., Sampson, N. A., Zaslavsky, A. M., \& Kessler, R. C. (2013). Prevalence, correlates, and treatment of lifetime suicidal behavior among adolescents: Results from the National Comorbidity Survey Replication Adolescent Supplement. JAMA Psychiatry, 70(3), 300-310. doi:10.1001/2013.jamapsychiatry.55

Payton, J., Wardlaw, D., Graczyk, P., Bloodworth, M., Tompsett, C., \& Weissberg, R. (2000). Social and emotional learning: a framework for promoting mental health and reducing risk behavior in children and youth. Journal of School Health, 70(5), 179-185. doi:10.1111/j.1746-1561.2000.tb06468.x

Perou, R., Bitsko, R. H., Blumberg, S. J., Pastor, P., Ghandour, R. M., Gfroerer, J. C., \& ... Huang, L. N. (2013). Mental health surveillance among children -- United States, 20052011. MMWR: Morbidity \& Mortality Weekly Report, 62(2), 1-35.

Quiroga, C. V., Janosz, M., Bisset, S., \& Morin, A. S. (2013). Early adolescent depression symptoms and school dropout: Mediating processes involving self-reported academic competence and achievement. Journal of Educational Psychology, 105(2), 552-560.

Rapee, R., Wignall, A., Sheffield, J., Kowalenko, N., Davis, A., McLoone, J., \& Spence, S. (2006). Adolescents' reactions to universal and indicated prevention programs for depression: Perceived stigma and consumer satisfaction. Prevention Science, 7(2), 167177.

Redding, S., \& Walberg, H. J. (2015). Indicators of effective SEL practice. In J. A. Durlak, C. E. Domitrovich, R. P. Weissberg, \& T. P. Gullotta (Eds.), Handbook of social and emotional learning: Research and practice (pp. 377-392). New York, NY: Guilford Press. 
Roosevelt, F. D. (1940). “Address at University of Pennsylvania.” The American Presidency Project. Retrieved from http://www.presidency.ucsb.edu/ws/?pid=15860

Salkind, Neil J. (2011) Statistics for people who (think they) hate statistics $\left(4^{\text {th }}\right.$ ed.). Los Angeles: SAGE.

Salovey, P., \& Mayer, J. D. (2004). Emotional intelligence. In P. Salovey, M. A. Brackett, \& J. D. Mayer (Eds.), Emotional intelligence: Key readings on the Mayer and Salovey model (pp. 1-27). Port Chester, NY: Dude Publishing.

Sanders, L. M., Shaw, J. S., Guez, G., Baur, C. \& Rudd, R. (2009). Health literacy and child health promotion; implications for research, clinical care, and public policy. Pediatrics 14(3), S306-S314.

Schachter, H. M., Girardi, A., Ly, M., Lacroix, D., Lumb, A. B., van Berkom, J, \& Gill, R (2008). Effects of school-based interventions on mental health stigmatization: a systematic review. Child and Adolescent Psychiatry and Mental Health, 2(1), 18-32.

Shochet, I., Dadds, M., Holland, D., Whitefield, K., Harnett, P., \& Osgarby, S. (2001). The efficacy of a universal school-based program to prevent adolescent depression. Journal of Clinical Child Psychology, 30(3), 303-315.

Sklad, M., Diekstra, R., Ritter, M. D., Ben, J., \& Gravesteijn, C. (2012). Effectiveness of schoolbased universal social, emotional, and behavioral programs: Do they enhance students' development in the area of skill, behavior, and adjustment? Psychology in the Schools, 49(9), 892-909. doi:10.1002/pits.21641

Skre, I., Friborg, O., Breivik, C., Johnsen, L. I., Arnesen, Y., \& Wang, C. A. (2013). A school intervention for mental health literacy in adolescents: effects of a non-randomized cluster controlled trial. BMC Public Health, 13, 873-888. 
Stan, C., \& Beldean, I. G. (2014). The development of social and emotional skills of studentsways to reduce the frequency of bullying-type events. Experimental results. ProcediaSocial and Behavioral Sciences, 114, 735-743. Fourth World Conference on Psychology, Counseling and Guidance. doi:10.1016/j.sbspro.2013.12.777

Stinson, D. W. (2011). When the 'burden of acting white' is not a burden: School success and African American male students. Urban Review, 43(1), 43-65.

Strunk, C. M., King, K. A., Vidourek, R. A., \& Sorter, M. T. (2014). Effectiveness of the Surviving the Teens ${ }^{\circledR}$ Suicide Prevention and Depression Awareness Program: An impact evaluation utilizing a comparison group. Health Education \& Behavior, 41(6), 605-613.

Sullivan, E. M., Annest, J. L., Simon, T. R., Feijun, L., \& Dahlberg, L. L. (2015). Suicide trends among persons aged 10-24 years_-United States, 1994-2012. MMWR: Morbidity \& Mortality Weekly Report, 64(8), 201-205.

Swartz, K. L. (2016). Adolescent depression awareness program. Retrieved from http://www.hopkinsmedicine.org/psychiatry/specialty_areas/moods/ADAP/

Swartz, K. L., Kastelic, E. A., Hess, S. G., Cox, T. S., Gonzales, L. C., Mink, S. P., \& DePaulo Jr., J. R. (2010). The effectiveness of a school-based adolescent depression education program. Health Education \& Behavior, 37(1), 11-22. 
Taylor, R. D., \& Dymnicki, A. B. (2007). Empirical evidence of social and emotional learning's influence on school success: A commentary on "Building Academic Success on Social and Emotional Learning: What Does the Research Say?," a book edited by Joseph E. Zins, Roger P. Weissberg, Margaret C. Wang, and Herbert J. Walberg. Journal of Educational \& Psychological Consultation, 17(2/3), 225-231. doi:10.1080/10474410701346725

Townsend, L., Ruble, A., Beaudry, M. B., Schweizer, B., Owen, M., Goode, C., ...Swartz, K. (2017). The association of school climate, depression literacy, and mental health stigma among high school students. Journal of School Health, 87(8), 567-574.

Velsor, P. (2009). School counselors as social-emotional learning consultants: Where do we begin? Professional School Counseling, 13(1), 50-58.

Wanless, S. B., Groark, C. J., \& Hatfield, B. E. (2015). Assessing organizational readiness. In J. A. Durlak, C. E. Domitrovich, R. P. Weissberg, \& T. P. Gullotta (Eds.), Handbook of social and emotional learning: Research and practice (pp. 360-376). New York, NY: Guilford Press.

Wei, Y., Hayden, J. A., Kutcher, S., Zygmunt, A., \& McGrath, P. (2013). The effectiveness of school mental health literacy programs to address knowledge, attitudes and help seeking among youth. Early Intervention in Psychiatry, 7(2), 109-121. doi:10.1111/eip.12010

Wei, Y., Kutcher, S., \& Szumilas, M. (2011). Comprehensive school mental health: An integrated "school-based pathway to care" model for Canadian secondary schools. Mcgill Journal of Education, 46(2), 213-229.

Weissberg, R. P., \& Cascarino, J. (2013). Academic learning + social-emotional learning = national priority. Phi Delta Kappan, 95(2), 8-13. 
Weissberg, R. P., Durlak, J. A., Domitrovich, C. E., \& Gullotta, T. P. (2015). Social and emotional learning: Past, present, and future. In R. P. Weissberg, J. A. Durlak, C. E. Domitrovich, \& T. P. Gullotta (Eds.), Handbook of social and emotional learning: Research and practice (pp. 3-19). New York, NY: Guilford Press.

Wickrama, T., \& Wickrama, K. (2010). Original article: Heterogeneity in adolescent depressive symptom trajectories: Implications for young adults' risky lifestyle. Journal of Adolescent Health, 47, 407-413. doi:10.1016/j.jadohealth.2010.02.013

Williamson, A. A., Modecki, K. L., \& Guerra, N. G. (2015). SEL programs in high school. In J. A. Durlak, C. E. Domitrovich, R. P. Weissberg, \& T. P. Gullotta (Eds.), Handbook of social and emotional learning: Research and practice (pp. 181-196). New York, NY: Guilford Press.

Yaroslavsky, I., Pettit, J. W., Lewinsohn, P. M., Seeley, J. R., \& Roberts, R. E. (2013). Heterogeneous trajectories of depressive symptoms: Adolescent predictors and adult outcomes. Journal of Affective Disorders, 148, 391-399. doi:10.1016/j.jad.2012.06.028

Zeidner, M., Matthews, G., \& Roberts, R. D. (2009). What we know about emotional intelligence: How it affects learning, work, relationships, and our mental health. Cambridge, MA: MIT Press.

Zeidner, M., Roberts, R., \& Matthews, G. (2002). Can emotional intelligence be schooled? A critical review. Educational Psychologist, 37(4), 215-231.

Zins, J. E., \& Elias, M. J. (2007). Social and emotional learning: Promoting the development of all students. Journal of Educational \& Psychological Consultation, 17(2/3), 233-255. doi:10.1080/10474410701413152 
Zins, J. E., Weissberg, R. P., Wang, M. C., \& Walberg, H. J. (Eds.). (2004). Building academic success on social and emotional learning: What does the research say? New York, NY: Teachers College Press. 


\section{APPENDIX A: JOHNS HOPKINS ADAP COORDINATOR EMAIL}

\section{Dear ADAP Instructor,}

Thank you so much for continuing to support ADAP by teaching the curriculum. We are so happy you have chosen to use the online testing system for the students! If you need any help or have any questions, please feel free to email or call me.

In this email you will find an attachment and a survey link. The attachment is the sign-in sheet. The sign in sheet is a PDF so that you can print it and have your students sign in as they take the online test. REMINDER- This is necessary for the ADAP team to be able to match up the students from pretest to posttest. A sample sign in sheet is attached for your convenience.

You can assign each student an ID number by going down your roster for each individual class (preferred method as it saves time), or you can have the students sign in next to a number as they enter the room. The student will type their entire ID number into the online test where it says "ADAP Student ID". As the instructor, we will need you to be very careful as you go around the room to be sure they are putting the ID number in correctly. Please note: the students can proceed through the test without an ID number (so they can work through the test while you circulate through the room) but they will not be able to submit the test until they have filled in the ID number.

The link below is the link to the student survey. Each student will need to type this link into their web browser to reach the pretest AND the posttest. We will not be sending you an additional link, please use this same link for the posttests 6 weeks after the students have received the curriculum. We suggest the following process:

If there is a board available, please use it to write the following items:
a. Student Survey Link: https://mrprcbcw.hosts.jhmi.edu/redcap/surveys/?s=MBVfoX
b. Your last name (the ADAP instructor's last name)
c. Today's date (there is a button labeled "Today" to click on rather than typing the date)
d. Whether you are administering the PRE or POST test today

1) Please have each student type the website link into their web browser in order to reach the survey. You can also email it to each student if that is faster for your group.

2) Direct the students to use the information on the board (listed above) to answer the first few questions. The rest of the questions are self-explanatory and they can work through at their own pace.

3) Remind the students that they can proceed in filling out the rest of the survey without an ID number and they can leave it blank until you (the ADAP instructor) come around and fill that in with them.

4) When they have completed the survey, they can submit it.

5) If any students receive an error message, it is because they did not answer something that is required. Just scroll back through the test and be sure everything is answered before submitting. 
6) Please wait 6 weeks after you have completed the curriculum and follow this process again to complete the posttest. Remember to use the same sign-in sheet with the pre-filled student names to fill in each student's unique ID number correctly.

Again, thank you so much for using this testing form! Please let us know if you have any issues and we look forward to receiving any feedback you would like to give us.

Courtney Schock

Research Program Coordinator

Adolescent Depression Awareness Program

Johns Hopkins Hospital

(p) 410-502-3447

(f) 410-955-0152 
APPENDIX B: SAMPLE ADAP CLASS SIGN IN SHEET

Sample High School

Class 1

\begin{tabular}{|c|c|c|c|}
\hline ID NUMBER & NAME & ID NUMBER & NAME \\
\hline 67001 & Hank Aaron & 67026 & Shirley Temple \\
\hline 67002 & Carl Anderson & 67027 & Letitia Tyler \\
\hline \multirow{7}{*}{ 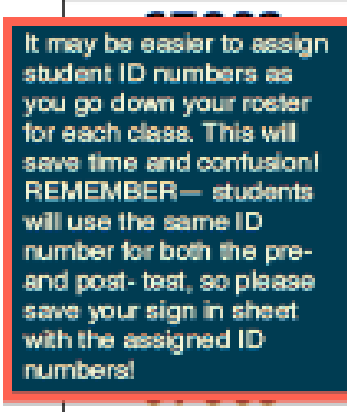 } & Brent AppeI & 67028 & Astiey Williams \\
\hline & Kevin Bacon & 67029 & Bruce Willis \\
\hline & Raven Baxter & 67030 & James Woife \\
\hline & Meg Cabot & \\
\hline & \multirow{2}{*}{ 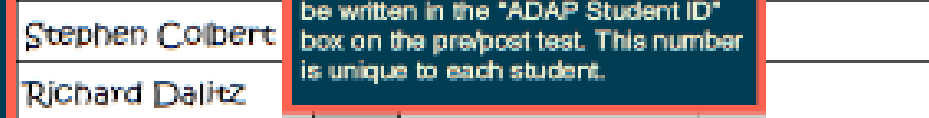 } & & \\
\hline & & & \\
\hline & Joan Davis & & \\
\hline 67010 & Michaet Faraday & & \\
\hline 67011 & Verna Felton & & \\
\hline 67012 & Glna Gershon & & \\
\hline 67013 & Steve Gibson & & \\
\hline 67014 & Edward Herrmam & \multirow{8}{*}{\multicolumn{2}{|c|}{ 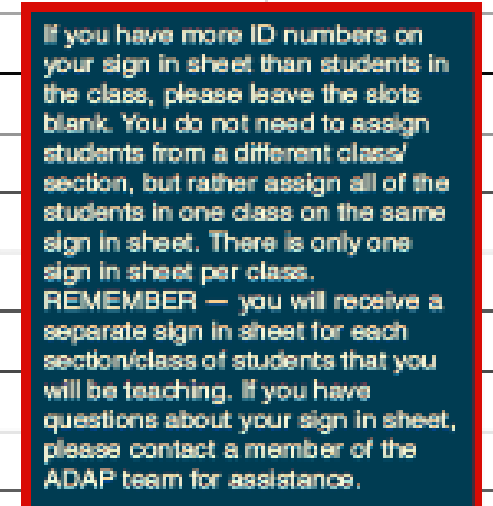 }} \\
\hline 67015 & Junie Jones & & \\
\hline 67016 & Anastasia Kelly & & \\
\hline 67017 & Philip Larkin & & \\
\hline 67018 & Jesse McCartney & & \\
\hline 67019 & Seth Myers & & \\
\hline 67020 & Lam Neeson & & \\
\hline 67021 & Alexa Nikolas & & \\
\hline 67022 & Barack Obama & & \\
\hline 67023 & Thomas Paine & & \\
\hline 67024 & Brad Penney & & \\
\hline 67025 & Rjcardo Sanchez & & \\
\hline
\end{tabular}

ADAP 


\section{APPENDIX C: ADOLESCENT DEPRESSION KNOWLEDGE QUESTIONNAIRE}
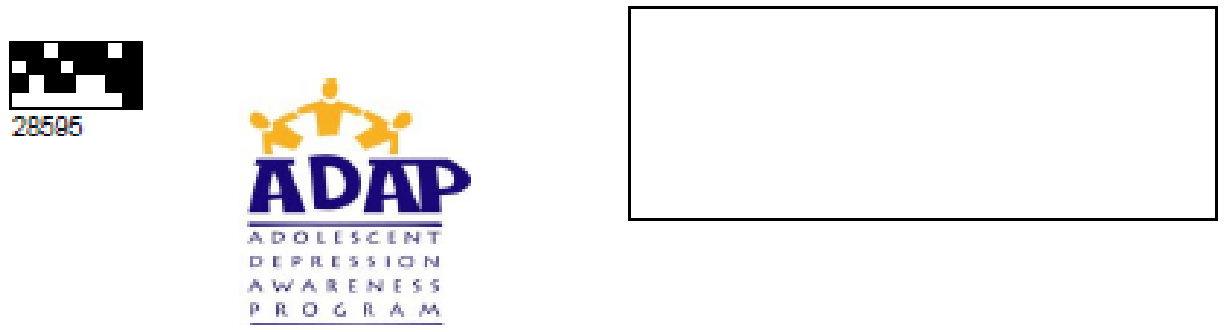

\section{ADAP Depression Knowledge Questionnaire: Pre-test}

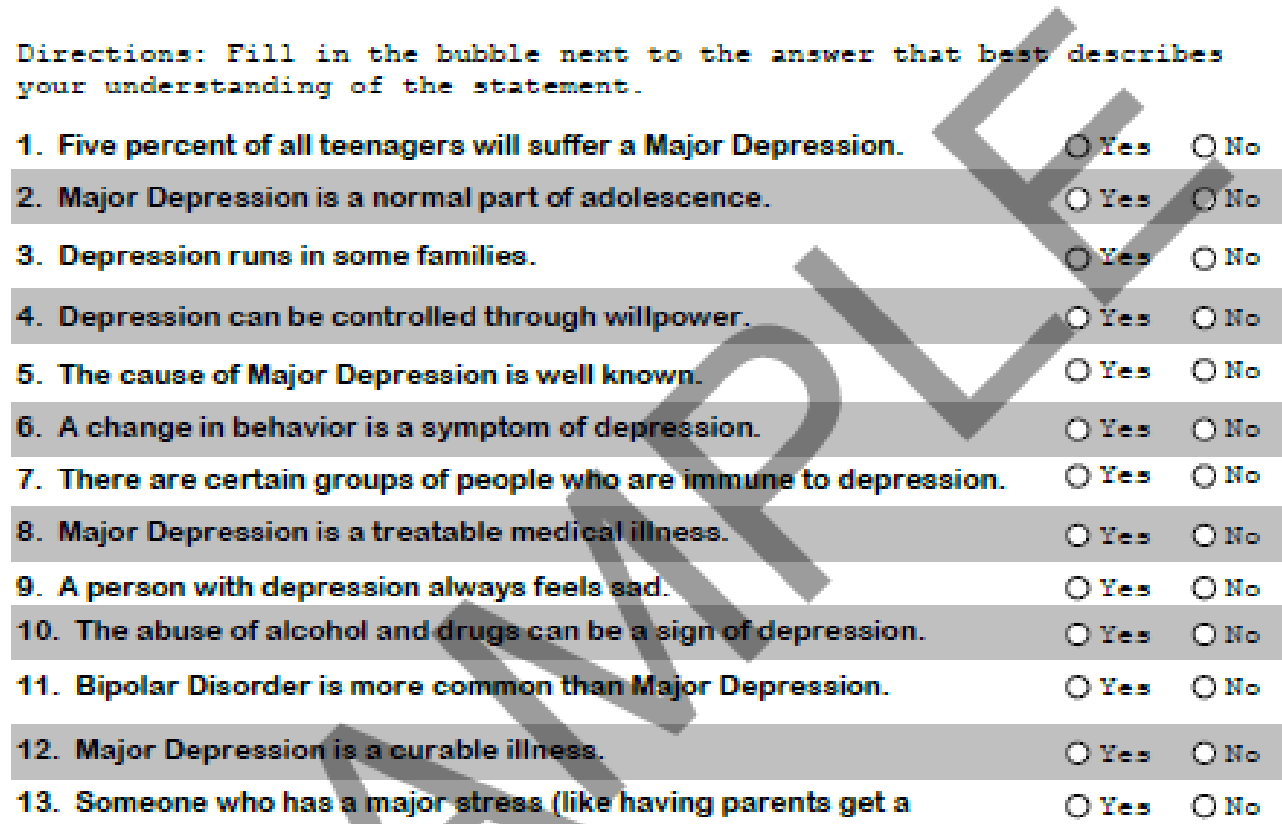

divorce)always develops a depressive illness.

\begin{tabular}{|c|c|c|}
\hline $\begin{array}{l}\text { 14. Behaviors such as eating disorders or substance abuse can } \\
\text { worsen mood disorders. }\end{array}$ & OYes & Ono \\
\hline 15. There are effective treatments for depression. & O Yes & ONo \\
\hline 16. A person with Bipolar Disorder always has a high mood. & OYes & Ono \\
\hline $\begin{array}{l}\text { 17. The process for diagnosing Major Depression is similar to other } \\
\text { medical conditions because you look for a cluster of symptoms. }\end{array}$ & O Yes & ONo \\
\hline 18. There is a test that can diagnose Major Depression. & OYes & Ono \\
\hline 19. Not needing sleep is a symptom of mania. & O Yes & O No \\
\hline 20. Irritable mood can be a symptom of Major Depression. & OYes & Ono \\
\hline
\end{tabular}


21. Rob's family is having financial problems, and they recently moved into a new school district. Rob misses his old school, especially his friends. He has not made many friends at his new school yet and sits alone most of the time at lunch. He feels nervous a lot of the school day but feels better once he gets home. He wonders when he will feel better about his new school. Sometimes he has a hard time concentrating on his schoolwork, but so far his grades have been good. He sees his old friends on weekends, and they have fun hiking and camping.

a. Fill in the bubble next to the answer that describes what is most likely wrong with Rob?

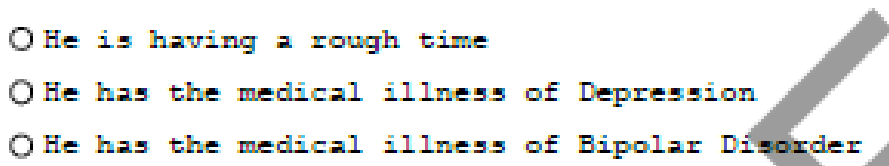

b. Fill in the bubble next to the answer that describes how confident are you about what is wrong with Rob?

$$
\begin{aligned}
& \text { O Not at all sure } \\
& \text { O Somewhat sure } \\
& \text { O Almost sure } \\
& \text { O Very sure }
\end{aligned}
$$

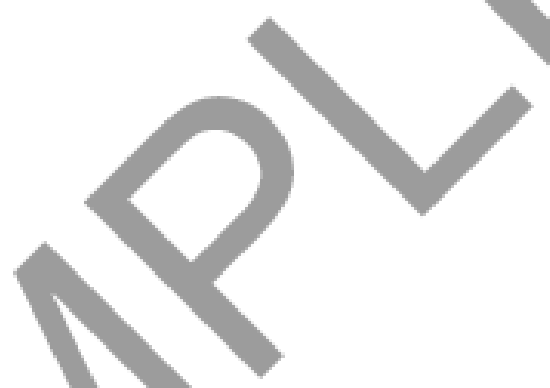

22. Michael broke up with his girlfriend a few weeks ago. After the breakup, he was upset and had trouble sleeping. Then one morning, his mood was much better. He was thinking very quickly and developed a plan to get her back. His plan involved dropping out of his high school and enrolling as a student in her performing arts magnet high school across town. He was not worried about what would happen with his grades or about giving up his position on the lacrosse team. He spent lots of money on new clothes to wear at his new high school, and he is convinced that with his new wardrobe, the kids at his new school would definitely elect him to be Homecoming King.

a. Fill in the bubble next to the answer that describes what is most likely wrong with Michael?

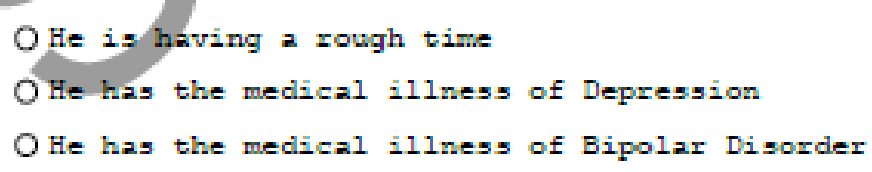

b. Fill in the bubble next to the answer that describes how confident are you about what is wrong with Michael?

$$
\begin{aligned}
& \text { O Not at all sure } \\
& \text { O Somewhat sure } \\
& \text { O Almost sure } \\
& \text { O Very sure }
\end{aligned}
$$


23. Alyssa's parents told her that they will be getting a divorce. For the past week, she has been crying a lot and fighting with her parents. She got a D on her chemistry test, but her grades are good in her other classes. She is able to sleep through the night, although she is worried about her family's problems. She spends her free time playing tennis and seeing movies with friends, which makes her feel better.

a. Fill in the bubble next to the answer that describes what is most likely wrong with Alyssa?

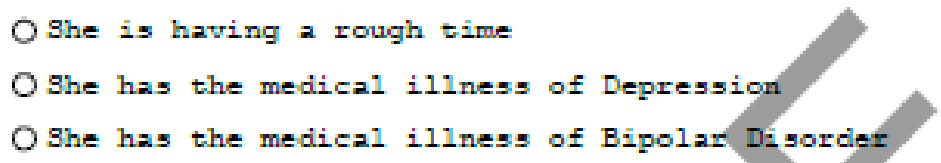

b. Fill in the bubble next to the answer that describes how confident are you about what is wrong with Alyssa?

$$
\begin{aligned}
& \text { ONot at al1 sure } \\
& \text { O Somewhat sure } \\
& \text { Olmost sure } \\
& \text { O Very sure }
\end{aligned}
$$

24. Rachel has been on the soccer team for the past two years. She has had a good time on the team and has made lots of friends. She tries out for the team again her junior year, but when she and her friends go to look at the list of who made the team, her name is not on it. She feels very sad and angry about this, and a month later, she does not feel better. Her grades have dropped in several classes. She feels that her friends on the team don't like her anymore and avoids them, even though they invite her to parties frequently. She doesn't have as much fun at the parties as she did in the past. She would rather just stay in bed. She still enjoys spending time with her cousins who live nearby.

a. Fill in the bubble next to the answer that describes what is most likely wrong with Rachel?

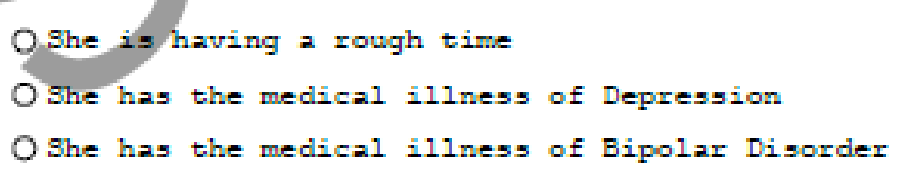

b. Fill in the bubble next to the answer that describes how confident are you about what is wrong with Rachel?

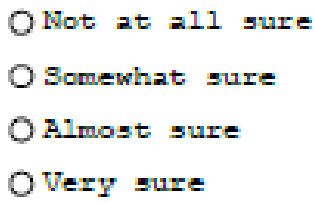


25. If you thought that you or a friend was depressed would you encourage him/her to ask for help?

26. Fill in the bubble next to the THREE people you would be most likely to ask for help:

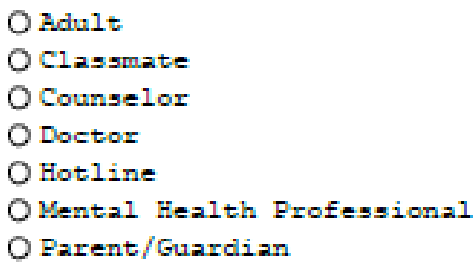

27. Fill in the bubble next to the BEST answer that describes what would make it difficult for you to get help for yourself or for a friend.

D Being judged by others

$\supset$ Denying having an illness

O Not knowing whom to ask for help

J Not wanting to lose a friendship

$\supset$ Having too much pride to ask for help

J Feeling embarrassed

Oeeling too depressed to $2 s k$ for help

OFearing the reaction of parents or other adults

$O$ Wैorrying others will find out

Deing afraid of getting treatment Q Nothing would stop me

J Worrying about what friends would think

28. If your friend tells you that he/she is depressed and asks you to keep it a secret because no one else knows, what would you do? (Select only one)

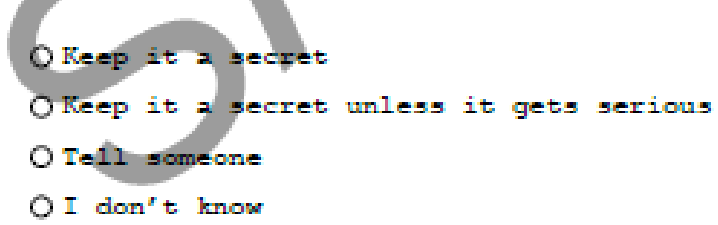

Please fill in the bubble next to your Gender: OMale O Female 


\section{APPENDIX D: PERMISSION FROM THE JOHNS HOPKINS HOSPITAL}

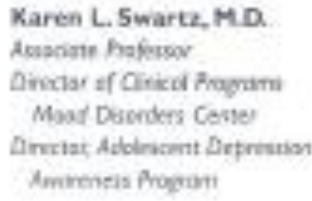

March 7, 2017

Ms. Antonette Minniti aminniti@d211.org

Dear Ms. Minniti;

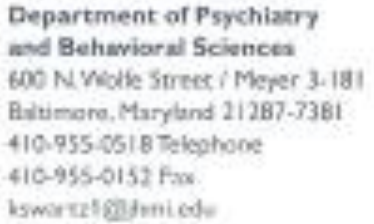

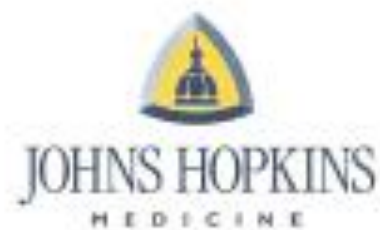

HED I C I N E

Antonette Minniti, permission to use secondary pre-test and post-test data collected by our program. This permission allows usage of ADAP's Depression Knowledge Questionnaire (ADKO) deidentified assessment data collected at Township High School District 211 for your dissertation study on depression education. The provided data will be cleaned by the ADAP team and will protect the identity of all students. You will only receive de-identified data.

Sincerely,

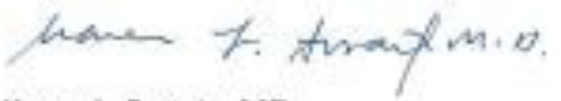

Karen L Swartz, MD 